\title{
USO DA TÉCNICA DE n-ALCANOS PARA MEDIR O APORTE DE NUTRIENTES ATRAVÉS DE ESTIMATIVAS DO CONSUMO DE FORRAGEM EM BOVINOS
}

\author{
DIMAS ESTRÁSULAS DE OLIVEIRA
}

Tese apresentada à Escola Superior de Agricultura "Luiz de Queiroz", Universidade de São Paulo, para obtenção do título de Doutor em Agronomia, Área de Concentração: Ciência Animal e Pastagens.

P I R A C I C A B A

Estado de São Paulo - Brasil

Julho -2003 


\title{
USO DA TÉCNICA DE n-ALCANOS PARA MEDIR O APORTE DE NUTRIENTES ATRAVÉS DE ESTIMATIVAS DO CONSUMO DE FORRAGEM EM BOVINOS
}

\author{
DIMAS ESTRÁSULAS DE OLIVEIRA \\ ZOOTECNISTA
}

Orientador: Prof. Dr. DANTE PAZZANESE D. LANNA

Tese apresentada à Escola Superior de Agricultura "Luiz de Queiroz", Universidade de São Paulo, para obtenção do título de Doutor em Agronomia, Área de Concentração: Ciência Animal e Pastagens.

P I R A C I C A B A

Estado de São Paulo - Brasil

Julho -2003 


\section{Dados Internacionais de Catalogação na Publicação (CIP) DIVISÃO DE BIBLIOTECA E DOCUMENTAÇÃO - ESALQ/USP}

\section{Oliveira, Dimas Estrásulas de}

Uso da técnica de n-alcanos para medir o aporte de nutrientes através de estimativas do consumo de forragem em bovinos / Dimas Estrásulas de Oliveira. - Piracicaba, 2003.

$129 \mathrm{p}$.

Tese (doutorado) - Escola Superior de Agricultura Luiz de Queiroz, 2003. Bibliografia.

1. Alimentação animal 2. Bovinos 3. Dieta animal 4. Digestibilidade 5. Forragem 6. Hidrocarbonetos 7. Metabolismo animal 8. Nutrientes para animais 9. Pastejo I. Título

CDD 636.2084

\section{"Permitida a cópia total ou parcial deste documento, desde que citada a fonte - $O$ autor"}


"Pesquisador antes de tudo, tem que ser honesto. E isto não se aprende."

(Prof. Ênio Rosa Prates - UFRGS)

"À memória de minha mãe, Pegi Marlene Estrásulas, professora, escritora e compositora, pelo amor, carinho, amizade e exemplo de caráter dedicados e ensinados durante os seus 59 anos de vida"

\section{DEDICO}

"Aos meus irmãos Ana, Tális e Marta, pelo amor, paciência, incentivo e companheirismo que marcam o nosso convívio de todas as horas"

OFEREÇO 


\section{AGRADECIMENTOS}

Ao Prof. Dr. Dante Pazzanese Duarte Lanna, pela oportunidade.

À Fundação de Amparo à Pesquisa do Estado de São Paulo (FAPESP), pela concessão da bolsa de estudos, recursos disponibilizados na forma de reserva técnica e pelo exemplo de seriedade na administração do dinheiro público.

À Pró-Reitoria de Pós-Graduação da USP, pelo auxílio concedido, permitindo-me participar em um evento científico fora do país.

Ao Prof. Dr. Sila Carneiro da Silva, pelo seu exemplo de organização e gosto pela docência, demonstrados em todas as suas aulas, pela amizade, trocas de idéia durante o transcorrer do curso e boa vontade em ler este trabalho.

Ao Prof. Dr. Carlos Guilherme Silveira Pedreira, pelas inúmeras vezes em que trocamos informações e pela oportunidade de dar uma aula, de sua disciplina, sobre métodos de avaliação de pastagens no Curso de PósGraduação.

A todos da Fazenda Santa Mônica, da EMBRAPA Gado de leite, que ajudaram durante os seis meses do trabalho experimental, em especial ao Ânderson Luís "Gambilu" com sua enorme capacidade de trabalho e responsabilidade ímpar.

Ao Dr. Luís Januário $M$. Aroeira e todos os funcionários e estagiários do laboratório de bromatologia da EMBRAPA Gado de leite. 
À Profa. Dra. Maria do Carmo Ruaro Peralba, do Instituto de Química da UFRGS, pela gentileza de ter emprestado a coluna capilar para as análises cromatográficas.

Ao Dr. Luiz Roberto Pimentel Trevisan "Malagueta", do Laboratório de Entomologia da ESALQ, pela ajuda nas análises cromatográficas.

À Fabiana Cristina Fracassi, funcionária do CENA, pela ajuda durante as pesagens dos padrões para cromatografia.

Aos colegas e ex-colegas de laboratório: Eduardo F. Delgado, Sérgio R. de Medeiros, Amanda A. Hayashi, Marina Hojaij, Elaine P. Souza, Liana Callegare, Fernanda P. Castro, Liliane Suguisawa, Luíza Bulle, Alexandre Berndt, Juliano Barbosa, Marco Antônio S. Gama, Rodrigo Almeida, Andréa Brasil, Maria A. Etchegaray, Max F. Fernandes, Oscar Queirós e Éric Leonardo, pela ajuda, companhia agradável e troca de experiências.

Ao colega Henrique Rocha de Medeiros, que, enquanto éramos colegas em uma disciplina, "segurou" a minha "barra" durante a época mais difícil da minha vida.

Aos colegas Cláudia Cristina Paro de Paz, Cláudio Manuel Rodrigues e Luís G. Barioni, pelas inúmeras trocas de idéia sobre análises estatísticas.

Ao Dr. Luís Orlindo Tedeschi (Cornell University), que, apesar da distância, muito contribuiu, para a manipulação estatística dos dados obtidos.

Aos demais colegas do curso pelo convívio e troca de informações.

Aos alunos da UFMG: Manoel Carlos Couto (doutorando), Kênia S. Guimarães e Walter S. Lisboa; da PUC de Curitiba: Gabriele Zôccoli e da Universidade de Lages: André Marca e Marcos R. Paterno, pela ajuda durante o experimento na Fazenda Santa Mônica.

I am very grateful to Dr. Hugh Dove (Division of Plant Industry - CSIRO, Australia) for his kind attention in help me with papers, e-mails and suggestion about the n-alkanes technique. His attitude was a demonstration of willingness and greatness. 
Ao Prof. Ênio Rosa Prates (UFRGS), pela amizade, ensinamentos transmitidos e exemplo de caráter e seriedade na vida pessoal e científica, dos quais jamais esquecerei.

À minha esposa Ivamara Rodrigues da Costa de Oliveira "Picurrucha", pelo imenso amor, enorme carinho, grande paciência, companheirismo e respeito, que norteiam a nossa relação.

À Agroceres Nutrição Animal Ltda, por flexibilizar o meu horário de trabalho nos momentos finais de conclusão deste trabalho. 


\section{SUMÁRIO}

Página

RESUMO ……………………………………………………....

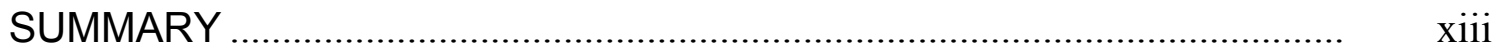

1 INTRODUÇÃO...............................................................................

2 REVISÃO DE LITERATURA .............................................................

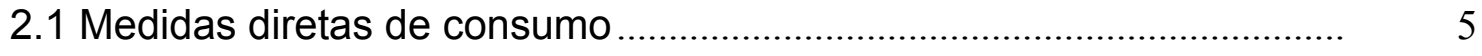

2.2 Medidas indiretas de consumo ............................................................ 6

2.2.1 Medidas diretas e indiretas de produção fecal ..................................... 7

2.3. n-Alcanos presentes na cera cuticular usados como indicadores....... $\quad 9$

2.3.1 Composição e variação do perfil de n-alcanos de plantas forrageiras tropicais....................................................................... 9

2.3.2 Utilização de n-alcanos como indicadores internos de

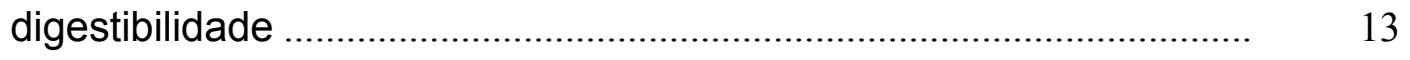

2.3.3 Uso de n-alcanos como indicadores para estimar o consumo de forragens em ruminantes domésticos.................................................. 14

2.3.4 Estimativas da composição botânica ou morfológica da forragem disponivel ou consumida.

2.3.5 Utilização de n-alcanos em estudos nutricionais com ruminantes selvagens....................................................................................... 22

2.3.6 Utilização de $\mathrm{n}$-alcanos em estudos nutricionais com animais não-ruminantes

3 VALIDAÇÃO DO USO DE CÁPSULAS DE LIBERAÇÃO CONTROLADA DE N-ALCANOS PARA ESTIMATIVA DE CONSUMO DE 


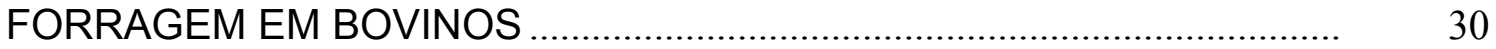

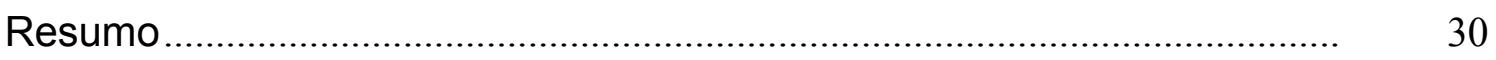

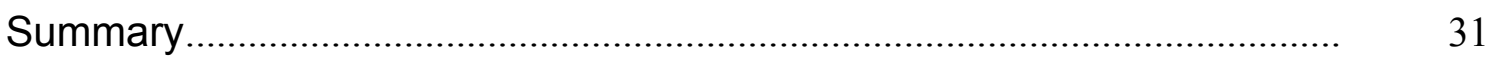

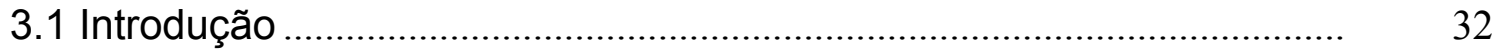

3.2 Material e Métodos ..........................................................................

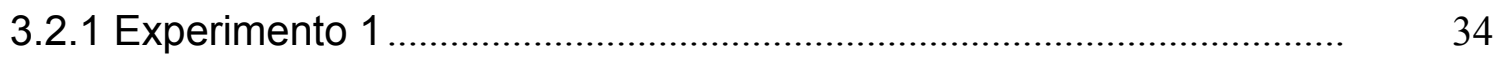

3.2.1.1 Procedimentos experimentais....................................................... 34

3.2.1.2 Extração de alcanos .......................................................................... 37

3.2.1.3 Análise cromatográfica..................................................................... 38

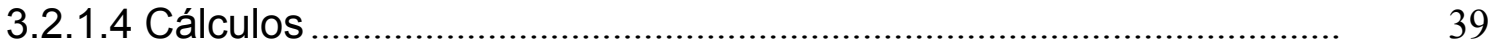

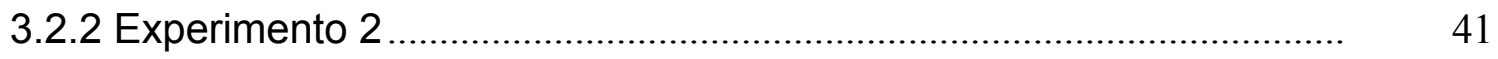

3.2.2.1 Procedimentos experimentais .......................................................... 41

3.2.3 Análise estatística ................................................................................

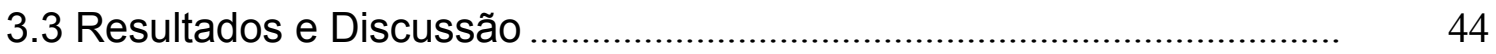

3.3.1 Taxa de liberação de n-alcanos dos experimentos em gaiolas de metabolismo e em regime de pastejo .................................................. 44

3.3.2 Análise de regressão com os animais em gaiolas metabólicas ........ $\quad 50$

3.3.3 Análise de regressão com os animais em pastagem .......................... $\quad 50$

3.3.4 Estimativas de consumo de forragem com $n$-alcanos nos animais em gaiolas ….................................................................................... 52

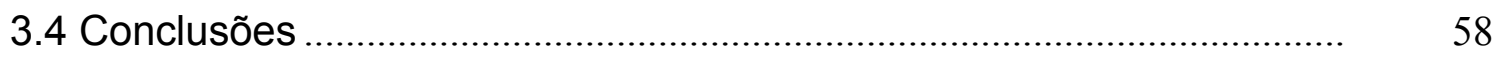

4 APORTE DE ENERGIA EM VACAS LEITEIRAS SUPLEMENTADAS COM ÁCIDO LINOLÉICO CONJUGADO (CLA) DETERMINADO ATRAVÉS DE ESTIMATIVAS DO CONSUMO DE FORRAGEM USANDO n-ALCANOS ....................................................................... 59

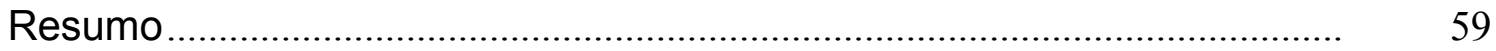

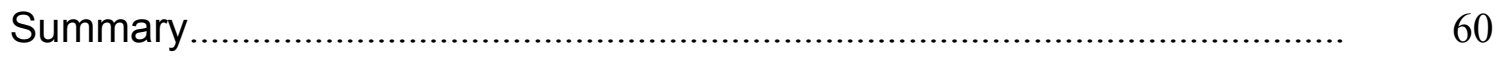

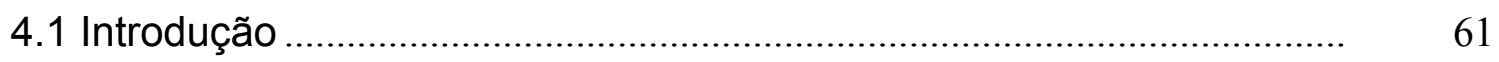

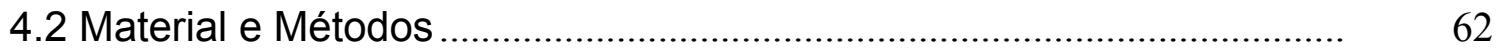

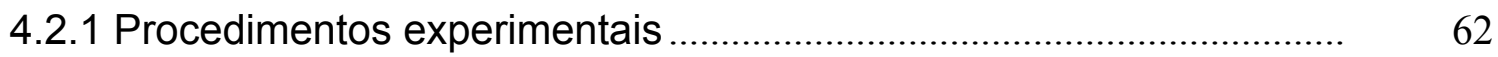




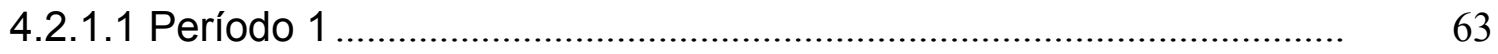

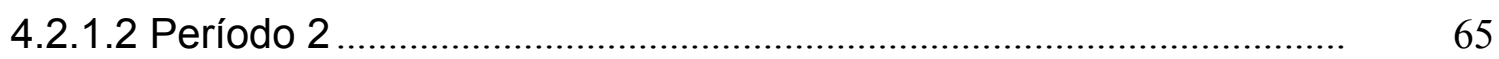

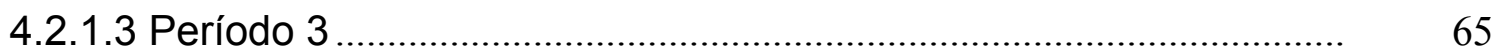

4.2.2 Amostragem e análise da forragem .................................................... 65

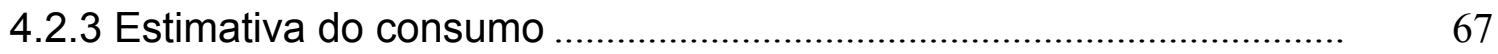

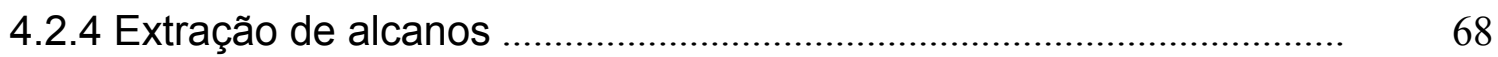

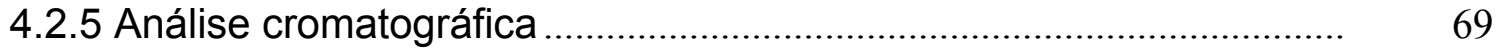

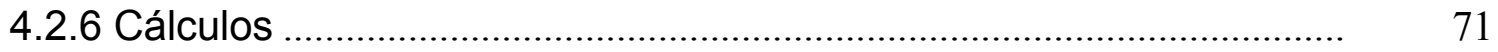

4.2.7 Análise estatística ..............................................................................

4.3 Resultados e Discussão ......................................................................

4.3.1 Perfil de n-alcanos das amostras de forragem e de seus

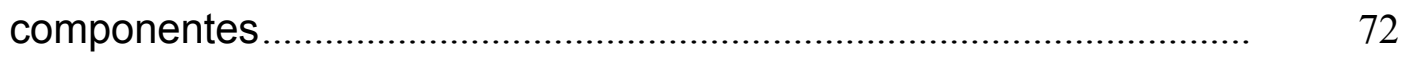

4.3.2 Estimativas de consumo obtidas com n-alcanos ................................ 78

4.3.3 Comportamento dos n-alcanos de cadeia ímpar da dieta $\left(C_{31}, C_{33}\right.$ e $\left.C_{35}\right)$ e de cadeia par fornecidos via cápsula $\left(C_{32}\right.$ e $\left.C_{36}\right) \ldots \quad 87$

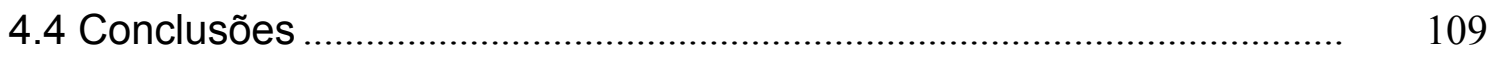

5 CONCLUSÕES GERAIS .................................................................... 111

5.1 Uso de $n$-alcanos em estudos de digestibilidade ................................... 111

5.2 Uso de n-alcanos em estudos de consumo de forragem....................... 111

5.3 Pesquisas futuras .................................................................................. 112

REFERÊNCIAS BIBLIOGRÁFICAS ....................................................... 113

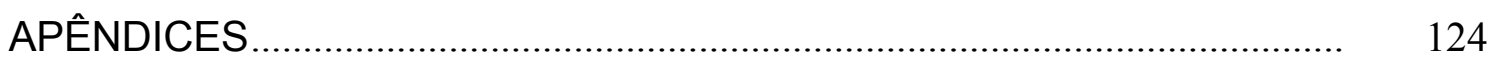




\title{
USO DA TÉCNICA DE n-ALCANOS PARA MEDIR O APORTE DE NUTRIENTES ATRAVÉS DE ESTIMATIVAS DO CONSUMO DE FORRAGEM EM BOVINOS
}

\author{
Autor: DIMAS ESTRÁSULAS DE OLIVEIRA \\ Orientador: Prof. Dr. DANTE PAZZANESE DUARTE LANNA
}

\section{RESUMO}

Os n-alcanos têm sido utilizados como indicadores em estudos de estimativas de consumo e composição botânica e/ou morfológica da dieta com ruminantes domésticos, selvagens e com animais não ruminantes. Foram realizados três experimentos, sendo que no primeiro foram avaliados a taxa de liberação de n-alcanos fornecidos via cápsulas de liberação controlada em animais fistulados no rúmen, alojados em gaiolas de metabolismo e, a validação da estimativa de consumo de forragem pelos animais submetidos a três tratamentos variando a relação volumoso : concentrado. No segundo foi avaliada a taxa de liberação de n-alcanos fornecidos via cápsula de liberação controlada com os mesmos animais em pastagem submetidos a três 
tratamentos com suplementação concentrada. As taxas foram medidas com o auxílio de um paquímetro removendo-se a cápsula via fístula ruminal, medindose a distância percorrida pelo êmbolo da cápsula que pressiona as pastilhas que contêm o indicador aos 3, 7, 10, 13 e 17 dias após a colocação no rúmen. Não houve efeito de dieta e da interação dieta e dia de medida $(P>0,05)$ sobre a taxa diária de liberação no rúmen tanto com os animais em gaiolas de metabolismo como em pastagem. Foi possível unir as equações geradas em cada experimento resultando em uma quantidade liberada de indicador de 345 mg.dia ${ }^{-1}$. O consumo estimado com o par $\mathrm{C}_{33}: \mathrm{C}_{32}$ de n-alcanos nos animais em gaiolas de metabolismo não diferiu do consumo observado $(P>0,05)$. No terceiro experimento objetivou-se determinar o perfil de n-alcanos de Cynodon nlemfüensis Vanderyst var nlemfüensis e estimar o consumo e a composição da dieta consumida por vacas leiteiras em pastejo suplementadas com ácido linoléico conjugado (CLA) ou em grupo controle (Megalac), utilizando regressão linear entre as exigências e o consumo de energia metabolizável, por dia. Foram encontrados $\mathrm{n}$-alcanos com o comprimento da cadeia de carbono variando entre 22 e 35 átomos, havendo uma predominância dos de cadeia ímpar sobre os pares, com o $\mathrm{C}_{33}, \mathrm{C}_{31}$ e $\mathrm{C}_{29}$ encontrados em maiores concentrações. Entre os $n$-alcanos de cadeia par, o $C_{26}, C_{28}$ e $C_{30}$ foram encontrados em maiores concentrações. No primeiro período de estudo, o consumo médio de matéria seca de forragem não diferiu $(P>0,05)$ entre os animais tratados com CLA ou não (CLA $=11,2$ vs. $\left.M E G=11,1 \mathrm{~kg} \cdot \mathrm{dia}^{-1}\right) . \mathrm{O}$ consumo de matéria seca total não diferiu $(P>0,05)$ entre os dois grupos de animais $\left(C L A=14,6\right.$ vs. $\left.M E G=14,3 \mathrm{~kg} \cdot \mathrm{dia}^{-1}\right)$. No terceiro período o consumo médio de matéria seca de forragem não diferiu $(P>0,05)$ entre os animais tratados com CLA ou não ( $C L A=11,8$ vs. $\left.M E G=12,6 \mathrm{~kg} \cdot \mathrm{dia}^{-1}\right)$. $\mathrm{O}$ consumo de matéria seca total não diferiu $(P>0,05)$ entre os dois grupos de animais (CLA = 15,4 vs. $\left.M E G=16,2 \mathrm{~kg} \cdot \mathrm{dia}^{-1}\right)$. No primeiro período as estimativas de consumo e 
de partes de plantas consumidas foram precisas e acuradas $(b=1, C V=9,3$ $\%)$. No terceiro período as estimativas foram precisas mas inacuradas $(b \neq 1$, CV $=5,0 \%$ ). No segundo período não foi possível estimar o consumo de forragem. Os n-alcanos naturais da dieta, $C_{31}, C_{33}$ e $C_{35}$ e, $C_{32}$ e $C_{36}$ sintéticos fornecidos via cápsula de liberação controlada e, as relações $C_{31}: C_{32}$ e $C_{33}: C_{32}$ apresentaram variações entre turnos e entre dias nas concentrações fecais. 


\title{
THE USE OF N-ALKANES TECHNIQUE TO MEASURE NUTRIENT UPTAKE THROUGH FORAGE INTAKE ESTIMATES IN BOVINES
}

\author{
Author: DIMAS ESTRÁSULAS DE OLIVEIRA \\ Adviser: Prof. Dr. DANTE PAZZANESE DUARTE LANNA
}

\section{SUMMARY}

$\mathrm{N}$-alkanes have been used as markers in studies of intake estimation and diet botanical and/or morphological composition with domestic and wild ruminants and non-ruminant animals. It has been done three experiments, which in the first was evaluated the $n$-alkanes release rate from controlled-release capsules in rumen-fistulated animals kept in metabolism cages. Also in the fist experiment was evaluated the validation of forage intake predictions for the animals allocated in three different forage : concentrate ratios. In the second experiment was evaluated the $n$-alkanes release-rate from controlled-release capsules with the same animals kept on pasture and allocated in three distinct treatments with concentrate supplementation. Release rates were measured with a caliper removing the capsule through ruminal fistula and measuring the distance passed through by the embolus capsule which push the tablets containing the marker at $3,7,10,13$, and 17 days after rumen insertion. There were not effect $(P>0.05)$ of diet and interaction between diet and day of measure 
in the daily release rate both in the animals maintained on the metabolism cages as on pasture. It was possible to combine the equations generated from each experiment resulting in a marker released amount of $345 \mathrm{mg} \cdot \mathrm{d}^{-1}$. The estimated intake with the n-alkanes $\mathrm{C}_{33}: \mathrm{C}_{32}$ pair in the metabolism cage animals did no differ $(P>0.05)$ from the actual intake. The objectives of the third experiment were to establish the $\mathrm{n}$-alkanes profile on Cynodon nlemfüensis Vanderyst var nlemfüensis and to estimate intake and morphological composition of the forage consumed by lactating dairy cows on pasture supplemented with conjugated linoleic acid (CLA) or Megalac (MEG), using a linear regression between the requirements and the daily intake of metabolizable energy. It was found nalkanes with the carbon chain length ranging between 22 and 35 atoms, being the odd chain prevalent over the even chain n-alkanes. The $\mathrm{C}_{33}, \mathrm{C}_{31}$, and $\mathrm{C}_{29} \mathrm{n}$ alkanes were found in higher concentrations. Among the even chain n-alkanes, the $\mathrm{C}_{26}, \mathrm{C}_{28}$, and $\mathrm{C}_{30}$ were found in higher concentrations. In the first study period the average forage dry matter intake did not differ $(P>0.05)$ between the animals supplemented with CLA or controls (CLA $=11.2$ vs. $M E G=11.1 \mathrm{~kg}^{- \text {day }^{-}}$ $\left.{ }^{1}\right)$. The total dry matter intake also did not differ $(P>0.05)$ between treatments $\left(\mathrm{CLA}=14.6\right.$ vs. $\left.\mathrm{MEG}=14.3 \mathrm{~kg} \cdot \mathrm{day}^{-1}\right)$. In the third study period the average forage dry matter intake did not differ $(P>0.05)$ between the animals supplemented with CLA or controls $\left(C L A=11.8\right.$ vs. $\left.M E G=12.6 \mathrm{~kg}^{-\mathrm{day}^{-1}}\right)$. The total dry matter intake also did not differ $(P>0.05)$ between treatments (CLA $=15.4$ vs. $\left.M E G=16.2 \mathrm{~kg} \cdot \mathrm{day}^{-1}\right)$. In the first study period, the estimates of forage intake and consumed plant parts were precise and accurate $(b=1$, C.V. $=9.3 \%)$, while in the third period the estimates were precise but inaccurate $(b \neq 1, C . V .=5.0 \%)$. 
In the second study period it was not possible to estimate the forage intake. The fecal concentrations of natural $n$-alkanes from the diet $\left(C_{31}, C_{33}\right.$, and $\left.C_{35}\right)$, the synthetic n-alkanes from controlled-release capsules $\left(C_{32}\right.$ and $\left.C_{36}\right)$, and the $\mathrm{C}_{31}: \mathrm{C}_{32}$ and $\mathrm{C}_{33}: \mathrm{C}_{32}$ ratios did alter between morning and afternoon samples and among days. 


\section{INTRODUÇÃO}

Em regiões tropicais, as pastagens podem constituir-se em consideráveis fontes de nutrientes para os rebanhos leiteiros e de corte, visto que ainda existem extensas áreas disponíveis para a produção animal. No Brasil, a área ocupada pelas plantas forrageiras tropicais perfazem 45 a 50 milhões de hectares da área de pastagens, somente na região Centro-Oeste e são cultivadas em, praticamente todo o território nacional. Há também indicações de que cerca de $50 \%$ da área agrícola do Estado de São Paulo estejam ocupados por pastagens, ressaltando a sua importância econômica neste Estado.

Devido ao seu alto potencial de produção de matéria seca, as plantas forrageiras tropicais dos gêneros Brachiaria , Panicum e Pennisetum formam a maioria das áreas de pastagens cultivadas. Somando-se a estas, as plantas do gênero Cynodon constituem também uma alternativa viável para alimentar os rebanhos, visto que apresentam características forrageiras desejáveis como a elevada produção de matéria seca, boa relação folha/haste, bom valor nutritivo e flexibilidade de manejo. Tais plantas têm sido bastante utilizadas para a alimentação de bovinos de corte e leiteiros em países como Cuba, Porto Rico e os Estados Unidos da América.

Em São Paulo e em grande parte do Brasil, onde as criações de ruminantes desenvolvem todo ou parte do ciclo de produção em condições de pastejo, a determinação do consumo, digestibilidade e material selecionado pelos animais é difícil, mas muito importante, porque, nessas condições, eles podem alterar a composição da sua dieta, quer por seleção de diferentes partes 
da planta ou por diferentes espécies de plantas que venham a compor a pastagem. Como as diferentes partes ou espécies de plantas forrageiras podem ter valores nutritivos diferentes, a identificação do que é consumido, da quantidade consumida, da digestibilidade e eficiência de utilização é de grande importância. Estimando-se o consumo, consegue-se aplicar as exigências nutricionais das várias espécies e categorias animais a um desempenho diário esperado e pode-se fazer inferências para avaliar até que ponto os diferentes alimentos utilizados são capazes de suprir essas necessidades, permitindo uma alimentação econômica e nutricionalmente correta.

O aprimoramento da metodologia para determinação do consumo e digestibilidade com animais em pastejo possibilitaria uma avaliação mais criteriosa de alterações no desempenho animal, com animais recebendo tratamentos de impacto positivo na exploração pecuária, como por exemplo: 1) o uso de produtos que melhoram a eficiência de utilização de nutrientes (CLA, bST); 2) o uso de modificadores ruminais que aumentam a disponibilidade de nutrientes dos alimentos, tais como os ionóforos; 3) na suplementação protéica (NNP e proteína verdadeira) através do uso de suplementos múltiplos (sais proteinados); 4) na avaliação e melhoramento genético de espécies de plantas forrageiras tropicais. Seriam também fundamentais na modelagem do processo de digestão e metabolismo de nutrientes e em simulações de sistemas de produção animal em pastagens.

Assim sendo, este trabalho tem por objetivos: 1) Medir a taxa de liberação de n-alcanos fornecidos como indicadores via cápsula de liberação controlada em duas situações distintas de alimentação; 2) Medir o efeito do CLA no consumo utilizando a metodologia de n-alcanos para estimar o 
consumo de forragem; 3) Tentar estimar as partes de plantas que foram consumidas através da metodologia de n-alcanos. 


\section{REVISÃO DE LITERATURA}

A descoberta de um método que estime adequadamente o consumo de matéria seca por animais em pastejo é essencial para que se possa utilizar o valor da pesquisa em pastagens, mas continua a ser elusivo (Burns et al., 1994).

Herbívoros domesticados ou selvagens, que vivem sob condições de pastejo, dependem da quantidade e do conteúdo de nutrientes das espécies e/ou partes de plantas que eles são capazes de ingerir, normalmente obtidas após seleção, na vegetação disponível (Mayes \& Dove, 2000). Estes animais são componentes de ecossistemas naturais ou agrícolas e o transcorrer normal do ciclo de vida de uma determinada população é influenciado não apenas pelo "status" nutricional de seus indivíduos mas, ainda, pelo tipo e quantidade de vegetação que eles consomem e que pode vir a afetar a distribuição desta e de outras espécies de animais dentro desses ecossistemas. Assim, um entendimento quantitativo da interação entre os animais e as plantas é fundamental para garantir a sustentabilidade de qualquer sistema de produção animal em pastagens.

A avaliação do valor nutritivo de forragens fornecidas a ruminantes envolve o conhecimento do consumo voluntário e da digestibilidade. A maioria destes estudos foram e ainda são conduzidos sob condições controladas através de experimentos convencionais de digestibilidade, onde é feita a coleta total de fezes e, assim, tem-se um controle da quantidade consumida. No entanto, este tipo de experimento envolve muito trabalho, custo elevado e um 
tempo muito longo. Além disso, as medidas obtidas sob condições controladas não podem ser extrapoladas para condições de pastejo.

Assim, para medir o consumo com animais em pastagens naturais ou cultivadas, pode-se usar medidas diretas ou então estimativas. Há várias revisões sobre esse assunto (Schneider \& Flatt, 1975; Dove \& Mayes, 1991) de maneira que, no texto que se segue, será feita uma breve abordagem sobre alguns aspectos importantes que envolvem essas metodologias. Uma abordagem mais profunda será feita sobre a técnica de uso de n-alcanos, enfocando principalmente estimativas de consumo e composição da dieta de animais em pastejo.

\subsection{Medidas diretas do consumo}

Podem estar relacionadas à pastagem e são obtidas medindo-se as quantidades de forragem pré e pós pastejo (Meijs et al., 1982). Este método possui como restrição a necessidade de uma correção para o crescimento da pastagem durante o período de pastejo, bem como para perdas de forragem, principalmente por pisoteio e pelo esterco dos animais. Outra restrição importante é a grande necessidade de intensa amostragem na pastagem e também o não fornecimento de uma estimativa de consumo individual pelos animais.

Medidas diretas de consumo ainda podem ser obtidas, pesando-se os animais de maneira contínua ou antes e após cada período de pastejo (Le Du \& Penning, 1982). Neste método são necessárias correções para perdas insensíveis de peso (respiração), produção de urina e fezes, além de ajustes para a água consumida. Tal técnica pode influenciar a atividade normal de pastejo dos animais devido ao alto grau de distúrbio imposto pelo manejo.

Outra forma de medir o consumo diretamente com os animais é monitorando-se o comportamento ingestivo do animal (Hodgson, 1982). 
Segundo esse autor, o consumo pode ser calculado através de variáveis envolvidas no comportamento ingestivo dos animais como o produto entre 0 tempo de pastejo, a taxa de bocados durante o pastejo e a quantidade de forragem em cada bocado. Como aspectos importantes que podem influenciar a acurácia das estimativas estão as variações individuais, diárias e/ou diurnas nos parâmetros considerados. Inerente à metodologia "per se", é importante ressaltar também que há necessidade de observar-se os animais durante um longo período de tempo, o que é trabalhoso e desconfortável, exigindo muita concentração por longos períodos de tempo. Também com relação a essa técnica, há necessidade do uso de animais fistulados no esôfago como a principal maneira de se obter a medida da quantidade de forragem obtida em cada bocado. Há atualmente uma série de procedimentos com o auxílio de aparelhos que podem superar algumas limitações das observações diretas, tais como a filmagem dos animais e o uso de equipamentos eletrônicos (Hodgson, 1982; Burns et al., 1994).

\subsection{Medidas indiretas do consumo}

A forma mais comum de se estimar o consumo (C) com ruminantes em pastejo é usando-se separadamente medidas da produção fecal (PF) e digestibilidade da forragem (D), de acordo com a equação: $C=P F /(1-D)$. Notase, então, que a estimativa do consumo é dependente de acuradas medidas da produção fecal e da digestibilidade, e que um erro na medida deste último

parâmetro terá mais influência sobre o valor de consumo obtido (Le Du \& Penning, 1982; Burns et al., 1994). 


\subsubsection{Medidas diretas e indiretas da produção fecal}

Le Du \& Penning (1982) comentaram que a produção fecal pode ser medida diretamente ou estimada. A produção fecal direta é obtida utilizando-se o método da coleta total com o uso de arreios e sacos para as fezes. As vantagens são o pouco trabalho laboratorial e instalações envolvidos, onde, basicamente, se faz a determinação de matéria seca e matéria orgânica. Como desvantagem, além de exigir muito trabalho, pode afetar o desempenho dos animais, há necessidade de cateterizar os animais, quando estes são fêmeas, para evitar a contaminação das fezes com urina, há um distúrbio sobre o comportamento normal dos animais e há, ainda, a possibilidade de subestimativa da produção fecal por perda de conteúdo.

Já com a produção fecal (PF) estimada, utiliza-se um indicador fornecido em quantidades diárias conhecidas ( $\mathrm{g}$ indicador.dia ${ }^{-1}$ ) e a produção de fezes é calculada pela relação entre a quantidade fornecida e a concentração do indicador nas fezes ( $g$ indicador. $g^{-1}$ fezes), segundo a equação: $P F=[(g$ indicador. $\left.\mathrm{dia}^{-1}\right) \times \mathrm{RF} /\left(\mathrm{g}\right.$ indicador. $\mathrm{g}^{-1}$ fezes)]. Importante também nesta equação, freqüentemente negligenciada é a recuperação fecal do indicador (RF), que quando não é medida deve ser considerada como $100 \%$.

Para essas avaliações, um primeiro aspecto importante é a escolha do indicador e as características que ele deve possuir, tendo-se como principais a indigestibilidade, recuperação fecal completa e fácil medida quando se busca um indicador ideal (Kotb \& Luckey, 1972). A classificação dos indicadores bem como das substâncias que já foram e ainda são utilizadas foi abordada em extensas revisões (Faichney, 1975; Piaggio, 1989; Genro, 1999) e não será, portanto, alvo de nova abordagem no presente texto.

Há, porém, outros aspectos importantes com relação ao indicador utilizado que podem influenciar a acurácia dos dados obtidos, tais como variação diurna e/ou diária de sua concentração nas fezes. Tais situações 
podem ocorrer como resultado da freqüência de dosagens, quando esse indicador é administrado em doses discretas, de variações no próprio consumo de alimento e de eventos no trato digestivo, influenciando a mistura do indicador com a digesta (Kotb \& Luckey, 1972), e irá resultar em amostragens fecais intermitentes que, mesmo assim, podem não representar a concentração fecal média do indicador, levando a erros na estimativa do consumo.

Outro aspecto importante da medida de consumo, utilizando-se a produção fecal estimada com um indicador é a necessidade de se ter a medida da digestibilidade da dieta. Este outro componente da equação pode ser calculado pela relação entre as concentrações de uma substância indigestível presente naturalmente no alimento e nas fezes produzidas. Tal procedimento seria interessante porque acomodaria as variações individuais do nível de consumo e efeitos até de carga parasitária e suplementos consumidos (Dove \& Mayes, 1991). Mas, devido às dificuldades de se encontrar uma substância considerada ideal para todas as situações, a digestibilidade é usualmente determinada pelo método in vitro.

Fundamental para esta determinação é a obtenção de uma amostra representativa da forragem consumida pelos animais, sendo as formas mais utilizadas a simulação do pastejo e o uso de animais com fístulas esofágicas. A primeira maneira de obtenção da amostra tem como principal inconveniente que a discrepância entre a amostra colhida pelo observador e aquela consumida pelos animais não é conhecida. Sob este ponto, Euclides et al. (1992) mostraram que não houve diferença entre a amostra obtida por pastejo simulado e extrusa para proteína bruta e digestibilidade in vitro da matéria orgânica. O uso de extrusa como amostra da forragem consumida ainda é considerado como preferencial, mas os animais com fístulas de esôfago necessitam cuidados especiais, podem adquirir vícios de pastejo e a amostra pode não ser representativa em grandes áreas (Holechek et al., 1982). Com 
relação à digestibilidade in vitro há também o inconveniente de se usar uma única medida de digestibilidade para todos animais.

\section{3 n-Alcanos presentes na cera cuticular usados como indicadores}

Dentre as várias substâncias que compõem a cera das plantas, surgiram diversas com potencial de utilização como indicadores, tais como os ácidos graxos de cadeia longa (Grace \& Body, 1981) e, especialmente, os hidrocarbonetos alifáticos saturados (n-alcanos) (Mayes \& Lamb, 1984).

Os n-alcanos são compostos orgânicos de cadeia aberta formados por carbono e hidrogênio, onde a diferença entre dois membros sucessivos da série é constante (são homólogos) e onde há o prefixo "n" (normal) para os diversos alcanos, por maiores que sejam as moléculas, desde que os átomos de carbono se encontrem em cadeia contínua, sem ramificações. As primeiras quatro substâncias da família dos alcanos são gases $\left(C_{1}\right.$ a $\left.C_{4}\right)$, os treze seguintes são líquidos $\left(C_{5} \quad C_{17}\right)$ e os que contêm 18 ou mais átomos de carbono são sólidos. Destes, os que contêm mais de 20 átomos de carbono são, também, chamados de parafinas (Morrison \& Boyd, 1972). A fórmula geral para quaisquer n-alcanos é $\mathrm{C}_{n} \mathrm{H}_{2 n+2}$.

\subsubsection{Composição e variação do perfil de $n$-alcanos de plantas forrageiras tropicais}

Com relação ao perfil e concentração dos vários n-alcanos, Kolattukudy (1976) afirmou que os hidrocarbonetos $C_{29}$ e $C_{31}$ são os principais alcanos do reino vegetal. Tulloch (1976) verificou que os alcanos estão presentes em todas as ceras, podendo variar as quantidades.

Em um trabalho onde foram avaliadas amostras de fenos de setária (Setaria vaginata, Spreng), milheto (Pennisetum americanum, Schum), capim 
napier (Pennisetum purpureum, Schum) em três estádios de maturidade: 96, 104 e 149 dias, correspondentes às alturas de 1,2, 1,5 e 1,8 m, respectivamente, e campo nativo predominantemente estival de três regiões do Rio Grande do Sul, Oliveira et al. (1997) identificaram n-alcanos com comprimentos da cadeia de carbono variando de 20 a 37 átomos e destes, os encontrados em maiores concentrações foram o $\mathrm{C}_{29}, \mathrm{C}_{31}$ e $\mathrm{C}_{33}$. Estes mesmos autores encontraram, ainda, quantidades consideráveis de $\mathrm{C}_{26}, \mathrm{C}_{28}$ e $\mathrm{C}_{30} \mathrm{em}$ um dos fenos de campo nativo.

Esses resultados corroboraram com aqueles encontrados por Laredo et al. (1991), que estudaram sete espécies de plantas forrageiras tropicais, sendo cinco gramíneas (Brachiaria decumbens, Digitaria decumbens, Pennisetum glaucum, Sorghum sp e Setaria sphacelata) e duas leguminosas (Leucaena leucocephala e Stylosanthes scabra). Tulloch (1976) comentou que os principais alcanos contêm número ímpar de carbono variando de $\mathrm{C}_{21}$ a $\mathrm{C}_{37}$, e que $\circ C_{31}$ é freqüentemente o que aparece em maior concentração, seguido pelo $\mathrm{C}_{29}$.

Delgado et al. (2000) estudaram 17 espécies de plantas tropicais, sendo 6 gramíneas (Saccharum officinarum Cuba cv. 323-68 e Mayarí 5514, Panicum maximum, Cynodon nlenfuensis, Brachiaria decumbens, Pennisetum purpureum cv. Cuba CT -115), 8 leguminosas (Leucaena leucocephala cv. Venezuela e Peru, Mucuna pruriens, Erythrina poeppigiana, Lisiloma bahamensis, Vigna unguiculata, Gliricidia sepium, Enterobium cyclocarpu) e 3 arbustivas de outras famílias (Gmelina arbórea, Sapindus saponaria, Brosimun alicastrum). Esses autores encontraram n-alcanos com comprimentos de $\mathrm{C}_{25}$ a $\mathrm{C}_{37}$, também com uma predominância dos ímpares sobre os pares e onde o $\mathrm{C}_{27}, \mathrm{C}_{29}, \mathrm{C}_{31}$ e $\mathrm{C}_{33}$ também foram encontrados em maiores concentrações. Muito interessante nesse trabalho foi a detecção do n-alcano $\mathrm{C}_{34}$ como componente natural do perfil de $n$-alcanos em duas espécies de leguminosas (Mucuna pruriens, Gliricidia sepium) e em três de gramíneas (Cynodon 
nlenfuensis, Brachiaria decumbens, Pennisetum purpureum cv. Cuba CT -115). Oliveira et al. (1997) comentaram em seu trabalho que isto poderia ocorrer, uma vez que encontraram esse referido n-alcano nas amostras de setária (Setaria vaginata, Spreng), milheto (Pennisetum americanum, Schum), capim napier (Pennisetum purpureum, Schum) e nos fenos de campo nativo de duas regiões diferentes do Estado do Rio Grande do Sul. Esse n-alcano é comumente usado como um padrão interno para a quantificação de n-alcanos e, segundo Mayes et al. (1986a) e, Dove et al. (1989), não estaria presente nas forragens e fezes. Como conseqüência, Oliveira et al. (1997) sugeriram que deveriam ser realizadas extrações sem a colocação do $\mathrm{C}_{34}$ como padrão interno, chamadas de "extrações em branco" e que fosse feito um ajuste na quantificação dos demais n-alcanos nas amostras.

Estudando as variações no perfil de n-alcanos, Laredo et al. (1991) encontraram uma diminuição dos n-alcanos $C_{27}, C_{29}, C_{33}$ e $C_{35}$ em folhas de diferentes idades para Pennisetum glaucum e do $C_{27}, C_{29}, C_{31}, C_{33}$ e $C_{35}$ para Sorghum sp. Da mesma forma, com os fenos de napier estudados, Oliveira et al. (1997) encontraram uma diminuição somente do $C_{33}$ e $C_{35}$.

Em um trabalho mais recente, Genro et al. (2001a) utilizaram amostras de três gramíneas tropicais (Brachiaria brizantha cv. Marandu, Panicum maximum cv. Mombaça e Pennisetum purpureum cv. Cameroon) obtidas pelo método do pastejo simulado e coletadas em três épocas do ano (meio do período seco, início do período das águas e final do período das águas). Esses autores identificaram e quantificaram n-alcanos de 27 a 35 átomos de carbono e verificaram uma grande variação entre as espécies e alguma entre os períodos nas concentrações de $\mathrm{C}_{29}, \mathrm{C}_{31}, \mathrm{C}_{33}$ e $\mathrm{C}_{35}$. Esses mesmos autores (2001b) estudaram as concentrações de $n$-alcanos em amostras estratificadas a cada $20 \mathrm{~cm}$ de altura, do nível do solo ao topo do dossel forrageiro, em uma pastagem de Panicum maximum cv. Mombaça, nas mesmas épocas do ano e separadas nas frações de haste + bainha e folha. Encontraram maiores 
concentrações dos $n$-alcanos $C_{31}, C_{33}$ e $C_{35}$ nas folhas amostradas no período seco. Dentro de estratos para as duas frações, encontraram uma redução no $\mathrm{C}_{33}$ para folhas nos estratos de $20-40 \mathrm{~cm}$ e acima de $40 \mathrm{~cm}$, e uma diminuição do $C_{31}, C_{33}$ e $C_{35}$ na fração haste + bainha no estrato de $0-20 \mathrm{~cm}$, no início da estação chuvosa. Esse trabalho revelou que a técnica de uso de n-alcanos em estudos de consumo pode ser afetada pela amostragem da forragem com gramíneas de hábito de crescimento ereto e cespitoso, sendo muito importante a obtenção de uma amostra representativa da dieta selecionada pelo animal.

Ainda tratando-se da composição de n-alcanos de espécies e/ou partes de uma mesma espécie de planta, Smith et al. (2001) estudaram variações nos perfis de n-alcanos de gramíneas nativas do sul da África. Foram analisadas 40 espécies durante a estação das águas e 23 durante a estação da seca. Esses autores separaram as amostras em um "pool" de espécies de plantas inteiras e nos componentes morfológicos inflorescência, haste e folhas. Encontraram nalcanos em maiores concentrações com cadeias variando de $\mathrm{C}_{25}$ a $\mathrm{C}_{35}$, sendo aqueles de cadeias mais curtas ou mais longas existentes em menores concentrações. Utilizaram os n-alcanos $\mathrm{C}_{25}, \mathrm{C}_{27}, \mathrm{C}_{29}, \mathrm{C}_{31}$ e $\mathrm{C}_{33}$ e observaram diferenças entre partes de plantas dentro e entre estações de amostragens. Comentaram, ainda, que a diferença entre as amostras de plantas inteiras nas duas estações foi devida à presença de determinada parte da planta em uma estação do ano e sua ausência em outra e exemplificaram, citando a presença de inflorescência na época das águas e sua ausência na estação seca. Mostraram também, através de análise de grupamento com 10 espécies que tiveram a amostragem completa (planta inteira, haste, folhas e inflorescência) nas duas estações, que houve menor similaridade no perfil de n-alcanos entre partes de plantas da mesma espécie do que entre plantas inteiras de diferentes espécies. Esse trabalho mostra a dificuldade existente quando se tenta identificar quais espécies são consumidas pelos animais, principalmente em pastagens naturais, onde o número de componentes pode ser muito variado, e 
quando há uma diferença muito acentuada no perfil de n-alcanos entre partes da planta de uma mesma espécie, o que faz com que cada parte da planta deva ser incluída separadamente no cálculo.

\subsubsection{Utilização de n-alcanos como indicadores internos de digestibilidade}

Em um estudo com ovinos que receberam uma dieta de azevém (Lolium multiflorum) e trevo branco (Trifolium repens) ad libitum, Mayes \& Lamb (1984) sugeriram que os $\mathrm{n}$-alcanos de cadeia longa poderiam ser úteis como indicadores para determinar a digestibilidade de forragens. Os mesmos autores concluíram, também, que houve um progressivo aumento na recuperação fecal conforme aumentou o comprimento da cadeia carbonada dos n-alcanos, sendo a recuperação do $C_{35}$ de $97,5 \%$, o que é uma das principais características desejáveis para que uma substância seja utilizada como um indicador interno em estudos de digestibilidade.

Piasentier et al. (1989) usaram amostras de alimento (Dactylis glomerata) e de fezes de ovinos obtidas em ensaios de digestibilidade in vivo conduzidos previamente para testar a adequabilidade dos n-alcanos com número ímpar de carbono $\left(\mathrm{C}_{27}\right.$ a $\left.\mathrm{C}_{33}\right)$ como indicadores de digestibilidade. A média de recuperação fecal dos n-alcanos alcançou um máximo de $83,4 \%$ com o $\mathrm{C}_{33}$, de maneira que a digestibilidade da matéria seca determinada foi sempre subestimada em maior ou menor extensão. Contudo, com os homólogos de maior comprimento de cadeia, $\mathrm{C}_{31}$ e $\mathrm{C}_{33}$, a correlação entre os coeficientes de digestibilidade in vivo com os estimados com os referidos n-alcanos foi de 0,80 e 0,84, respectivamente.

Recentemente, Oliveira et al. (2000) trabalharam com amostras de fenos de setária (Setaria vaginata, Spreng), milheto (Pennisetum americanum, Schum), capim napier (Pennisetum purpureum, Schum) em três estádios de maturidade: 96, 104 e 149 dias, correspondentes às alturas de 1,2, 1,5 e 1,8 m, 
respectivamente, e fezes, oriundas de experimentos convencionais de digestibilidade com ovinos realizados entre os anos de 1978 e 1982 no Rio Grande do Sul. Utilizaram o n-alcano $\mathrm{C}_{35}$ como indicador interno de digestibilidade e os coeficientes de digestibilidade obtidos com o indicador foram subestimados tanto para matéria seca (4,68 unidades percentuais) como para matéria orgânica (4,43 unidades percentuais), devido à recuperação média do $\mathrm{C}_{35}$ ter sido inferior a $100 \%$, mas os coeficientes de correlação obtidos entre as medidas in vivo e com indicador para matéria seca e matéria orgânica foram considerados bons $(0,87$ e 0,85 , respectivamente) e o coeficiente angular obtido através de regressão linear entre as medidas in vivo e estimadas não diferiu da unidade sugerindo que os métodos foram equivalentes e que as estimativas obtidas com 0 indicador foram precisas. Nesse trabalho, o coeficiente de correlação obtido entre a digestibilidade in vivo da matéria seca e a estimada com $0 \mathrm{C}_{35}$ foi maior que os coeficientes de correlação encontrados por Piasentier et al. (1989) usando os n-alcanos $C_{31}$ e $C_{33}$ para a mesma medida, devido ao fato de a recuperação fecal do $C_{35}(91,76 \%)$ ter sido bem superior às do $\mathrm{C}_{31}$ e $\mathrm{C}_{33}$, $(79,8$ e $83,4 \%$, respectivamente), obtidas pelos referidos autores.

\subsubsection{Uso de $n$-alcanos como indicadores para estimar o consumo de forragens em ruminantes domésticos}

O primeiro trabalho usando $n$-alcanos presentes na cera das plantas como indicadores para estimar o consumo de forragens por ruminantes foi o de Mayes et al. (1986a), que trabalharam com ovinos e estudaram as recuperações fecais de n-alcanos $\mathrm{C}_{27}$ a $\mathrm{C}_{35}$ da forragem (Lolium perenne) e de $\mathrm{n}$-alcanos de cadeia par, $\mathrm{C}_{28}$ e $\mathrm{C}_{32}$ fornecidos oralmente. As recuperações fecais dos $n$-alcanos presentes na forragem (de cadeia ímpar) aumentaram com o aumento do comprimento da cadeia $\left(\mathrm{C}_{27}=71,3 \%, \mathrm{C}_{29}=74,5 \%, \mathrm{C}_{31}=85,4\right.$ $\%, \mathrm{C}_{33}=89,1 \%$ e $\mathrm{C}_{35}=93,1 \%$ ). $\mathrm{A}$ recuperação do n-alcano sintético $\mathrm{C}_{28}$ 
fornecido oralmente foi levemente maior que as do $\mathrm{C}_{27}$ e $\mathrm{C}_{29}$ natural da forragem, e as do n-alcano sintético $\mathrm{C}_{32}$ fornecido oralmente e do $\mathrm{C}_{33}$ natural da forragem foram as mesmas. O consumo médio estimado, usando o par de nalcanos $\mathrm{C}_{32}$ fornecido oralmente e $\mathrm{C}_{33}$ natural da forragem, foi idêntico ao consumo real. Os autores concluíram que estimativas exatas do consumo de forragem são passíveis de obtenção, usando-se para o cálculo, um par de nalcanos: um sintético de cadeia par fornecido oralmente e um de cadeia ímpar, natural da forragem.

Segundo Dove \& Mayes (1991), a grande contribuição do trabalho citado anteriormente foi que as recuperações fecais incompletas dos n-alcanos de cadeia par, fornecidos oralmente, e do ímpar da forragem não têm importância, desde que sejam iguais. Assim, os erros associados com as recuperações fecais incompletas anular-se-iam no numerador e denominador (ver equações abaixo). Nota-se, então, que nas fezes somente é exigida a relação das concentrações dos $n$-alcanos, natural da forragem e o sintético fornecido oralmente. Se essas forem estimadas com similares "vícios" irão anular-se. Assim, recuperações fecais idênticas dos n-alcanos, da forragem (ímpar) e fornecido (par) são o pré-requisito para obtenção de estimativas exatas do consumo de forragem.

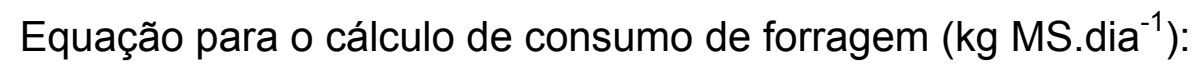

$$
\mathrm{C}=\left[(\mathrm{Fi} / \mathrm{Fp}){ }^{*} \mathrm{Dp}\right] /\left[\mathrm{Hi}-(\mathrm{Fi} / \mathrm{Fp}){ }^{*} \mathrm{Hp}\right]
$$

Caso sejam usados suplementos concentrados e, se estes contiverem tanto o n-alcano de cadeia ímpar (Ci) como o de cadeia par (Cp), a equação passa a ser:

$$
\mathrm{C}=\left\{[\mathrm{Fi} / \mathrm{Fp}]{ }^{*}\left(\mathrm{Dp}+\mathrm{I}^{*} \mathrm{Cp}\right)-\mathrm{I}^{*} \mathrm{Ci}\right\} /\left[\mathrm{Hi}-(\mathrm{Fi} / \mathrm{Fp}){ }^{*} \mathrm{Hp}\right]
$$


Onde:

$\mathrm{Fi}$ = concentração $\left(\mathrm{mg} \cdot \mathrm{kg}^{-1} \mathrm{MS}\right)$ do n-alcano de cadeia ímpar nas fezes;

$\mathrm{Fp}=$ concentração $\left(\mathrm{mg} \cdot \mathrm{kg}^{-1} \mathrm{MS}\right)$ do n-alcano de cadeia par nas fezes;

$\mathrm{Dp}=$ quantidade do n-alcano sintético de cadeia par fornecido $(\mathrm{p})\left(\mathrm{mg}^{\mathrm{kg}} \mathrm{kg}^{-1} \mathrm{MS}\right)$;

$\mathrm{Hi}=$ concentração (mg. $\mathrm{kg}^{-1} \mathrm{MS}$ ) do n-alcano de cadeia ímpar natural da forragem;

$\mathrm{Hp}=$ concentração ( $\left.\mathrm{mg} \mathrm{kg}^{-1} \mathrm{MS}\right)$ do n-alcano de cadeia par na forragem;

$\mathrm{I}$ = consumo de concentrado $\left(\mathrm{kg} \mathrm{MS} \cdot \mathrm{dia}^{-1}\right)$;

$\mathrm{Cp}=$ concentração ( $\mathrm{mg}_{\mathrm{kg}} \mathrm{kg}^{-1} \mathrm{MS}$ ) do n-alcano de cadeia par no concentrado;

$\mathrm{Ci}$ = concentração ( $\mathrm{mg} \mathrm{kg}^{-1} \mathrm{MS}$ ) do n-alcano de cadeia ímpar no concentrado;

Assim, o método pode ser particularmente útil, permitindo estimativas do consumo de forragem em animais recebendo suplementação alimentar.

Mayes et al. (1986b) trabalharam com ovinos lactentes alojados individualmente e recebendo $1 \mathrm{~kg}$ de leite.dia ${ }^{-1}$, com acesso ad libitum à forragem fresca (Lolium perenne). Os animais foram dosados com cápsulas de gelatina contendo $C_{32}$ e, com base nas recuperações fecais $(81,6$ e 81,7 \%), usaram o par $\mathrm{C}_{33}: \mathrm{C}_{32}$, respectivamente, para estimar o consumo de forragem. $\mathrm{A}$ discrepância média entre o consumo observado e o estimado foi de 0,4 g.dia ${ }^{-1}$. A partir dos resultados, concluíram que boas estimativas do consumo de forragem por cordeiros lactentes poderiam ser obtidas usando os $n$-alcanos $C_{33}$ da forragem e $\mathrm{C}_{32}$ fornecido oralmente como indicadores interno e externo, respectivamente.

Com o objetivo de estudar diferenças no desempenho de duas raças de ovinos com diferentes tamanhos corporais adultos e em duas comunidades vegetais contrastantes, Osoro et al. (1999) forneceram os n-alcanos $C_{24}, C_{32} \mathrm{e}$ $\mathrm{C}_{36}$ em péletes de papel, uma vez ao dia, e utilizaram os $n$-alcanos $C_{33}$ da forragem e $\circ \mathrm{C}_{32}$ para os cálculos das estimativas de consumo. Detectaram diferenças no consumo voluntário de forragem, expresso em termos absolutos 
ou por unidade de peso metabólico, entre as raças estudadas, indicando que a metodologia pode ser sensível em detectar diferenças entre raças dentro de uma mesma espécie animal, podendo ajudar em estudos de melhoramento genético e de comportamento e ecologia do pastejo, nos quais haja variações na estrutura física e nutricional da forragem e onde determinados genótipos possam vir a se adaptar melhor.

Utilizando outra espécie animal, Merchant (1996) trabalhou com caprinos em um experimento que teve como objetivo determinar o efeito da altura de uma planta invasora (Juncus effusus L.) em uma pastagem de gramíneas sobre o consumo total e a proporção desta na dieta dos animais. Utilizou péletes de papel impregnados com $\mathrm{C}_{28}, \mathrm{C}_{32}$ e $\mathrm{C}_{36}$, fornecidos uma vez ao dia aos animais. Estimou o consumo com o par $\mathrm{C}_{33}: \mathrm{C}_{32}$, natural da forragem e fornecido oralmente. Foram encontradas diferenças no consumo da pastagem e da planta invasora entre os períodos de estudo, e no consumo da pastagem como afetado pelos tratamentos (três alturas controladas da planta invasora).

Esses dois trabalhos referidos anteriormente, também utilizaram a técnica de alcanos para estimar concomitantemente a digestibilidade da dieta através da produção fecal estimada com o n-alcano $\mathrm{C}_{36}$. Essa possibilidade é muito interessante uma vez que usa-se valores individuais de digestibilidade da dieta, acomodando-se diferenças que possam existir entre animais, raças ou até espécies que estejam sendo trabalhadas. Além disso, considera também as diferenças de digestibilidade provocadas por diferenças no consumo.

Com o objetivo de avaliar o potencial dos $n$-alcanos como indicadores para predizer o consumo de vacas leiteiras submetidas a uma dieta à base de feno, Unal et al. (1997) mantiveram três vacas da raça Holandês fistuladas no rúmen, em baias individuais, e submetidas a três níveis diferentes de oferta de alimento, mais $1 \mathrm{~kg}$ de cevada amassada, por animal, por dia. Os animais foram dosados via fístula com papel de filtro impregnado com os n-alcanos $C_{32}$ e $C_{36}$ ( $0,5 \mathrm{~g}$ de cada). $\mathrm{O}$ consumo foi predito usando as relações do $\mathrm{n}$-alcano $\mathrm{C}_{33}$ 
natural do alimento e os sintéticos $C_{32}$ e $C_{36}$, fornecidos via fístula ruminal. Segundo os autores, as melhores estimativas do consumo foram obtidas com a relação $\mathrm{C}_{33}: \mathrm{C}_{32}$, sendo que a relação $\mathrm{C}_{33}: \mathrm{C}_{36}$ consistentemente subestimou o consumo. Sabe-se que uma das prerrogativas, para que a relação n-alcano de cadeia ímpar (natural do alimento) e n-alcanos de cadeia par (fornecido) possa ser usada na estimativa do consumo, é que as recuperações fecais sejam similares. Nesse trabalho, as recuperações fecais médias foram $88 \%$ para o $\mathrm{C}_{32}, 93 \%$ para o $\mathrm{C}_{33}$ e $102 \%$ para $\circ \mathrm{C}_{36}$, havendo, portanto, maior similaridade entre as recuperações fecais do par $\mathrm{C}_{33}: \mathrm{C}_{32}$ quando comparado com o par $\mathrm{C}_{33}: \mathrm{C}_{36}$.

Com plantas tropicais, Genro et al. (2000) obtiveram estimativas de consumo com três espécies de gramíneas (Brachiaria brizantha cv. Marandu, Panicum maximum cv. Mombaça e Pennisetum purpureum cv. Cameroon) em três épocas do ano (meio da seca, início das águas e fim das águas). Estes autores utilizaram bovinos de corte da raça Nelore, dosados duas vezes ao dia com péletes contendo $\mathrm{C}_{32}$ ou $\mathrm{C}_{36}$. Utilizaram os $\mathrm{n}$-alcanos $\mathrm{C}_{33}$ ou $\mathrm{C}_{35}$ naturais da forragem e as relações $C_{33}: C_{32}$ ou $C_{35}: C_{36}$ para estimar o consumo. Comentaram que quando utilizaram o $\mathrm{C}_{35}$ como um indicador interno no período do fim das águas para o cultivar Mombaça, o consumo voluntário de matéria seca foi menor do que o esperado considerando a oferta de forragem. Comentaram, ainda, que houve uma baixa concentração do $\mathrm{C}_{35}$ nesse cultivar em todas as épocas de avaliação, o que pode ter influenciado nas estimativas. Concluíram que a técnica forneceu estimativas razoáveis do consumo voluntário de matéria seca, e que o n-alcano $\mathrm{C}_{35}$ não foi um bom indicador interno para o cálculo. Há alguns relatos na literatura que recomendam uma concentração mínima de $50 \mathrm{mg} \cdot \mathrm{kg}^{-1}$ de matéria seca para que um alcano possa ser usado nas estimativas do consumo (Laredo et al., 1991; Dove \& Mayes, 1991). 


\subsubsection{Estimativas da composição botânica ou morfológica da forragem disponível ou consumida}

Possivelmente, o primeiro indício de que se poderia usar a diferença entre o perfil de n-alcanos entre partes de uma mesma planta ou entre espécies de plantas, para estimar quais destas são consumidas, veio do trabalho feito por Oró et al. (1965), que verificaram uma grande similaridade entre o perfil de n-alcanos de fezes de bovinos e o da forragem consumida (Medicago arabica), e que os animais selecionaram, em favor da fração folha, já que existiu uma melhor correlação entre o perfil de n-alcanos desta com aqueles encontrados nas fezes.

Com combinações conhecidas de espécies compondo uma pastagem, Dove (1992) utilizou seis conjuntos de misturas contendo duas, três ou quatro espécies. Extraiu a fração de n-alcanos nas espécies individuais e nas misturas e, utilizando equações simultâneas, estimou acuradamente a composição da mistura de forragens, quando houve até três espécies. Com quatro espécies, sendo duas gramíneas e duas leguminosas, estimou acuradamente a quantidade de gramíneas mas não conseguiu, individualmente, distinguir bem as espécies leguminosas, estimando muito bem, contudo, o conteúdo total de leguminosas.

Dove \& Mayes (1991) comentaram sobre alguns aspectos importantes desse método que deveriam ser considerados, tais como: a) para uma maior sensibilidade na estimativa, o conteúdo total de n-alcanos das espécies deveria ser semelhante, mas os seus perfis deveriam ser bastante diferentes; b) o número máximo de espécies que poderiam ser separadas seria limitado ao número de n-alcanos usados nas equações, para a estimativa.

Em um estudo para quantificar o consumo de partes de plantas por animais em pastejo, Dove et al. (1992) utilizaram 18 ovinos machos castrados 
em piquetes de uma pastagem consorciada de Lolium rigidum e Vulpia bromoides. Na metade dos piquetes foi feita uma aplicação de glifosato com o intuito de retardar a senescência, principalmente da fração haste, o que resultaria em consumos diferentes. Dosificaram os animais, por 12 dias, com o $\mathrm{n}$-alcano $\mathrm{C}_{32}$ e coletaram direto do reto, por 6 dias, as amostras de fezes e utilizaram o par $\mathrm{C}_{31}: \mathrm{C}_{32}$ para estimar o consumo. Encontraram maiores valores para o consumo de matéria orgânica e matéria orgânica digestível nos piquetes que receberam a aplicação de glifosato. Esses autores colheram forragem de ambos os piquetes, fizeram a separação morfológica da forragem em folha, bainha, haste e inflorescência e, em um teste com animais estabulados, ofereceram as frações separadamente em pares (com glifosato vs. sem glifosato). Observaram que os animais consumiram mais da fração haste com aplicação de glifosato. Utilizaram o procedimento de otimização através de quadrados mínimos para estimar que combinação de frações de plantas melhor explicava o perfil de n-alcanos nas fezes. Disseram que os padrões de consumo diferiram entre os animais, e que aqueles que pastejaram a forragem sem o glifosato tiveram o consumo composto de lâminas foliares, bainhas e inflorescências, sem nenhuma haste. Contrariamente, naqueles animais que pastejaram a forragem com glifosato, a fração haste foi a mais consumida. Esses resultados foram consistentes quando comparados com aqueles obtidos com animais estabulados. Esse trabalho é um indicativo de que as concentrações diferentes de n-alcanos em frações da planta e aquelas das fezes produzidas podem ser exploradas para se tentar estimar quais partes das plantas são consumidas, principalmente em pastagens monoespecíficas.

Já Newman et al. (1995) fizeram uma simulação com uma dieta de azevén e trevo e alertaram para o fato de que os n-alcanos usados nas equações são escolhidos arbitrariamente, podendo haver mais de uma solução, e que, por isso não se usa toda a informação disponível (mais n-alcanos do perfil das plantas) e que, em algumas vezes, podem ser encontradas soluções 
erradas, como uma proporção negativa de uma determinada espécie, na mistura. Esses mesmos autores desenvolveram uma técnica baseada no uso dos quadrados mínimos com matrizes matemáticas para estimar as quantidades de cada espécie na dieta, colocando uma restrição para não haver valores negativos na resolução, no caso de dietas com duas espécies. Muito relevante nesse trabalho foi a introdução de um ajuste para a recuperação fecal, que varia com o comprimento da cadeia de carbono, quando se usa o perfil de n-alcanos das fezes, na estimativa.

Para superar esse problema, em dietas com mais de duas espécies de plantas, Dove \& Moore (1995) desenvolveram um método de otimização chamado de quadrados mínimos não negativos, onde, além de superar os problemas já descritos acima, o procedimento de estimativa da composição da dieta consumida poderia ser feita em misturas de mais de duas espécies. Esses autores re-analisaram com este novo procedimento os dados de Dove (1992) e os valores estimados não diferiram, quando comparados com os reais.

Testando três procedimentos para estimar a composição da dieta em vacas lactantes estabuladas que receberam uma dieta de azevém perene (Lolium perenne) e trevo branco (Trifolium repens) mais cevada como concentrado, Hameleers \& Mayes (1998) concluíram que o procedimento dos quadrados mínimos não negativos é uma forma acurada de estimar a composição da dieta consumida, mesmo quando um dos componentes está presente em pequena proporção.

Estudando a variação nos perfis de n-alcanos entre espécies e partes de planta dentro de espécies e, usando análises discriminantes para separá-las, Dove et al. (1996), (com gramíneas e leguminosas) e Chen et al. (1998), (com gramíneas, uma mistura de gramínea e leguminosa e uma pastagem degradada de gramínea e leguminosa) concluíram que as variações nos perfis podem ser exploradas para estimar espécies em misturas de plantas forrageiras ou na dieta consumida pelos animais. 


\subsubsection{Utilização de $n$-alcanos em estudos nutricionais com ruminantes selvagens}

Preocupados com a falta de informações sobre as estratégias de alimentação de animais selvagens mantidos em cativeiro, Hatt et al. (1998) utilizaram a técnica de n-alcanos como indicadores para estimativas de consumo, digestibilidade e composição da dieta em seis girafas (Giraffa camelopardalis), sendo três machos e três fêmeas. Os animais receberam feno de trevo (Trifolium hybridum), uma mistura de concentrado comercial, suplemento vitamínico e uma mistura de aveia amassada e farelo de trigo na proporção de 1:1. Os animais também receberam batatas, couve, cenouras e bananas, três vezes por semana. Os n-alcanos $\mathrm{C}_{28}, \mathrm{C}_{32}$ e $\mathrm{C}_{36}$ foram borrifados sobre o concentrado comercial fornecido aos animais. O consumo utilizando o par de n-alcanos $\mathrm{C}_{33}: \mathrm{C}_{32}$ foi subestimado e consequentemente a produção fecal estimada com $\circ \mathrm{C}_{36}$ e a digestibilidade também foram menores. Os autores atribuíram esses resultados às variações diurnas nas concentrações fecais da relação $\mathrm{C}_{33}: \mathrm{C}_{32}$.

Ainda com a espécie anterior e com a intenção de investigar a importância do estado nutricional sobre a ocorrência de uma doença comum chamada síndrome da mortalidade peraguda, Clauss et al. (2001) testaram quatro substâncias diferentes (Co-EDTA, lignina em detergente ácido, cinza insolúvel em ácido e o $\mathrm{n}$-alcano $\mathrm{C}_{36}$ ) utilizadas como indicadores em um estudo de digestibilidade em girafas cativas. A dieta base dos animais era feno de alfafa mais concentrado comercial, um suplemento de vitamina $\mathrm{E}$ e quantidades controladas de "faia" (Fagus sylvatica), "sicamoro" (Acer pseudoplatanus) e "aveleira" (Corylus avellana). O Co-EDTA foi fornecido em um pedaço de banana e $\circ \mathrm{C}_{36}$ impregnado nos péletes do concentrado comercial. Os péletes com $\circ \mathrm{C}_{36}$ eram fornecidos primeiro, e duas vezes ao dia, para garantir $\mathrm{o}$ 
consumo do indicador. Durante o período de coleta, os alimentos e sobras eram pesados diariamente e as amostras de fezes coletadas direto do chão, várias vezes ao dia. Os autores concluíram que os valores obtidos com o $\mathrm{C}_{36}$ foram mais precisos, quando comparados com os valores da literatura em dietas semelhantes. Nesse estudo os autores assumiram uma recuperação fecal de $95 \%$ para $\circ \mathrm{C}_{36}$, (citando um trabalho com ovinos) e não fizeram coleta total das fezes dos animais. Dessa forma, os dados de recuperação fecal obtidos no trabalho possuem erros que não são independentes dos existentes da estimativa da produção fecal e, consequentemente, dos valores de digestibilidade obtidos.

Trabalhando com fêmeas gestantes de uma espécie de cervo (Cervus elaphus canadensis), Gedir \& Hudson (2000a) mantiveram os animais em pequenos piquetes totalmente sem vegetação, onde recebiam alfafa em cubos, em quantidades monitoradas eletronicamente, e usaram cápsulas de liberação controlada, contendo os $\mathrm{n}$-alcanos $\mathrm{C}_{32}$ e $\mathrm{C}_{36}$, para estimar o consumo, digestibilidade e a produção fecal. Estimaram também as recuperações fecais dos n-alcanos com comprimentos de $\mathrm{C}_{27}$ ao $\mathrm{C}_{36}$. $\mathrm{O}$ consumo foi estimado com os pares $C_{31}: C_{32}$ e $C_{33}: C_{32}$, e encontraram superestimativas de $2,2 \%$ e $6,5 \%$, respectivamente com os pares $\mathrm{C}_{33}: \mathrm{C}_{32}$ e $\mathrm{C}_{31}: \mathrm{C}_{32}$. Mediram também a taxa de liberação diária dos indicadores fornecidos pela cápsula, sendo esta superior àquela indicada pelo fabricante. Concluíram que a técnica pode ser usada para fornecer uma estimativa confiável do consumo com essa espécie de cervo, principalmente em dietas uniformes. Comentaram também que as cápsulas de liberação controlada de $n$-alcanos podem ser uma forma mais vantajosa de fornecer os indicadores para esses animais, eliminando a necessidade de fornecimento diário do indicador. Nesse trabalho não foi realizada coleta total de fezes dos animais. Embora os animais estivessem em piquetes, o monitoramento diário e a colheita de fezes do chão poderia ter sido feita e então medidas as recuperações fecais dos vários n-alcanos envolvidos nesse estudo. 
Estes mesmos autores em (2000b) trabalharam com fêmeas da mesma espécie animal, em pastejo, e utilizaram novamente cápsulas de liberação controlada contendo $\circ \mathrm{C}_{32}$ para estimar o consumo dos animais em quatro fases distintas do seu ciclo produtivo (começo e final da gestação, pico e final de lactação). Usaram também parâmetros de comportamento ingestivo como a taxa de bocados, o peso de bocado e o tempo de pastejo para estimar o consumo. Comentaram que nesse estudo as estimativas de consumo obtidas com os parâmetros de comportamento ingestivo foram maiores que aquelas obtidas com n-alcanos e concluíram que os resultados obtidos eram encorajadores, mas que seriam necessárias mais pesquisas para que se tivesse estimativas confiáveis de consumo com herbívoros selvagens. Nesse trabalho, os autores simularam o pastejo para obterem um peso de bocado e corrigiram-no para a diferença entre a largura da almofada dentária e a mão do observador. Talvez este aspecto de simulação possa ter influenciado na estimativa.

Um aspecto importante nesses últimos dois trabalhos citados é o método utilizado de extração de n-alcanos, que omite um passo (saponificação com solução alcoólica de $\mathrm{KOH}$ ) da metodologia comumente usada, tornando-o mais rápido.

\subsubsection{Utilização de n-alcanos em estudos nutricionais com animais não- ruminantes}

Trabalhando com salmões do ártico, Gudmundsson \& Halldorsdottir (1995) fizeram um experimento para avaliar a utilização dos n-alcanos $C_{28}$ e $C_{32}$ como indicadores externos de digestibilidade e não encontraram diferenças entre os valores de digestibilidade para gordura obtidos com os referidos nalcanos e nem entre esses e outros dois indicadores também utilizados (óxido crômico e celite). Concluíram que os n-alcanos poderiam ser utilizados como 
indicadores para a determinação da digestibilidade de alimentos para peixes. Importante nesse trabalho é a ressalva feita em função da pouca quantidade de n-alcanos na maioria dos alimentos utilizados para peixes, o que praticamente elimina a possibilidade de utilizá-los como indicadores internos.

Com o objetivo de estudar a utilização de n-alcanos para estimar o consumo, digestibilidade e a seleção de alimentos em uma espécie de ave, Hatt et al. (2001) trabalharam com pombos (Columba livia) alojados individualmente. Os n-alcanos $\mathrm{C}_{28}, \mathrm{C}_{32}$ e $\mathrm{C}_{36}$ foram incorporados a uma mistura comercial de sementes, previamente à peletização. Foram realizados dois experimentos, sendo que, no primeiro, foram determinados digestibilidade e consumo. $O$ período experimental foi de 10 dias, sendo a coleta total e amostragem do alimento feita nos últimos 4 dias e as estimativas do consumo realizada com o par $\mathrm{C}_{31}: \mathrm{C}_{32}$, com e sem ajuste para a recuperação fecal. Comentaram que os $\mathrm{n}$ alcanos fornecidos não tiveram efeito sobre a fisiologia digestiva e consumo das aves. O consumo médio estimado com ajuste para a recuperação fecal foi muito próximo daquele observado (24,7 vs. 24,6 $\mathrm{g}_{\text {dia }}{ }^{-1}$, respectivamente), mas subestimado em $16 \%$ quando não houve ajuste. Com relação à composição da dieta, usaram o procedimento dos quadrados mínimos não negativos de Dove \& Moore (1995), e a diferença média entre os valores estimados e observados foi de $2,5 \%$. Nesse trabalho, a recuperação fecal do $C_{31}$, presente no alimento, foi muito diferente daquela do $\mathrm{C}_{32}$ fornecido (68 vs. $81 \%$ ), o que vicia a técnica e faz com que haja necessidade de ajuste. Contudo, os resultados podem ter sido influenciados pela enorme diferença na ingestão dos dois n-alcanos estudados, tendo em vista que a concentração do $C_{31}$ no alimento foi muito menor que a quantidade fornecida aos animais. Esse trabalho foi pioneiro nas estimativas desses parâmetros em aves, e foi importante também porque resultou na modificação da metodologia de extração de alcanos através da redução em cerca de 10 vezes o tamanho da amostra e quantidade de reagentes utilizados. 
Ciente da dificuldade de medir o consumo e a digestibilidade da matéria seca e a produção fecal dos animais em situações de campo, Ordakowski et al. (2001) realizaram um experimento com eqüinos que consistiu de dois ensaios de digestão onde foram testados cinco $n$-alcanos de cadeia ímpar $\left(C_{25}, C_{27}, C_{29}\right.$, $\mathrm{C}_{31}$ e $\mathrm{C}_{33}$ ), naturais da forragem, como indicadores internos de digestibilidade e quatro tipos de dietas a base de feno ou feno mais concentrado. As recuperações fecais dos $n$-alcanos foram feitas através das concentrações fecais e das dietas com as respectivas quantidades produzidas e consumidas. Além disso, estimaram a recuperação fecal pelo coeficiente de regressão obtido da equação entre as quantidades médias de alcanos nas fezes e aquelas da dieta. As recuperações fecais variaram de 71 a 92 \% e não tiveram relação com o aumento do comprimento da cadeia de carbono. Fizeram ajustes para as médias de recuperações fecais de n-alcanos e as digestibilidades estimadas não diferiram daquelas obtidas com a coleta total de fezes. Os autores concluíram que, com a utilização de n-alcanos, pode-se obter estimativas acuradas da digestibilidade da matéria seca. No entanto, os autores ressaltaram que as recuperações fecais incompletas dos n-alcanos sugeriam que os eqüinos poderiam ser capazes de metabolizar n-alcanos em alguma extensão, podendo se fazer necessário algum tipo de ajuste para as recuperações fecais. Devido as recuperações fecais não aumentarem com o aumento do comprimento da cadeia de carbonos, (como acontece em ruminantes) os autores conseguiram obter um único dado de recuperação fecal por regressão linear, fato que pode ser interessante sob condições de pastejo mas que não pode ser adotado como regra geral.

Também com eqüinos, O'keefe \& McMeniman (1998) utilizaram sete dietas e usaram os $n$-alcanos $\mathrm{C}_{32}$ e $\mathrm{C}_{36}$ como indicadores externos para estimar a composição da dieta pelo procedimento de Dove \& Moore (1995). Não encontraram aumento da recuperação fecal em relação ao aumento do comprimento da cadeia de carbono e a composição da dieta foi estimada com 
uma acurácia de 5,4\%. Dos resultados obtidos, foi possível observar que as recuperações fecais dos n-alcanos fornecidos e dos homólogos naturais da dieta foram bastante diferentes, quando comparados com aquelas geradas em experimentos com bovinos.

Relacionando esse trabalho com o de Ordakowski et al. (2001), para os mesmos n-alcanos estudados, a recuperação fecal média foi de 80,98 \pm 6,8 \% para o primeiro contra $89,2 \pm 7,05 \%$ do segundo. Isso sugere cautela com relação ao uso de um único valor de recuperação fecal para os vários n-alcanos estudados, mesmo que alguns relatos da literatura indiquem que não há aumento da recuperação fecal com o aumento do comprimento da cadeia de carbono.

Segundo Hofmann (1989), sob o ponto de vista morfofisiológico de estratégia de alimentação, pode-se classificar os ruminantes em seletores, como sendo aqueles que consomem um determinado grupo de plantas e/ou partes de plantas altamente digestíveis, e aqueles que ingerem forragem mais fibrosa e um grupo intermediário, que pode apresentar um comportamento alternado conforme a vegetação disponível.

Com relação a estudos com pequenos herbívoros não ruminantes mas também considerados animais seletores, Hulbert et al. (2001) estudaram as causas da variação sazonal na dieta de lebres (Lepus timidus L.). Esses autores investigaram se o padrão individual de seleção do habitat em lebres, medido por rádio telemetria, refletiu em uma flexibilidade na composição da dieta de maneira semelhante, utilizando a metodologia de n-alcanos para estimar a composição botânica da dieta ingerida. Separaram a área de vegetação sob estudo em três tipos diferentes identificados em relação ao nível do mar, onde a vegetação variava desde áreas dominadas por gramíneas forrageiras (Lolium perenne L.) até florestas. Utilizaram 118 animais separados por sexo, e classificaram as fêmeas em reprodutivas ou não. Destes, 18 animais foram monitorados por rádio colar e alocados a uma das três áreas de 
forragem segundo observações prévias. Mediram a massa de forragem nas respectivas áreas a cada três meses e separaram os componentes em espécies, obtendo a quantidade de cada espécie para cada animal. De 41 animais, incluindo aqueles com rádio colar, coletaram amostras de fezes na primavera/verão e no outono/inverno, permitindo analisar a dieta em relação à forragem disponível dentro de cada área. Conseguiram separar as espécies ingeridas e identificar o perfil da dieta no período de um ano, detectando, inclusive, variações mensais na composição da dieta. Os autores concluíram que o método foi muito adequado para estimar a variação na composição da dieta porque os animais tiveram uma dieta relativamente simples e os perfis de $\mathrm{n}$-alcanos foram suficientemente diferentes entre as espécies ingeridas. Os autores não fizeram ajustes para as recuperações fecais dos n-alcanos utilizados na estimativa pela impossibilidade de fazer a medida em condições de pastejo, e basearam-se em dados existentes com outros herbívoros não ruminantes.

Hulbert \& Andersen (2001) usaram experimentos em ambientes naturais na costa da Noruega e utilizaram a metodologia de n-alcanos para estimar a composição botânica da dieta em um estudo comparando a competição por alimento entre lebres (Lepus timidus L.) e uma espécie de cervídeo (Capreolus capreolus). Tais animais caracterizam-se por possuirem a mesma estratégia de alimentação, mas diferem consideravelmente em tamanho corporal e sistema digestivo. Concluíram que há uma intensa competição entre as espécies quando as mesmas cohabitam, principalmente quando há escassez de alimentos.

Dove \& Mayes (1999) citaram que Woolnough ${ }^{1}$ comparou alguns métodos para estimar a composição botânica da dieta de cangurus (Macropus giganteus) e de "vombates" (Lasiorhinus krefftii), entre eles os n-alcanos. Este 
autor não encontrou diferenças nos resultados obtidos utilizando n-alcanos quando comparados com análise microhistológica das fezes, mas salientou que, nas amostras avaliadas com este último método, houve uma grande proporção de material não identificado. Além disso, com a metodologia de nalcanos encontrou que as espécies de plantas selecionadas por essas duas espécies de animais herbívoros foram similares em uma mesma área de estudo.

Mayes \& Dove (2000) citaram que Gannon ${ }^{2}$ encontrou que a utilização de n-alcanos como indicador forneceu estimativas confiáveis de consumo com suínos criados de forma extensiva. Comentaram, também, que Wilson ${ }^{3}$ et al. encontraram diferentes recuperações fecais entre os n-alcanos de cadeia ímpar naturais do alimento $\left(\mathrm{C}_{33}\right)$ e o sintético de cadeia par fornecido aos animais $\left(\mathrm{C}_{32}\right)$, o que levou a erro nas estimativas de consumo com essa espécie de animal. É importante ressaltar que alguns trabalhos com eqüinos, já citados anteriormente, mostraram que, ao contrário do que ocorre com ruminantes, não houve aumento da recuperação fecal dos n-alcanos com o aumento do comprimento da cadeia de carbonos. O trabalho de Wilson ${ }^{3}$ et al., citados por Mayes \& Dove (2000) mostrou que esta peculiaridade não ocorre em todas as espécies de animais não ruminantes que possam vir a consumir forragens.

\footnotetext{
${ }^{1}$ Woolnough, A. P. The feeding ecology of northern hairy-nosed wombat, Lasiorhinus krefftii. PhD (Thesis) - Australian National University, 1998.

${ }^{2}$ Gannon, M. A. The energy balance of pigs outdoors. PhD (Thesis) - University of Nothingham, 1996.

${ }^{3}$ Wilson, H.; Sinclair, A.G.; Hovell, F.D.B; Mayes, R.W.; Edwards, S.A. Validation of the n-alkane technique for measuring herbage intake in sows. Proceedings of The British Society of Animal Science, p.171, 1999.
} 


\section{VALIDAÇÃO DO USO DE CÁPSULAS DE LIBERAÇÃO CONTROLADA DE N-ALCANOS PARA ESTIMATIVA DO CONSUMO DE FORRAGEM EM BOVINOS}

\section{Resumo}

Os n-alcanos têm sido utilizados como indicadores em estudos nutricionais com herbívoros ruminantes e não ruminantes. Foram realizados dois experimentos para avaliar: 1) a taxa de liberação de n-alcanos fornecidos via cápsulas de liberação controlada, em confinamento ou em pastagem; 2) validar a estimativa do consumo de forragem com animais em gaiolas metabólicas. Foram utilizados seis animais com fístula ruminal que, em gaiolas de metabolismo, receberam os seguintes tratamentos: a) $80: 20-80 \%$ de volumoso e $20 \%$ de concentrado; b) $60: 40$ - $60 \%$ de volumoso e $40 \%$ de concentrado; c) $40: 60$ - $40 \%$ de volumoso e $60 \%$ de concentrado, em uma dieta a base de silagem de milho. Em pastejo, receberam três tratamentos: a) só pasto (Brachiaria brizantha cv. Marandu); b) pasto mais uma suplementação de $0,3 \%$ do peso vivo; c) pasto mais uma suplementação de $0,6 \%$ do peso vivo. As taxas foram medidas retirando-se a cápsula via fístula e medindo-se a distância percorrida pelo êmbolo da cápsula que pressiona as pastilhas contendo o indicador aos 3, 7, 10, 13 e 17 dias após sua colocação no rúmen. Não houve efeito de dieta e da interação dieta vs. dia de medida $(P>0,05)$ sobre as taxas diárias de liberação de n-alcanos no rúmen. Essas taxas, multiplicadas 
pela quantidade de cada n-alcano existente por milímetro de pastilha que compõem a cápsula, resultaram em valores médios 6,9 e 14,8 \% menores do que o valor indicado pelo fabricante para $\circ \mathrm{C}_{32}$, para as condições de gaiola $\mathrm{e}$ pasto, respectivamente. Para $\circ \mathrm{C}_{36}$ os valores médios foram 15,9 e $23,1 \%$ menores para as condições de gaiola e pasto, respectivamente. A quantidade média de $\mathrm{C}_{32}$ liberada no rúmen nos animais em gaiola foi $372 \mathrm{mg} \mathrm{dia}^{-1} \mathrm{e}$ em pastagem $341 \mathrm{mg} \mathrm{dia}^{-1}$. Estatisticamente foi possível unir as equações geradas para cada situação resultando em uma quantidade liberada do indicador de 345 mg.dia ${ }^{-1}$. O consumo estimado com o par $\mathrm{C}_{33}: \mathrm{C}_{32}$ de $\mathrm{n}$-alcanos nos animais em gaiolas não diferiu dos valores observados $(P<0,05)$.

\section{VALIDATION OF N-ALKANES CONTROLLED RELEASE CAPSULES TO ESTIMATE FORAGE INTAKE BY CATTLE}

\section{Summary}

The n-alkanes have been used as markers on nutritional studies with ruminant and non-ruminant herbivores. Two trials were conduced to: 1) evaluate the rate of $n$-alkanes realease from commercial capsules placed in the rumen of fistulated animals in metabolic cages or on pastures; 2) validate the technique to estimate the voluntary forage intake measured in metabolic cages. Six fistulated Nelore steers were placed in metabolic cages and fed diets with different forage to concentrate ratios: a) $80: 20$, b) $60: 40$ and c) 40:60 where corn silage was the only roughage source. On the grazing trial animals received three different treatments a) grazing Brachiaria brizantha cv. Marandu, b) grazing plus 0,3 $\%$ LW/DM of a supplement or c) grazing plus $0,6 \% \mathrm{LW}$ of a supplement. The rates of $n$-alkanes release were measured by the capsule's plunger distance 
traveled after 3, 7, 10, 13 and 17 days after rumen infusion. There was no effect of diet type or interaction between diet and day of measurement $(P>0,05)$ on rates of alkane release for the conditions of metabolic cage or grazing. Those rates when multiplied by the $\mathrm{n}$-alkanes concentrations per $\mathrm{mm}$ of tablets that compose the capsules resulted on mean values 6,9 and $14,8 \%$ lower than proposed by the manufacturer for $\mathrm{C}_{32}$, for metabolic cage and pasture condition, respectively. In addition, the values of $\mathrm{C}_{36}$ were 15,9 and $23,1 \%$ lower for metabolic cage and pasture conditions, respectively. The mean $\mathrm{C}_{32}$ released in the rumen of animals housed in metabolic cages was 372 mg.day $^{-1}$ and 341 mg.day ${ }^{-1}$ for grazing animals. It was statistically possible to join both equations

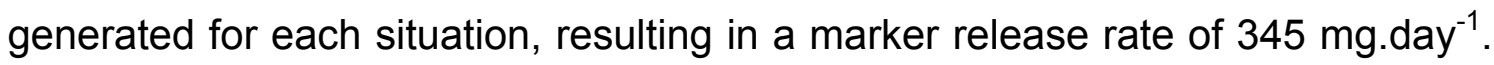
The dry matter intake estimated with the $\mathrm{C}_{33}: \mathrm{C}_{32}$ pair of $n$-alkanes did not differ $(P<0,05)$ from the intake observed for animal in metabolic cages.

\subsection{Introdução}

Os n-alcanos são hidrocarbonetos alifáticos saturados presentes na cera cuticular das plantas, com comprimento da cadeia variando entre 21 e 37 átomos de carbono, e têm sido utilizados como indicadores fecais em estudos nutricionais com ruminantes domésticos, selvagens e com animais nãoruminantes.

Em trabalho pioneiro de estimativa de consumo em ruminantes essas substâncias foram fornecidas como indicadores externos sob a forma de péletes feitos de tiras de papel filtro impregnadas com os n-alcanos sintéticos (Mayes et al., 1986a). Trabalhando com ovinos, Dove et al. (1989) forneceram os n-alcanos $\mathrm{C}_{28}$ e $\mathrm{C}_{32}$ na forma de cápsulas de gelatina, contendo celulose em pó previamente acrescida da dose do n-alcano dissolvido em n-hexano ou nheptano. Utilizando um procedimento diferente, Vulich et al. (1991) misturaram os n-alcanos com o solvente e a celulose em pó resultando em uma suspensão 
homogênea que, após evaporada e seca, foi colocada em cápsulas de gelatina. Testando outra proposta, Marais et al. (1996) forneceram a ovinos os n-alcanos impregnados em partículas de uma gramínea (Pennisetum clandestinum Hochst) suspensas em uma solução de água e goma xantana $(0,4 \%)$ e fornecidas em doses através de pistolas dosadoras ou seringas descartáveis.

Esses procedimentos impõem um certo grau de distúrbio aos animais tendo em vista que o fornecimento da dose do indicador é feito pelo menos uma vez ao dia. Além disso, o fornecimento de doses discretas do indicador pode levar a variações diurnas em sua excreção fecal, resultando em erros nos cálculos do consumo. Como o uso de n-alcanos em estimativas de consumo é um tanto diferente de outros indicadores (base do método é a relação fecal na excreção entre um n-alcano de cadeia ímpar natural do alimento e seu homólogo de cadeia par fornecido), pode haver variações nas quantidades absolutas desde que não haja variação na relação fecal entre os dois n-alcanos.

Havendo a possibilidade de variação diurna e/ou diária na concentração fecal dos indicadores, o desenvolvimento de aparelhos de liberação controlada poderia auxiliar na minimização dessa fonte de erro. Assim, cientes desse problema, Dove et al. (1991) e Dove et al. (2002) trabalharam com ovinos intactos e fistulados no rúmen, alojados em gaiolas metabólicas, com os quais testaram o funcionamento de um aparelho de liberação controlada dos nalcanos sintéticos $\mathrm{C}_{28} \quad \mathrm{e}_{32}$ colocado dentro do rúmen. Com a remoção periódica do aparelho via fístula, calcularam a taxa de liberação, que teve um coeficiente de variação de 4,1\%. Esses autores comentaram ainda que, após o período de equilíbrio na liberação, alcançado cinco dias após a dosificação, as concentrações fecais dos n-alcanos sintéticos foram menos erráticas do que aquela de outro $n$-alcano sintético $\left(\mathrm{C}_{36}\right)$, também fornecido diariamente, uma vez ao dia, sob a forma de péletes de papel. Esse estudo mostrou que havia possibilidade de se usar um aparelho de liberação controlada para o fornecimento de n-alcanos sintéticos em estimativas de consumo. 
O objetivo deste trabalho foi medir a taxa de liberação de n-alcanos sintéticos fornecidos através de cápsulas de liberação controlada (MCM Alkanes código 60421 - Captec, NZ), validar a estimativa do consumo em bovinos de corte alojados em gaiolas de metabolismo e, também, medir a taxa de liberação dessas cápsulas com os animais em regime de pastejo.

\subsection{Material e Métodos}

\subsubsection{Experimento 1}

\subsubsection{Procedimentos experimentais}

Durante o mês de junho de 2001, foi realizado no Instituto de Zootecnia de Nova Odessa um experimento de digestibilidade com coleta total de fezes, no qual foram utilizados seis novilhos da raça Nelore, castrados, com idade de 18 meses e peso vivo médio de $380 \mathrm{~kg}$, fistulados no rúmen. Os animais foram mantidos em gaiolas metabólicas com livre acesso a água e receberam três dietas diferentes, dois animais por dieta, formuladas segundo o Sistema de Cornell (Sistema de Carboidratos e Proteína Líquidos de Cornell - CNCPS versão 4.2, Fox et al., 2000) visando fornecer quantidades necessárias às exigências do rúmen e do animal. $\mathrm{Na}$ Tabela 1 estão as proporções, ingredientes e a composição química estimada das dietas. Os tratamentos aos quais os animais foram submetidos foram, em base seca: a) $80: 20-80 \%$ de volumoso e $20 \%$ de concentrado; b) $60: 40-60 \%$ de volumoso e $40 \%$ de concentrado; c) 40:60 - $40 \%$ de volumoso e $60 \%$ de concentrado. 
Tabela 1. Proporções dos ingredientes (volumoso:concentrado) e a composição química estimada das dietas, em base seca

\begin{tabular}{lccc}
\hline Ingrediente (\%) & $80: 20$ & $60: 40$ & $40: 60$ \\
\hline Silagem de milho & 79,6 & 58,5 & 39,4 \\
Milho triturado & 4,2 & 9,4 & 13,5 \\
Sorgo moído & 2,8 & 8,0 & 13,5 \\
Farelo proteinoso de milho & 2,1 & 4,6 & 6,0 \\
Farelo de soja & 3,5 & 3,6 & 5,4 \\
Farelo de Algodão & 2,2 & 3,6 & 4,0 \\
Uréia & 1,3 & 1,0 & 0,5 \\
Casca de soja & 2,8 & 9,8 & 16,2 \\
Mistura Mineral $^{*}$ & 1,5 & 1,5 & 1,5
\end{tabular}

Composição química estimada, \%

MS

34,0

40,0

49,0

NDT

71,0

73,0

77,0

PB

14,2

14,8

14,9

* Sulfato de cálcio $(28,1 \%)$, calcário (46,8 \%), cloreto de sódio $(18,7 \%)$, sulfato de manganês $(0,34 \%)$, fosfato bicálcico $(5,2 \%)$, sulfato de cobre $(0,08 \%)$, sulfato de zinco $(0,12 \%)$, sulfato de cobalto $(0,004 \%)$, selenito de sódio $(0,004 \%)$

Os ingredientes de cada concentrado foram misturados sem a casca de soja porque esta era peletizada, sendo misturada e homogeneizada com a silagem e o restante do concentrado diretamente no cocho. A quantidade fornecida de alimento foi de $100 \mathrm{~g}$ de matéria seca. $\mathrm{kg}^{-1} \mathrm{PVJ}^{0,75}$ (peso vivo em jejum).

Os tratamentos foram alocados aos animais fistulados segundo um delineamento completamente casualizado tendo duas repetições (animais) por tratamento. 
Após uma semana de adaptação às dietas, cada novilho recebeu, via fístula ruminal, uma cápsula de liberação controlada contendo $8 \mathrm{~g}$ de $\mathrm{n}$ dotriacontano $\left(\mathrm{C}_{32}\right)$ e $8 \mathrm{~g}$ de $\mathrm{n}$-hexatriacontano $\left(\mathrm{C}_{36}\right)$ (MCM Alkanes código 60421 - Captec, NZ). A cápsula correspondia a um cilindro de plástico com 16 $\mathrm{cm}$ de comprimento e 3,8 cm de diâmetro, fechada em uma extremidade e com um êmbolo com mola de arame. Esse êmbolo pressionava cinco pastilhas de celulose impregnadas com os $\mathrm{n}$-alcanos que, em contato com a digesta e o líquido do rúmen, começavam a liberar os referidos indicadores. A cápsula possuia também uma "asa" com $18 \mathrm{~cm}$ anexada à extremidade fechada para evitar que os animais a regurgitassem. As cápsulas foram amarradas à borda da fístula por um fio de nylon com comprimento que permitisse a sua movimentação dentro do rúmen com a digesta. Nos dias 3, 7, 10, 13 e 17 após a inserção no rúmen, cada cápsula foi removida, rapidamente borrifada com água morna, feita a medida da distância percorrida pelo êmbolo com um paquímetro e rapidamente retornada ao rúmen. Essa medida foi feita em quatro pontos diametralmente opostos (em cruz) ao longo do perímetro da secção transversal da cápsula. Duas cápsulas do mesmo lote usado neste estudo foram desmanchadas, as espessuras, os pesos de cada uma das dez pastilhas determinados e a quantidade de cada n-alcano, em duas pastilhas, determinada para cálculo da quantidade de cada n-alcano por pastilha e por milímetro de pastilha.

Após sete dias da colocação das cápsulas, foi medido o consumo e as sobras, diariamente, e feita a coleta total de fezes do oitavo ao décimo segundo dia.

As fezes totais foram coletadas uma vez ao dia em caixa coletora posicionadas atrás das gaiolas. Após pesagem do material coletado, $10 \%$ foi amostrado, acondicionado em saco plástico e colocado em freezer a $-20^{\circ} \mathrm{C}$. As amostras de silagem e concentrado foram coletadas diariamente (1 kg para 
silagem e 0,2 kg para concentrado), pesadas e congeladas. Ao final do período, as amostras foram homogeneizadas e compostas por animal por período.

\subsubsection{Extração de alcanos}

As amostras de silagem de milho, concentrados e fezes foram secas a $60^{\circ} \mathrm{C}$ em estufa de circulação forçada de ar, moídas em peneira de malha de 1 $\mathrm{mm}$ e a extração e determinação do conteúdo de n-alcanos nas amostras, em duplicata, foram feitas utilizando-se a metodologia descrita por Dillon \& Stakelum (1990a), com as seguintes modificações: a) o solvente utilizado foi $n$ heptano em substituição ao n-hexano e b) usou-se um aparelho de banho-maria substituindo o bloco aquecedor durante a saponificação. Uma amostra de 1,5 g para silagem e concentrados, $0,5 \mathrm{~g}$ para fezes e $0,05 \mathrm{~g}$ para as pastilhas foi colocada em tubos de ensaio Pyrex de $25 \times 200 \mathrm{~mm}$ (silagem e concentrados) e $20 \times 100 \mathrm{~mm}$ (fezes e pastilhas) com tampas com rosca. Adicionou-se a cada amostra $0,25 \mathrm{mg}$ de n-tetratriacontano $\left(\mathrm{C}_{34}\right.$, Sigma) como um padrão interno. Em seguida, foram adicionados $14 \mathrm{~mL}$ para silagem e concentrados e $7 \mathrm{~mL}$ para fezes e pastilhas de uma solução etanólica de Hidróxido de Potássio $(\mathrm{KOH}$, Carlo Herba) $1 \mathrm{M}$, permanecendo os tubos em repouso por 30 minutos e colocados em banho-maria a $90^{\circ} \mathrm{C}$ por quatro horas. Após o resfriamento das amostras, em torno de 20 minutos, foram adicionados $14 \mathrm{~mL}$ de $\mathrm{n}$-heptano (Sigma) mais $4 \mathrm{~mL}$ de água destilada para os alimentos e $7 \mathrm{~mL}$ de $\mathrm{n}$-heptano mais $2 \mathrm{~mL}$ de água destilada para fezes e pastilhas. O conteúdo dos tubos foi agitado vigorosamente por 30 segundos. A camada superior foi removida e retida em béquer de $50 \mathrm{~mL}$, e fez-se outra adição de $\mathrm{n}$-heptano sendo a extração repetida e adicionada à primeira. O conteúdo dos béqueres foi evaporado em capela com exaustão à temperatura ambiente.

A camada removida foi reconstituída em $2,5 \mathrm{~mL}$ de n-heptano e aplicada no topo de uma coluna descartável (Alltech código 17312) contendo sílica gel 
70-230 mesh (Merck) suspensa em n-heptano, com um volume de leito de 5 $\mathrm{mL}$. Os alcanos foram eluídos em vidros transparentes com $20 \mathrm{~mL}$ de $\mathrm{n}$ heptano e evaporados à temperatura ambiente em capela com exaustão.

Os eluatos dos alimentos e fezes foram redissolvidos em 1,9 mL de $\mathrm{n}$ heptano e colocados em vidros para cromatografia (Hewlett Packard código 5182-0714) previamente à análise cromatográfica. Os eluatos das pastilhas foram redissolvidos em $10 \mathrm{~mL}$ e colocados $1,9 \mathrm{~mL}$ em vidros para cromatografia (Hewlett Packard código 5182-0714), também previamente à análise cromatográfica.

\subsubsection{Análise cromatográfica}

A análise cromatográfica foi feita utilizando-se uma coluna capilar CP-Sil 8CB (Crompack) com $30 \mathrm{~m} \times 0,25 \mathrm{~mm} \times 0,25 \mu \mathrm{m}$ de espessura de filme, em um cromatógrafo a gás (Thermoquest, Thermofinningam - USA) com detector de ionização de chama. A temperatura do injetor foi de $280^{\circ} \mathrm{C}$ e a do detector de $310^{\circ} \mathrm{C}$. A temperatura da coluna foi programada para iniciar com $200^{\circ} \mathrm{C}$ por 1 minuto e posteriormente a taxa de aquecimento foi de $6^{\circ} \mathrm{C}$ por minuto com uma temperatura final de $300^{\circ} \mathrm{C}$ mantida por 15 minutos. $\mathrm{O}$ gás carregador foi $\mathrm{o}$ hélio, com velocidade linear de $32 \mathrm{~cm}$.segundo ${ }^{-1}$. Os gases da chama, nitrogênio, hidrogênio e oxigênio tiveram taxas de fluxo de 30, 35 e 430 $\mathrm{mL}$.minuto ${ }^{-1}$, respectivamente. O modo de injeção foi do tipo "split" com uma razão de 20:1 e a amostra de $2 \mu \mathrm{L}$ foi injetada automaticamente.

A área sob cada pico referente a cada n-alcano foi determinada utilizando-se um software da ChromQuest (Chromquest versão 2.53) em um microcomputador. A identificação de cada n-alcano foi feita através da análise de correlação e regressão linear entre o número de carbonos da cadeia e o logarítmo dos tempos de retenção. As áreas de cada pico foram convertidas nas quantidades de cada n-alcano por referência ao padrão interno (n- 
tetratriacontano) segundo Mc Nair \& Bonnelli (1968). Também foram feitas extrações sem a adição do padrão interno nas amostras de alimentos, chamadas de "extrações em branco", para verificar se esse n-alcano não era um componente natural do perfil de alcanos dos alimentos. Onde ele foi encontrado, sua área foi subtraída daquela detectada usando o padrão. Os cálculos do fator de resposta para cada n-alcano foram feitos por referência ao padrão interno usando os procedimentos de Untz (1982).

$\mathrm{Na}$ sequência, foram calculadas as quantidades de cada n-alcano em um quilograma de matéria seca de alimentos, fezes e pastilhas. As duas pastilhas

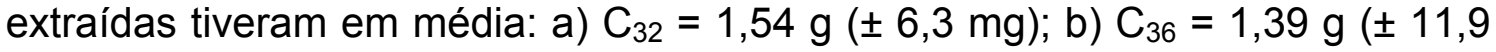
$\mathrm{mg}$ ). É conveniente ressaltar que esses valores encontrados estão dentro da margem de $\pm 5 \%$ para as quantidades de cada $n$-alcano e $\pm 5 \%$ para o peso de cada pastilha em relação aos valores reais fornecidos pelo fabricante $(1,52 \mathrm{~g}$ para o $\mathrm{C}_{32}$ e 1,53 g para o $\mathrm{C}_{36}$ ) para o lote de cápsulas usados neste estudo.

\subsubsection{Cálculos}

Da cápsula desmanchada, obteve-se uma espessura média de cada pastilha de 10,3 $( \pm 0,06) \mathrm{mm}$, ou seja, $149,5 \mathrm{mg}$ de $C_{32}$ e $135 \mathrm{mg}$ de $C_{36}$ por milímetro ( $\mathrm{g}$ de $\mathrm{Cn}$.espessura ${ }^{-1}$ média para o $\mathrm{C}_{32}$ e $\mathrm{C}_{36}$, respectivamente). Nas cápsulas intactas, a distância média da parte fechada do cilindro até o início do êmbolo foi de $86,85( \pm 0,05) \mathrm{mm}(\mathrm{DI})$. A cada dia de medida e para cada animal obteve-se uma distância parcial média $\left(\mathrm{DP}_{3-17}\right)$, da qual foi subtraída a distância média inicial (DI), obtendo-se assim a distância percorrida pelo êmbolo em milímetros a cada data de medição (DISTA). As taxas diárias de liberação foram calculadas como o quociente entre os valores de DISTA e o número de dias correspondentes a cada intervalo entre as medições. 
$\mathrm{O}$ valor de recuperação fecal (RFn) dos n-alcanos (n) $\mathrm{C}_{31}, \mathrm{C}_{32}, \mathrm{C}_{33}, \mathrm{C}_{35} \mathrm{e}$ $\mathrm{C}_{36}$ foi calculado com base no consumo observado (Co), na produção fecal em $\mathrm{kg}$ de matéria seca (PF) e nas concentrações dos respectivos n-alcanos (mg. $\mathrm{kg}^{-1}$ de MS) na dieta ( $\left.\mathrm{Di}\right)$ e nas fezes (Fe), de acordo com a seguinte fórmula (1):

$$
\mathrm{RFn}=[(\mathrm{PF} \times \mathrm{Fe}) /(\mathrm{Co} \times \mathrm{Di})] \times 100
$$

O cálculo da estimativa do consumo de matéria seca foi feito utilizandose o par de n-alcanos $\mathrm{C}_{33}$, de cadeia ímpar e natural da dieta, e $\mathrm{C}_{32}$, de cadeia par e sintético, fornecido via cápsula de liberação controlada, de acordo com a equação proposta por Mayes et al. (1986a) (2):

$$
C=\left\{F_{i} / F_{p} \times\left[D_{p}+\left(C_{c} \times C_{p}\right)\right]-\left(C_{c} \times C_{i}\right)\right\} /\left[F_{o i}-\left(F_{i} / F_{p}\right) \times F_{o p}\right]
$$

Onde:

$\mathrm{C}=$ consumo diário de forragem $\left(\mathrm{kg} \mathrm{MS} \cdot \mathrm{dia}^{-1}\right)$;

$\mathrm{F}_{\mathrm{i}}=$ concentração (mg. $\mathrm{kg}^{-1}$ de MS) do n-alcano de cadeia ímpar nas fezes;

$F_{p}=$ concentração (mg. $\mathrm{kg}^{-1}$ de MS) do n-alcano de cadeia par nas fezes;

$D_{p}=$ quantidade do n-alcano sintético de cadeia par, fornecido $\left(\mathrm{mg} \cdot \mathrm{dia}^{-1}\right)$;

$\mathrm{F}_{\mathrm{oi}}=$ concentração $\left(\mathrm{mg} \cdot \mathrm{kg}^{-1}\right.$ de $\left.\mathrm{MS}\right)$ do $\mathrm{n}$-alcano de cadeia ímpar natural da forragem;

$F_{o p}=$ concentração $\left(\mathrm{mg} \cdot \mathrm{kg}^{-1}\right.$ de MS) do n-alcano de cadeia par natural da forragem;

$\mathrm{C}_{\mathrm{c}}=$ consumo de concentrado $\left(\mathrm{kg} \mathrm{MS} \cdot \mathrm{dia}^{-1}\right)$;

$\mathrm{C}_{\mathrm{p}}=$ concentração $\left(\mathrm{mg} \cdot \mathrm{kg}^{-1}\right.$ de $\left.\mathrm{MS}\right)$ do $\mathrm{n}$-alcano de cadeia par natural do concentrado;

$\mathrm{C}_{\mathrm{i}}=$ concentração $\left(\mathrm{mg} \cdot \mathrm{kg}^{-1}\right.$ de $\mathrm{MS}$ ) do n-alcano de cadeia ímpar natural do concentrado; 


\subsubsection{Experimento 2}

\subsubsection{Procedimentos experimentais}

Entre os meses de janeiro e fevereiro de 2002, foram utilizados seis animais da raça Nelore, fistulados no rúmen, com peso vivo médio de $470 \mathrm{~kg}$ ( \pm $36,8)$ e 24 meses de idade, para realização de medições da taxa de liberação dos mesmos n-alcanos do Experimento 1 em condições de pastejo. Os mesmos animais, dois por tratamento, juntamente com mais 11 animais intactos, tiveram acesso a uma pastagem de Brachiaria brizantha cv. Marandu e foram rotacionados entre 3 piquetes de um hectare dentro de uma parcela maior, com 21 dias de ocupação e 42 dias de descanso, e foram suplementados, uma vez ao dia, com concentrados (Tabela 2) segundo três tratamentos: a) só pasto; b) pasto mais uma suplementação em base de matéria seca de $0,3 \%$ do peso vivo; c) pasto mais uma suplementação em base de matéria seca de 0,6 \% do peso vivo. O objetivo dos tratamentos com suplementação foi de fornecer a mesma quantidade de proteína bruta por kg de peso vivo aos animais intactos que tinham em média $350 \mathrm{~kg}$. 
Tabela 2. Proporções dos ingredientes, composição química determinada dos concentrados, consumo de concentrado ( $\mathrm{kg}$ de MS) e massa média de forragem $\left(\mathrm{kg}^{\mathrm{h}} \mathrm{ha}^{-1}\right)$

\begin{tabular}{lcc}
\hline Ingredientes & $0,3 \% \mathrm{PV}$ & $0,6 \% \mathrm{PV}$ \\
\hline Polpa de citrus & 15,3 & 52,4 \\
Farelo proteinoso de milho & 75,6 & 42,4 \\
Uréia & 4,9 & 2,9 \\
Mistura mineral $^{*}$ & 4,2 & 2,3
\end{tabular}

Composição química determinada, \%

MS

88,1

88,4

PB

40,8

23,8

FDN

41,7

34,9

Consumo de concentrado

1,4

2,8

Massa média de forragem

5998

5998

* Idem experimento 1

Os procedimentos para colocação das cápsulas e determinações foram os mesmos relatados anteriormente no Experimento 1.

\subsubsection{Análise estatística}

O efeito de dieta, em gaiola ou em pastagem, sobre as distâncias percorridas pelos êmbolos de cada cápsula e as taxas de liberação de nalcanos no rúmen em cada data de avaliação foram testados através do procedimento PROC MIXED. Considerou-se como efeitos fixos a dieta e sua interação com as datas de avaliação para as distâncias percorridas, e a dieta, as datas de avaliação e sua interação para as taxas de liberação. A taxa de liberação de n-alcanos foi estimada como sendo o coeficiente angular (b) da 
regressão linear entre a distância percorrida pelo êmbolo (DISTA) e o número de dias após a colocação das cápsulas no rúmen, determinada usando-se o procedimento PROC REG. Através dos comandos $r$, cli e clm dentro do procedimento citado acima, fez-se a análise dos resíduos estudentizados "Student Residual" que foi utilizada para indicar observações "outliers" na estimativa dos parâmetros. Se o resíduo estudentizado se apresentasse fora da faixa -2 a 2, era considerado como um "outlier" e retirado da análise. Foi realizado também o teste com a finalidade de verificar se as equações provenientes dos dados de gaiolas de metabolismo e de animais em pastejo poderiam ser agrupadas, o que resultaria em uma maior precisão das estimativas. Para tal, utilizou-se os procedimentos de Neter \& Waserman (1996), testando-se a igualdade dos interceptos e coeficientes angulares (b) entre os dois tipos de equação através de intervalo de confiança de $95 \%$.

A acurácia das estimativas do consumo de cada novilho com a técnica do duplo n-alcano nos animais em gaiolas de metabolismo foi determinada pela análise de regressão entre os valores estimados e os observados, testando se o coeficiente angular da regressão (b) era diferente de 1 pelo comando TEST do PROC REG. O erro tendencioso associado à técnica foi testado usando o teste " $\mathrm{t}$ " de Student com o procedimento TTEST para comparações emparelhadas, em que a média das diferenças entre as medições estimadas com os indicadores e observadas representa o "vício" associado à técnica. Todas as análises estatísticas foram feitas usando-se o pacote estatístico SAS (2001). 


\subsection{Resultados e Discussão}

\subsubsection{Taxa de liberação de $n$-alcanos dos experimentos em gaiolas de metabolismo e em regime de pastejo}

Os dados foram analisados separadamente para cada situação avaliada, gaiola ou pastagem. Durante o experimento em pastagem houve a troca de dois animais participantes do experimento em gaiolas por outros mais mansos, que permitiam mais facilmente as medidas a campo. Para a análise de regressão dos dados foram desconsiderados os valores relativos ao dia 17 após a colocação da cápsula no rúmen dos animais, tanto nas gaiolas como em pastagem, pois não era possível uma boa visualização do êmbolo. Além disso, as medidas obtidas até o dia 13 estavam dentro do período normalmente utilizado para as coletas fecais quando da realização de estimativas de consumo ( 7 dias para estabilização da liberação dos n-alcanos no rúmen e 5 dias de coleta). Nas Tabela 3 e 4 são apresentados os valores das distâncias parciais e das respectivas taxas de liberação de n-alcanos calculadas com os animais em gaiolas metabólicas.

Dos dados da Tabela 3, nota-se que somente duas observações do animal 1 nos dias 10 e 13 foram excluídas da análise de regressão após a análise dos resíduos. Não houve efeito de dieta e nem da interação dieta e dia de medição $(P>0,05)$ sobre as distâncias parciais percorridas pelo êmbolo das cápsulas. 
Tabela 3. Distâncias ( $\mathrm{mm}$ ) percorridas pelos êmbolos das cápsulas colocadas no rúmen de animais em gaiolas de metabolismo

\begin{tabular}{lccccccc}
\hline & & & \multicolumn{5}{c}{ Distância, mm } \\
Animal & Dietas & Cáps. N & 3 dias & 7 dias & 10 dias & 13 dias & 17 dias \\
\hline 4 & $80: 20$ & 59 & 7,55 & 17,35 & 24,88 & 31,13 & 50,10 \\
6 & $80: 20$ & 61 & 7,00 & 17,65 & 26,50 & 33,93 & 50,70 \\
1 & $40: 60$ & 56 & 7,80 & 18,05 & $28,83^{\#}$ & $37,15^{\#}$ & 50,50 \\
5 & $40: 60$ & 60 & 8,20 & 16,63 & 23,55 & 31,90 & 50,30 \\
2 & $60: 40$ & 57 & 8,15 & 18,13 & 25,43 & 31,90 & 47,80 \\
3 & $60: 40$ & 58 & 7,20 & 18,00 & 26,15 & 33,68 & 47,80 \\
& & & & & & & \\
Média & & & 7,65 & 17,63 & 25,30 & 32,51 & 49,53 \\
CV(\%) & & & 6,4 & 3,2 & 4,6 & 3,8 & 2,7 \\
\hline Valores excluídos durante a análise de regressão linear pela análise dos & resíduos \\
estudentizados & & & & & &
\end{tabular}

Com relação às taxas de liberação diárias de n-alcanos no rúmen, não houve efeito de dia de medição, dieta e nem da interação dieta e dia de medição $(P>0,05)$ (Tabela 4). 
Tabela 4. Taxas de liberação $\left(\mathrm{mm}^{\mathrm{dia}}{ }^{-1}\right)$ de $\mathrm{n}$-alcanos entre os dias 3 e 17 após a dosificação de animais em gaiolas de metabolismo

\begin{tabular}{|c|c|c|c|c|c|c|c|}
\hline \multirow[b]{2}{*}{ Animal } & \multirow[b]{2}{*}{ Dietas } & \multirow[b]{2}{*}{ Cáps. No } & \multicolumn{5}{|c|}{ Taxas, mm.dia ${ }^{-1}$} \\
\hline & & & 3 dias & 7 dias & 10 dias & 13 dias & 17 dias \\
\hline 4 & $80: 20$ & 59 & 2,52 & 2,48 & 2,49 & 2,39 & 2,95 \\
\hline 6 & $80: 20$ & 61 & 2,33 & 2,52 & 2,65 & 2,61 & 2,98 \\
\hline 1 & $40: 60$ & 60 & 2,73 & 2,38 & $2,36^{\#}$ & $2,45^{\#}$ & 2,96 \\
\hline 5 & $40: 60$ & 56 & 2,60 & 2,58 & 2,88 & 2,86 & 2,97 \\
\hline 2 & $60: 40$ & 57 & 2,72 & 2,59 & 2,54 & 2,45 & 2,81 \\
\hline 3 & $60: 40$ & 58 & 2,40 & 2,57 & 2,62 & 2,59 & 2,81 \\
\hline Média & & & 2,55 & 2,52 & 2,64 & 2,58 & 2,91 \\
\hline $\mathrm{CV}(\%)$ & & & 6,3 & 3,2 & 5,7 & 7,0 & 2,7 \\
\hline
\end{tabular}

\# Valores excluídos pela análise dos resíduos estudentizados

Com os animais em pastagem, pode-se observar na Tabela 5 que, baseado na análise dos resíduos, foram excluídos os dados do animal 1. Os resultados das taxas diárias de liberação dos n-alcanos estão na Tabela $6 . \mathrm{Na}$ condição de pastagem, não houve efeito de dieta nem da interação dieta e dia de medição $(P>0,05)$ sobre as distâncias parciais percorridas pelo êmbolo das cápsulas. Com relação às taxas de liberação, não houve efeito de dia de medição, dieta ou da interação dieta e dia de medição $(P>0,05)$. 
Tabela 5. Distâncias $(\mathrm{mm})$ percorridas pelos êmbolos das cápsulas colocadas no rúmen de animais em regime de pastejo

\begin{tabular}{lccccccc}
\hline & & \multicolumn{6}{c}{ Distância, mm } \\
Animal & Dietas & Cáps. No & 3 dias & 7 dias & 10 dias & 13 dias & 17 dias \\
\hline 1 & Braquiária & 91 & $9,75^{\#}$ & $18,95^{\#}$ & $26,13^{\#}$ & $33,48^{\#}$ & 49,50 \\
4 & Braquiária & 93 & 8,35 & 17,10 & 24,50 & 31,08 & 47,40 \\
2 & Braq.+0,3\%PV & 87 & 7,33 & 16,08 & 23,18 & 30,30 & 49,70 \\
3 & Braq.+0,3\%PV & 94 & 7,23 & 16,80 & 23,88 & 30,08 & 49,80 \\
5 & Braq.+0,6\%PV & 92 & 7,68 & 15,80 & 23,80 & 30,43 & 49,53 \\
6 & Braq.+0,6\%PV & 95 & 7,80 & 15,85 & 23,25 & 29,80 & 48,58 \\
& & & & & & & \\
Média & & & 7,68 & 16,33 & 23,72 & 30,34 & 49,08 \\
CV(\%) & & & 5,8 & 3,16 & 2,3 & 1,6 & 1,9 \\
$\#$ \#alon
\end{tabular}

\# Valores excluídos durante a análise de regressão linear pela análise dos resíduos

Tabela 6. Taxas de liberação $\left(\mathrm{mm}^{\mathrm{d}} \mathrm{dia}^{-1}\right)$ de n-alcanos entre os dias 3 e 17 após a dosificação de animais em regime de pastejo

\begin{tabular}{lccccccc}
\hline & & & \multicolumn{5}{c}{ Taxas, mm.dia $^{-1}$} \\
Animal & Dietas & Cáps. N & 3 dias & 7 dias & 10 dias & 13 dias & 17 dias \\
\hline 1 & Braquiária & 91 & $3,25^{\#}$ & $2,71^{\#}$ & $2,61^{\#}$ & $2,58^{\#}$ & 2,91 \\
4 & Braquiária & 93 & 2,78 & 2,44 & 2,45 & 2,39 & 2,79 \\
2 & Braq.+0,3\%PV & 87 & 2,44 & 2,30 & 2,32 & 2,33 & 2,92 \\
3 & Braq.+0,3\%PV & 94 & 2,41 & 2,40 & 2,39 & 2,31 & 2,93 \\
5 & Braq.+0,6\%PV & 92 & 2,56 & 2,26 & 2,38 & 2,34 & 2,91 \\
6 & Braq.+0,6\%PV & 95 & 2,60 & 2,26 & 2,33 & 2,29 & 2,86 \\
& & & & & & & \\
Média & & & 2,56 & 2,33 & 2,37 & 2,33 & 2,89 \\
CV(\%) & & & 5,8 & 3,6 & 2,2 & 1,6 & 1,7 \\
\hline \#Varos
\end{tabular}

\# Valores excluídos pela análise dos resíduos 
Os resultados mostram que não houve a necessidade de se estabelecer taxas de liberação para cada situação de alimentação, caracterizada pela variação das proporções entre volumoso e concentrado bem como tipo de volumoso. Importante também foi a não significância dos efeitos de dia de medição após a dosificação, dieta e interação entre eles sobre as taxas diárias de liberação nas duas condições estudadas, indicando que a quantidade dos indicadores liberada diariamente ao longo do período de coleta foi uniforme. Isso significa que as cápsulas apresentaram um padrão homogêneo de liberação de n-alcanos para todas as condições testadas, indicando relativa segurança do uso das cápsulas de liberação controlada para o fornecimento de n-alcanos em condições de alimentação onde variaram não só aspectos químicos, mas também físicos das dietas, levando a dinâmicas diferentes de ambientes ruminais sem prejuízo nas estimativas. Sob o aspecto físico da dieta, este pode ser mais alterado na situação de pastagem mas, a julgar pelo coeficiente de variação $(2,7 \%)$ e pelo erro padrão da regressão obtida $(0,53$ $\mathrm{mm}$ ), esses aspectos não foram relevantes no presente experimento. Em termos práticos, as situações de alimentação utilizadas neste trabalho refletem as condições de dietas de confinamentos de bovinos de corte ou sistemas de produção de leite exclusivamente em pastagem, com ou sem a utilização de suplementação concentrada. Nessas situações, a técnica poderia ser empregada com sucesso.

Dove et al. (2002) utilizaram um procedimento semelhante a este avaliando um aparelho de liberação controlada para o fornecimento dos nalcanos $\mathrm{C}_{28}$ e $\mathrm{C}_{32}$ com o fornecimento de $\mathrm{C}_{36}$ sob a forma de péletes de papel, em um estudo com ovinos, e encontraram uma maior homogeneidade na liberação dos indicadores da cápsula quando comparados aos péletes de papel. Comentaram também que não houve evidência de um padrão curvilinear na taxa de liberação dos n-alcanos fornecidos via cápsula. 
Ainda com n-alcanos, Genro (1999) mediu, entre os dias 7 e 15 após a colocação da cápsula (tipo YC 60393, Captec - NZ) no rúmen a taxa de liberação dos n-alcanos $\mathrm{C}_{32}$ e $\mathrm{C}_{36}$ através do monitoramento das concentrações fecais em amostras colhidas duas vezes ao dia no reto de um bovino alojado em uma gaiola metabólica, recebendo feno de Braquiária (Brachiaria sp.) mais concentrado (0,5 \% do PV). Esse autor comentou que houve variação na taxa de liberação de ambos n-alcanos, e que entre os dias 12 e 14 após a colocação no rúmen houve uma queda nas concentrações fecais dos n-alcanos. Contudo, é importante ressaltar que esse autor não comentou se havia $C_{32}$ e/ou $C_{36}$ naturalmente no perfil de n-alcanos do feno fornecido, o que pode ter influenciado as concentrações fecais obtidas.

Trabalhando com outro tipo de indicador, Parker et al. (1989) testaram o efeito de quatro tipos de forragem e de seis níveis de consumo sobre a liberação de óxido crômico de cápsulas de liberação controlada com ovinos e encontraram uma interação entre o tipo de alimento e a taxa de liberação do indicador. Esses autores fizeram medidas entre os dias 3 e 42 após a inserção das cápsulas no rúmen, e comentaram que as diferenças foram pequenas, sendo que para experimentos de campo com tipos similares de alimentos uma única regressão linear poderia ser usada para determinar a taxa de liberação. É conveniente ressaltar que o coeficiente de determinação obtido no referido trabalho foi muito próximo do obtido neste trabalho (0,98 vs. 0,99 , respectivamente). Também trabalhando com cápsulas de liberação controlada de cromo, Williamson et al. (2000) encontraram taxas de liberação menores (entre 1,4 e $23,4 \%$ ) do indicador comparativamente àquela indicada pelo fabricante.

A julgar alguns dos fatores que poderiam influenciar a liberação de indicadores, tais como o material que compõe e a tensão da mola que pressiona as pastilhas, o material no qual os indicadores estão impregnados, bem como as interações possíveis com o ambiente ruminal, pode-se notar que 
não é incomum encontrar diferenças entre os valores nominais das taxas de liberação de indicadores fornecidos pelos fabricantes e aqueles medidos em cada condição experimental.

\subsubsection{Análise de regressão com os animais em gaiolas metabólicas}

A equação de regressão obtida foi: DISTA $(\mathrm{mm})=0,19+2,49$ DIA. O modelo linear foi significativo $(P<0,0001)$, assim como coeficiente de regressão (b) foi diferente de zero $(P<0,0001)$. $O$ coeficiente de determinação $\left(r^{2}=0,99\right)$ demonstra que o tempo explicou quase toda a variação na liberação dos nalcanos. O coeficiente de variação foi de $4,2 \%$, muito próximo daquele $(4,1 \%)$ obtido por Dove et al. (2002) com um procedimento semelhante, avaliando um aparelho de liberação controlada de n-alcanos em estudo com ovinos. O coeficiente de regressão $2,49 \mathrm{~mm}$ multiplicado pela quantidade do indicador que deve haver em cada milímetro resultou em um valor médio de $372 \mathrm{mg}$ de $\mathrm{C}_{32}$ e $336 \mathrm{mg}$ de $\mathrm{C}_{36}$ sendo liberados diariamente, valores estes 7 e $16 \%$ menores dos indicados pelo fabricante $(400 \mathrm{mg})$. Em uma simulação feita utilizando-se o valor de liberação do $\mathrm{C}_{32}$ indicado pelo fabricante obteve-se uma estimativa de consumo cerca de $9,2 \%( \pm 1,5 \%)$ maior do que aquela obtida com o valor medido. Este fato deve ser considerado importante tendo em vista o alto custo de cada cápsula (aproximadamente US\$25.0).

\subsubsection{Análise de regressão com os animais em pastagem}

A equação obtida para o teste em pastagem foi: DISTA $(\mathrm{mm})=0,69+$ 2,28 DIA. O modelo e o coeficiente angular também foram significativos $(P<0,0001)$ e os valores do coeficiente de determinação e do coeficiente de variação foram 0,99 e 2,7 \%, respectivamente, mostrando também nessa condição de alimentação que o tempo explicou quase toda a variação na 
liberação dos n-alcanos. Segundo a equação, as quantidades liberadas diariamente dos indicadores em condições de pastagem foram de $341 \mathrm{mg}$ para o $\mathrm{C}_{32}$ e $308 \mathrm{mg}$ para o $\mathrm{C}_{36}$.

Embora o coeficiente de variação da medida com os animais em gaiolas de metabolismo possa ser considerado bom, na condição de pastagem houve um coeficiente de variação menor, talvez em função da manutenção de uma ingestão mais constante de alimento através do pastejo, mesmo naqueles animais suplementados, o que pode não ter ocorrido nas gaiolas porque a alimentação foi fornecida duas vezes ao dia. Além disso, embora não tenha sido estudado, outras possíveis razões seriam a motilidade, volume ruminal e taxa de diluição das fases líquida e sólida.

Após os experimentos 1 e 2, fez-se o teste estatístico para comparação das duas equações. Caso fossem iguais, poder-se-ia obter uma equação única com maior número de observações. Para tal, utilizou-se os procedimentos de Neter \& Waserman (1996).

Na Tabela 7 são apresentados os parâmetros das regressões para cada situação isolada e em conjunto.

Tabela 7. Equações das regressões entre as distâncias parciais (DISTA, mm) e os dias após a colocação das cápsulas no rúmen, coeficientes de determinação $\left(r^{2}\right)$, coeficiente de variação $(C V, \%)$ e erro padrão da regressão (EPR, mm)

\begin{tabular}{lcccc}
\hline Condição & \multicolumn{1}{c}{ Equação } & $r^{2}$ & CV & EPR \\
\hline Gaiola & DISTA $=0,19+2,49$ DIA & 0,99 & 4,2 & 0,85 \\
Pasto & DISTA $=0,69+2,28$ DIA & 0,99 & 2,7 & 0,53 \\
Gaiola + Pasto & DISTA $=0,76+2,31$ DIA & 0,99 & 3,7 & 0,69 \\
\hline
\end{tabular}


Foi verificado que as regressões foram iguais $(P>0,05)$ e então, para uma maior precisão na estimativa do coeficiente angular (b), ou seja, da quantidade do indicador liberada, pode-se usar a regressão com os dois conjuntos de dados. A quantidade do $\mathrm{C}_{32}$ e do $\mathrm{C}_{36}$ liberadas segundo a regressão conjunta foi de 345 e $312{\mathrm{mg} . \mathrm{dia}^{-1}}^{-1}$, respectivamente.

É conveniente ressaltar também que a partir das taxas de liberação obtidas e da quantidade do indicador por milímetro de pastilha nas cápsulas, o tempo de duração (vida útil) das cápsulas seria de 20 e 22 dias, respectivamente, para gaiolas de metabolismo e pasto. Esses valores estão dentro do prazo dado pelo fabricante que situa-se entre 17 e 23 dias.

\subsubsection{Estimativas de consumo de forragem com n-alcanos nos animais em gaiolas}

Foram identificados $\mathrm{n}$-alcanos com comprimentos de cadeia variando de 22 a 36 átomos de carbono na silagem de milho e nos três concentrados fornecidos aos animais. Na silagem de milho, os n-alcanos encontrados em maiores concentrações foram o $C_{31}, C_{29}, C_{27}$ e $C_{33}$, respectivamente, corroborando as informações da literatura de que os n-alcanos com cadeias ímpares seriam os predominantes. As concentrações de $\mathrm{C}_{31}$ e $\mathrm{C}_{33}$ encontradas neste trabalho foram maiores que aquelas reportadas por García et al. (2000) para silagem de milho (17,4 e 9,9 mg. $\mathrm{kg}^{-1}$ de MS, respectivamente).

Nos concentrados, as concentrações foram menores que aquelas da silagem de milho, e os $\mathrm{n}$-alcanos encontrados em maiores concentrações foram o $\mathrm{C}_{27}, \mathrm{C}_{29}$ e $\mathrm{C}_{31}$, sendo o $\mathrm{C}_{27}$ e $\mathrm{C}_{29}$ não mostrados. Na Tabela 8 são mostradas as quantidades dos $\mathrm{n}$-alcanos de $\mathrm{C}_{31}$ a $\mathrm{C}_{36}$ para os ingredientes das dietas $\mathrm{e}$ fezes com exceção do $\mathrm{C}_{34}$, que foi usado como padrão interno. 
Tabela 8. Concentração de n-alcanos nos ingredientes e fezes ( $\left.\mathrm{mg} \cdot \mathrm{kg}^{-1} \mathrm{MS}\right)$

\begin{tabular}{|c|c|c|c|c|c|}
\hline Ingrediente/Animais & $\mathrm{C}_{31}$ & $\mathrm{C}_{32}$ & $\mathrm{C}_{33}$ & $\mathrm{C}_{35}$ & $\mathrm{C}_{36}$ \\
\hline Silagem de milho & 45 & 12 & 25 & 6 & 5 \\
\hline Conc. da dieta $80: 20$ & 5 & 4 & nd & nd & 2 \\
\hline Conc. da dieta 60:40 & 11 & 8 & 5 & 2 & 2 \\
\hline Conc. da dieta 40:60 & 5 & 3 & 2 & nd & 1 \\
\hline Casca de Soja & 20 & 7 & 5 & nd & 2 \\
\hline 4 & 127 & 152 & 63 & 18 & 91 \\
\hline 6 & 88 & 155 & 47 & 12 & 118 \\
\hline 1 & 77 & 159 & 39 & 10 & 114 \\
\hline 5 & 77 & 150 & 41 & 10 & 126 \\
\hline 2 & 77 & 152 & 37 & 9 & 112 \\
\hline 3 & 77 & 151 & 36 & 9 & 110 \\
\hline Média* & 87 & 153 & 44 & 11 & 112 \\
\hline $\mathrm{CV}(\%)^{*}$ & 23 & 2 & 23 & 28 & 10 \\
\hline
\end{tabular}


Tabela 9. Consumos de forragem estimados com o par $\mathrm{C}_{33}: \mathrm{C}_{32}$ de $\mathrm{n}$-alcanos e observados (kg MS.dia $\left.{ }^{-1}\right)$

\begin{tabular}{lcc}
\hline Animais & Consumo estimado & Consumo observado \\
\hline 4 & 7,6 & 6,6 \\
6 & 5,2 & 6,5 \\
1 & 4,2 & 4,8 \\
5 & 4,7 & 4,5 \\
2 & 4,1 & 3,5 \\
3 & 4,0 & 3,5 \\
& & \\
Média & 5,0 & 4,9 \\
CV (\%) & 28,0 & 28,5 \\
\hline
\end{tabular}

Houve uma relação linear $(P<0,05)$ entre os consumos estimados e os observados. O coeficiente de determinação foi de 0,65 e o coeficiente de variação de 18,7 \%, sendo a equação resultante: ConsObs $=0,86+0,81$ ConsC $_{33}: \mathrm{C}_{32}$. Da Tabela 8 pode-se observar que as concentrações fecais do $\mathrm{C}_{33}$ para os animais 4 e 6 foram 64 e $22 \%$ maiores que a média de excreção dos outros animais $(38,3 \pm 2,2 \%)$. Na Figura 1 pode-se observar a relação entre as duas medidas. Para ter-se uma idéia da adequação e do "erro tendencioso" da metodologia, fez-se uma análise entre os valores estimados e observados através do teste "t" de Student para comparações emparelhadas, que revelou que e a diferença média $(0,1 \mathrm{~kg})$ não foi significativa $(P>0,05)$. Contudo, deve-se interpretar com cautela esse resultado em virtude do número de animais utilizados.

A acurácia da técnica também foi avaliada testando-se se o coeficiente de regressão era diferente de 1 e o resultado foi negativo $(P>0,05)$. Isso sugere que uma variação no consumo estimado reflete igualmente no consumo 
observado embora ressalve-se aqui também que deve-se ter cautela na interpretação deste resultado em virtude do número de animais utilizados.

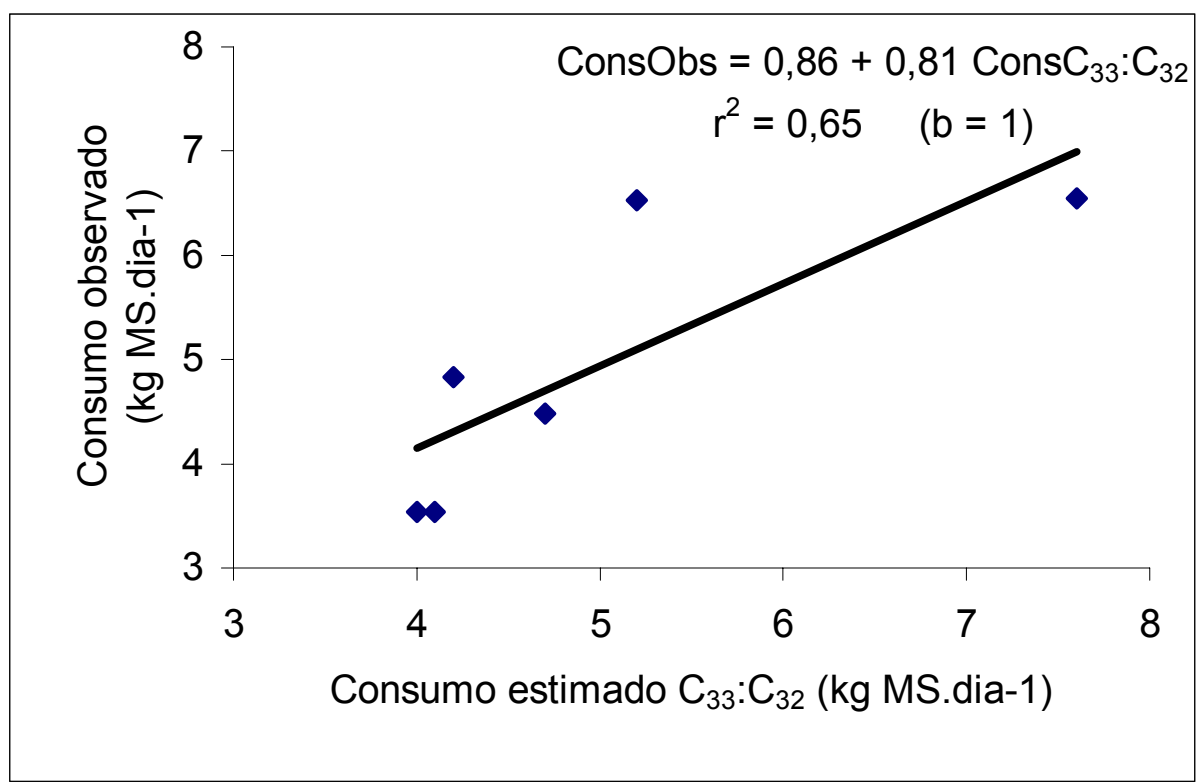

Figura 1 - Relação entre os consumos observado e estimado com o par $\mathrm{C}_{33}: \mathrm{C}_{32}$ de n-alcanos

Flutuações nas concentrações absolutas dos indicadores nas fezes podem advir de flutuações no consumo e/ou na digestão da dieta, sendo provavelmente esta última opção o que deva ter ocorrido neste caso, uma vez que $\circ \mathrm{C}_{33}$ é um componente natural da dieta e nota-se, pela Tabela 8, que as concentrações do $C_{32}$ foram mais uniformes do que as do $C_{33}$ (médias $=153 \mathrm{mg}$ $\pm 3,3$ vs. $44 \mathrm{mg} \pm 10,0$, respectivamente).

Neste experimento usou-se além da silagem de milho mais dois tipos de alimentos concentrados em cada dieta. Essa junção de vários ingredientes pode levar a diferentes taxas de passagem da fase sólida e líquida da digesta alterando a relação cinética entre o indicador liberado pela cápsula e aquela do indicador introduzido com o alimento, levando a estimativas de consumo não 
satisfatórias. Embora a estimativa média possa ser considerada boa, há que se considerar esses aspectos. Há também uma possibilidade de erro analítico, principalmente pela baixa concentração dos n-alcanos da dieta, inclusive do $\mathrm{C}_{33}$ usado como indicador interno no cálculo, fato esse já comentado por Laredo et al. (1991) e Dove \& Mayes (1991).

Outra consideração importante que influencia a estimativa do consumo são as recuperações fecais, mostradas na Tabela 10.

Tabela 10. Recuperações fecais dos n-alcanos $C_{31}$ a $C_{36}$, para cada animal (\% do consumido)

\begin{tabular}{lccccc}
\hline Animal & $\mathrm{C}_{31}$ & $\mathrm{C}_{32}$ & $\mathrm{C}_{33}$ & $\mathrm{C}_{35}$ & $\mathrm{C}_{36}$ \\
\hline 4 & 119 & 96 & 108 & 134 & 71 \\
6 & 78 & 92 & 75 & 84 & 85 \\
1 & 88 & 106 & 85 & 94 & 93 \\
5 & 82 & 87 & 83 & 90 & 89 \\
2 & 120 & 114 & 116 & 151 & 102 \\
3 & 111 & 106 & 106 & 139 & 93 \\
& & & & & \\
Média & 100 & 100 & 95 & 115 & 89 \\
CV & 19 & 10 & 17 & 25 & 12 \\
\hline
\end{tabular}

A técnica de uso de n-alcanos tem como premissa fundamental a similar recuperação fecal de n-alcanos homólogos utilizados como indicadores interno (cadeia ímpar oriundo da dieta) e externo (cadeia par fornecido). Pode-se observar também que, nos animais 4, 6 e 1 há uma maior discrepância entre as recuperações fecais dos dois indicadores utilizados no cálculo, o que leva à obtenção de estimativas de consumo de forragem mais distantes dos valores observados. 
Pode-se observar, ainda, que há recuperações fecais maiores que 100 \%. Recuperações fecais superestimadas podem advir tanto por uma subestimativa do consumo ou das concentrações de alcanos nos alimentos, ou, por uma superestimativa da produção fecal ou das concentrações de alcanos nas fezes. O consumo e a produção fecal foram medidos diariamente, então é provável que tenha ocorrido algum erro na medida das concentrações de alcanos nos alimentos ou nas fezes. Provavelmente houve erro na extração de alcanos dos alimentos em virtude das baixas concentrações dos n-alcanos naturais, principalmente no caso do $\mathrm{C}_{33}$ e $\mathrm{C}_{35}$, aumentando assim o erro analítico. Há relatos na literatura de valores de recuperação fecal maiores que $100 \%$ (Berry et al., 2000, com C $32=117 \%, C_{33}=105 \%$ e $C_{36}=118 \%$ ), (Gedir \& Hudson, 2000, com $\mathrm{C}_{36}=113 \%$ ), (O'Keefe \& McMeniman, 1998, com $\mathrm{C}_{35}=$ $177 \%$ ), (Rooney, 2000, com C $27=112,5 \%, C_{29}=107$ a $119 \%, C_{31}=108$ a $320 \%, \mathrm{C}_{33}=108 \%$ e $\mathrm{C}_{36}=101$ a $110 \%$ ) sendo que O'Keefe \& McMeniman (1998) comentaram a respeito de que baixas concentrações dos n-alcanos na dieta poderiam levar a identificação de recuperações anômalas, imprecisas e inexatas e, Rooney (2000) alertou para a obtenção de uma amostra da dieta que fosse representativa daquela que os animais consumissem. Também pode contribuir para tal erro as variações diárias no consumo e, consequentemente, nas produções fecais. Quando se compõe as amostras de fezes durante o período de coleta e há tais variações, naturalmente ocorre a composição também dos "erros" associados a essas variações. No entanto, a análise da Tabela 10 revela porque os valores estimados não diferiram significativamente dos valores observados: pode-se notar que, por exemplo para o animal 2, que teve as maiores recuperações fecais acima de $100 \%$ para os $n$-alcanos $C_{33} \mathrm{e}$ $\mathrm{C}_{32}$ usados na estimativa, essas foram praticamente as mesmas $\left(\mathrm{C}_{32}=114 \mathrm{e}\right.$ $\mathrm{C}_{33}=116 \%$ ), ou seja, mesmo acima de $100 \%$, o erro foi comum aos dois nalcanos usados como indicadores e elas foram muito próximas uma da outra, o que é o pré-requisito fundamental para a estimativa. Para os outros animais 
elas também não foram muito diferentes e, na média, foram de 100 e $95 \%$, respectivamente para o $\mathrm{C}_{32}$ e $\mathrm{C}_{33}$.

\subsection{Conclusões}

A cápsula de liberação controlada foi um meio eficiente de fornecer uma dose constante de n-alcanos sintéticos utilizados como indicadores em estudos nutricionais com bovinos de corte.

A cápsula possui a vantagem de ser fornecida uma única vez, diminuindo o manejo imposto aos animais.

Recuperações fecais similares entre os alcanos homólogos utilizados no calculo da estimativa de consumo são fundamentais para o funcionamento da técnica.

As estimativas de consumo de forragem obtidas pela técnica de $n$ alcanos não diferiram dos valores observados com os animais mantidos em gaiolas de metabolismo. 


\section{APORTE DE ENERGIA EM VACAS LEITEIRAS SUPLEMENTADAS COM ÁCIDO LINOLÉICO CONJUGADO (CLA) DETERMINADO ATRAVÉS DE ESTIMATIVAS DO CONSUMO DE FORRAGEM USANDO n-ALCANOS}

\section{Resumo}

A técnica de n-alcanos tem sido utilizada para estimar o consumo de forragem por animais em pastejo e também para estimar a composição botânica ou morfológica da dieta consumida. Com o objetivo de determinar o perfil de n-alcanos de Cynodon nlemfüensis Vanderyst var nlemfüensis e estimar o consumo de forragem e composição da dieta de vacas em pastejo suplementadas com CLA, foi realizado um experimento com 3 períodos utilizando os $\mathrm{n}$-alcanos como indicadores. Foram encontrados $\mathrm{n}$-alcanos com comprimento da cadeia de carbono variando entre 22 e 35 átomos, havendo uma predominância dos de cadeia ímpar sobre os pares, com o $C_{33}, C_{31}$ e $C_{29}$ encontrados em maiores concentrações. Os n-alcanos $\mathrm{C}_{26}, \mathrm{C}_{28}$ e $\mathrm{C}_{30}$ estiveram presentes em maiores concentrações entre os n-alcanos de cadeia par. No primeiro período de estudo, consumo médio de matéria seca de forragem não diferiu $(P>0,05)$ entre os animais controle $(M E G)$ ou tratados com CLA (CLA = 11,2 vs. $\left.M E G=11,1 \mathrm{~kg} \cdot \mathrm{dia}^{-1}\right)$. $\mathrm{O}$ consumo de matéria seca total não diferiu $(P>0,05)$ entre os dois grupos de animais (CLA $\left.=14,6 \mathrm{vs.} M E G=14,3 \mathrm{~kg}^{-\mathrm{dia}^{-1}}\right)^{\text {. }}$. No terceiro período o consumo médio de matéria seca de forragem não diferiu $(P>0,05)$ entre os animais sob tratamento $\left(C L A=11,8\right.$ vs. $\left.M E G=12,6 \mathrm{~kg} \cdot \mathrm{dia}^{-1}\right)$. 
O consumo de matéria seca total não diferiu entre os dois grupos de animais $\left(C L A=15,4\right.$ vs. $\left.M E G=16,2 \mathrm{~kg} \cdot \mathrm{dia}^{-1}\right)$. No primeiro período, o uso de n-alcanos mostrou-se preciso e acurado ( $b=1, C V=9,3 \%$ ) na estimativa do consumo de forragem e de partes de plantas. No período 3 a estimativa do consumo médio de forragem e de partes de plantas foi preciso mas inacurado $(b \neq 1, C V=5,0$ $\%$ ) porque os $n$-alcanos apresentaram um comportamento diferente, com variações entre turnos e dias nas concentrações fecais de $C_{31}, C_{33}$ e $C_{35}$, naturais da forragem, $\mathrm{C}_{32}$ e $\mathrm{C}_{36}$ sintéticos, fornecido via cápsula de liberação controlada, e nas relações entre o $\mathrm{C}_{31}: \mathrm{C}_{32}$ e $\mathrm{C}_{33}: \mathrm{C}_{32}$. No período 2 não foi possível a estimativa do consumo de forragem.

\section{ENERGY UPTAKE ON LACTATING DAIRY COWS SUPEMENTED WITH CONJUGATED LINOLEIC ACID (CLA) ESTABLISHED THROUGH FORAGE INTAKE ESTIMATES USING N-ALKANES}

\section{Summary}

The $\mathrm{n}$-alkanes technique has been utilized to predict forage intake in grazing animals and also to estimate the consumed botanical or morphological diet composition. The objectives of this experiment were to establish the nalkanes profile on Cynodon nlemfüensis Vanderyst var nlemfüensis and to estimate intake and morphological composition of the forage consumed by lactating dairy cows on pasture supplemented with conjugated linoleic acid (CLA), in three periods using n-alkanes as markers. It was used a linear regression between the requirements and the daily intake of metabolizable energy. It was found $\mathrm{n}$-alkanes with the carbon chain length ranging between 22 and 35 atoms, being the odd chain prevalent over the even chain n-alkanes. The $\mathrm{C}_{33}, \mathrm{C}_{31}$, and $\mathrm{C}_{29} \mathrm{n}$-alkanes were found in higher concentrations. Among the 
even chain n-alkanes, the $\mathrm{C}_{26}, \mathrm{C}_{28}$, and $\mathrm{C}_{30}$ were found in higher concentrations. In the first study period the average forage dry matter intake did not differ $(P>0.05)$ between the animals supplemented with CLA or controls (CLA $=11.2$ vs. $\left.M E G=11.1 \mathrm{~kg}^{-d a y}{ }^{-1}\right)$. The total dry matter intake also did not differ $(P>0.05)$ between treatments $\left(\mathrm{CLA}=14.6 \mathrm{vs} . \mathrm{MEG}=14.3 \mathrm{~kg}^{\mathrm{day}}{ }^{-1}\right)$. In the third study period the average forage dry matter intake did not differ $(P>0.05)$ between the animals supplemented with CLA or controls $(C L A=11.8$ vs. $M E G=12.6 \mathrm{~kg}$. day $\left.{ }^{1}\right)$. The total dry matter intake also did not differ $(P>0.05)$ between treatments $\left(C L A=15.4\right.$ vs. $\left.M E G=16.2 \mathrm{~kg} \cdot \mathrm{day}^{-1}\right)$. In the first study period, the estimates of forage intake and consumed plant parts were precise and accurate $(b=1, C . V$. $=9.3 \%)$, while in the third period the estimates were precise but inaccurate $(b \neq$ 1 , C.V. $=5.0 \%$ ). In the second study period it was not possible to estimate the forage intake. The fecal concentrations of natural $n$-alkanes from the diet $\left(\mathrm{C}_{31}\right.$, $\mathrm{C}_{33}$, and $\left.\mathrm{C}_{35}\right)$, the synthetic $\mathrm{n}$-alkanes from controlled-release capsules $\left(\mathrm{C}_{32}\right.$ and $\mathrm{C}_{36}$ ), and the $\mathrm{C}_{31}: \mathrm{C}_{32}$ and $\mathrm{C}_{33}: \mathrm{C}_{32}$ ratios did alter between morning and afternoon samples and among days.

\subsection{Introdução}

A quantidade de matéria seca consumida por animais em pastejo é, na sua essência, desconhecida (Burns et al., 1994). O método comumente utilizado para estimativas de consumo emprega medidas isoladas da produção fecal e da digestibilidade in vitro da forragem, sendo esta última o principal inconveniente desse tipo de estimativa em virtude de empregar um único valor para todos os animais, desconsiderando a própria influência do consumo sobre a digestibilidade da forragem. Assim, muitos esforços têm sido feitos na tentativa de identificar algum método que estime precisa e acuradamente o consumo de forragem, o que permitiria medir e avaliar de forma mais segura e criteriosa alterações no desempenho de animais recebendo tratamentos com impacto positivo na exploração pecuária. Permitiria, também, um maior 
entendimento e integração entre o conhecimento das exigências nutricionais dos animais e a maneira como seriam atendidas pela forragem disponível para pastejo.

A técnica de n-alcanos vem sendo usada para estimar o consumo de forragem por animais em pastejo e baseia-se na utilização de um n-alcano de cadeia ímpar, componente natural da forragem, e de um n-alcano de cadeia par, sintético, o qual é fornecido aos animais (Mayes et al., 1986a). Como premissa básica, essa técnica requer que a recuperação fecal dos dois nalcanos utilizados na estimativa seja igual ou muito próxima, mesmo que não seja integral (Dove \& Mayes, 1991).

Este trabalho teve por objetivos: a) estimar, utilizando a metodologia de n-alcanos, o aporte de energia e a eficiência alimentar em vacas lactantes pastejando uma planta forrageira tropical (Cynodon nlemfüensis Vanderyst var. nlemfüensis) e recebendo ácido linoléico conjugado em suas dietas; b) determinar o perfil de n-alcanos da planta forrageira e de seus componentes morfológicos lâminas foliares e haste + bainha das folhas; c) estimar o consumo relativo de partes da planta (lâminas foliares e haste+bainha das folhas).

\subsection{Material e Métodos}

\subsubsection{Procedimentos experimentais}

Entre os meses de dezembro de 1999 e março de 2000 foi realizado, na Fazenda Experimental Santa Mônica ( $43^{\circ} 42^{\prime}$ Oeste, $22^{\circ} 21^{\prime}$ Sul), da Embrapa Gado de Leite, município de Valença, RJ, um experimento utilizando 30 vacas mestiças Holandês x Gir previamente escolhidas do rebanho experimental de acordo com a produção de leite do ano anterior, número de parições, condição corporal e peso vivo. 
Foram realizados três períodos de avaliação do consumo de forragem, separados pela época de aplicação de cápsulas de liberação controlada de nalcanos e nominados de períodos 1, 2 e 3 .

\subsubsection{Período 1}

Entre os dias 13 e 25 de dezembro de 1999 realizou-se a primeira dosagem das cápsulas, via oral, com o auxílio de um aplicador. Como os animais não pariram ao mesmo tempo, neste primeiro período de avaliação 10 animais, de um total de 30 , foram designados ao acaso, dois a dois, a cada um

dos seguintes tratamentos: a) inclusão de $150 \mathrm{~g}$ de Megalac (Dwight \& Church, sais de cálcio de óleo de palma) - Controle; e b) inclusão de 150 g de CLA-60 (Dwight \& Church, sais de cálcio de uma mistura de isômeros de ácido linoléico conjugado - CLA, contendo a seguinte proporção: $24 \%$ do cis9-trans11, 35 \% do cis10-trans $12,15 \%$ do cis8-trans $10,17 \%$ do trans11-trans 13 e $9 \%$ de outros).

Todos os animais receberam 4,0 kg (matéria fresca) de um suplemento concentrado, fornecido igualmente duas vezes ao dia após as ordenhas da manhã e da tarde, com a seguinte composição (\% MS): milho moído 58,5 \%, farinha de peixe $25 \%$, farelo de soja $5,5 \%$, farelo de trigo $5,5 \%$ e premix vitamínico-mineral 5,5\%.

Os tratamentos foram adicionados ao suplemento concentrado sempre na primeira refeição da manhã para garantir o consumo, de forma que se houvesse sobra ela seria repassada na refeição da tarde. O suplemento concentrado e a dieta foram inicialmente formulados segundo simulações feitas pelo Sistema de Cornell (Sistema de Carboidratos e Proteína Líquidos de Cornell - CNCPS versão 3.1, Fox et al., 1999) e o concentrado formulado para complementar a forragem ingerida no pasto de forma que a dieta suprisse 115 $\%$ das exigências estimadas de proteína metabolizável do grupo controle. A forragem utilizada como padrão nas simulações foi Cynodon plectostachyus e 
sua composição em base seca, no "default" do software, foi: $35 \%$ de matéria seca, $75 \%$ de FDN, 9,7\% de lignina, $15 \%$ de proteína bruta, $30 \%$ de N-FDN, $8 \%$ de N-FDA, 1,6 \% de EE e $8 \%$ de MM. Os ingredientes que compuseram o concentrado e as respectivas composições químicas em base seca são mostrados na Tabela 1.

Tabela 1. Composição química determinada dos ingredientes que compuseram o concentrado (em base seca)

\begin{tabular}{lccccc}
\hline Comp. Quím. & Milho Moído & F. Peixe 1 & F. Peixe 2 & F. de Soja & F. de Trigo \\
\hline MS (\%) & 88,0 & 86,5 & 92,5 & 86,6 & 87,4 \\
PB (\%) & 7,9 & 53,8 & 52,0 & 46,5 & 14,2 \\
EE (\%) & 3,8 & 10,3 & 6,2 & 1,4 & 2,7 \\
FDN (\%) & 31,5 & - & - & 17,0 & 50,6 \\
N-FDN (\%) & 0,6 & - & - & 0,4 & 0,7 \\
FDA (\%) & 3,8 & - & - & 8,2 & 14,3 \\
N-FDA (\%) & 0,1 & - & - & 0,1 & 0,04 \\
MM (\%) & 1,4 & 20,4 & 32,7 & 6,7 & 5,1 \\
Px Vit./Min. ${ }^{*}$ & - & - & - & - & -
\end{tabular}

${ }^{*}$ Cálcio (37,5 \%), Fósforo (19,5\%), Magnésio (4,5\%), Enxofre (1,5\%), Sódio (27 \%), Cobre $(0,02 \%)$, Ferro $(0,03 \%)$, Manganês $(0,03 \%)$, Zinco $(0,05 \%)$, Cobalto $(0,0009 \%)$, Selênio $(0,0008 \%)$, Vit. A (20.000 UI), Vit. D (6.000 UI), Vit. E (100 UI)

Foram utilizados dois lotes de farinha de peixe neste experimento em virtude da mesma ter sido doada por uma empresa privada. A farinha identificada como número 1 foi utilizada no primeiro período e a de número 2 no segundo e terceiro períodos, respectivamente.

Os 30 animais, 10 sob tratamento e os outros 20 foram mantidos em 14 piquetes de 0,5 ha cada separados por cerca elétrica, numa área total de 7 ha, em pastejo rotacionado de capim estrela-africana (Cynodon nlemfüensis Vandderyst var. nlemfüensis) com um período de ocupação de dois dias e 26 dias de descanso, totalizando um ciclo de pastejo de 28 dias. 


\subsubsection{Período 2}

Este período foi iniciado em 17 de janeiro com o fornecimento de novas cápsulas de n-alcanos aos animais, e terminou em 29 de janeiro de 2000. Todos os procedimentos experimentais utilizados foram os mesmos, sendo que neste período houve a alocação adicional de mais dez animais aos mesmos tratamentos e da mesma forma, perfazendo um total de 20 animais sob tratamento mais 10 não tratados.

\subsubsection{Período 3}

Este período foi iniciado em 25 de fevereiro com o fornecimento de novas cápsulas de n-alcanos aos animais e terminou em 9 de março de 2000. Todos os procedimentos experimentais utilizados com relação ao fornecimento das cápsulas de $n$-alcanos foram os mesmos dos períodos anteriores, sendo que neste período houve a alocação de mais dez animais em substituição aos dez primeiros utilizados no primeiro período, aos mesmos tratamentos e da mesma forma. Devido a problemas climáticos, uma infestação por "lagarta militar" (Spodoptera frugiperda) e um ataque de formigas cortadeiras, a quantidade de animais fazendo o rodízio nos piquetes foi somente os 20 que estavam sob tratamento.

\subsubsection{Amostragem e análise da forragem}

A massa de forragem em pré pastejo e o resíduo pós-pastejo foram determinados através do corte, a $10 \mathrm{~cm}$ do solo de toda a forragem contida no interior de dez círculos de $0,25 \mathrm{~m}^{2}$ de área, por piquete, alocados ao acaso.

A altura da massa de forragem em pré e pós-pastejo foi medida utilizando-se uma régua graduada, em duas linhas diagonais traçadas dentro do 
piquete formando um " $X$ ". Foram tiradas 30 medidas a cada dez passos, medindo-se a altura da planta imediatamente ao lado da perna direita.

A densidade volumétrica foi calculada como o quociente entre a massa de forragem em pré ou pós-pastejo e a respectiva altura.

Foram escolhidas quatro áreas representativas do piquete para a medição do estrato da pastagem, previamente à entrada dos animais, e esta medição foi feita utilizando-se duas folhas de madeira compensada com $52 \mathrm{~cm}$ de altura e $40 \mathrm{~cm}$ de largura, com cortes horizontais à base, sendo o primeiro a $7 \mathrm{~cm}$ de altura e mais oito a cada $5 \mathrm{~cm}$. Essas duas folhas eram colocadas em pé, dentro do círculo, a uma distância aproximada de $22 \mathrm{~cm}$ uma da outra. Em seguida, as duas folhas de madeira eram juntadas uma contra a outra, rente ao solo, de forma que a pastagem entre elas ficasse firme. A pastagem era cortada rente ao solo e as duas folhas eram colocadas em cima de um estrado de madeira. Isto permitia a visualização, através dos cortes horizontais nas folhas de madeira, da forragem em diferentes alturas. $O$ corte foi feito a $28 \mathrm{~cm}$ da base devido a observações prévias e medições da altura média do resíduo de forragem deixado pelos animais na saída de cada piquete.

Da amostra obtida fez-se a separação dos componentes morfológicos lâmina foliar, haste+bainha das folhas e material senescente/morto. Com base na amostra total, obteve-se as quantidades dos componentes convertendo-se então a percentuais da massa de forragem total. Para obtenção da amostra de forragem consumida pelos animais, utilizou-se a técnica do pastejo simulado nos dias um e dois de ocupação dos piquetes. Para tal, seguia-se por 30 minutos mais de um animal dentro do piquete, procurando cobrir toda a área pastejada. Nesse tipo de amostragem fez-se também a separação morfológica dos componentes lâmina foliar, haste+bainha das folhas e material senescente/morto em uma sub-amostra do total coletado.

As amostras de forragem dos estratos e do pastejo simulado foram feitas nos piquetes onde coincidiram os períodos de coletas de fezes para as estimativas do consumo. Procedeu-se a secagem das amostras em estufa com 
ventilação forçada, a $60^{\circ} \mathrm{C}$ até massa constante. Em seguida, as amostras secas foram moídas em peneira de malha de $1 \mathrm{~mm}$ e armazenadas em recipientes plásticos para posterior análise.

Nas amostras de forragem obtidas pelo método do pastejo simulado, dos componentes lâmina foliar, haste+bainha das folhas, material senescente/morto e concentrados, foram feitas determinações de matéria seca (MS), matéria orgânica (MO) e proteína bruta (PB) segundo o AOAC (1995). Também segundo o AOAC (1995), foram feitas determinações de matéria seca (MS) e matéria orgânica (MO) nas amostras de fezes e da forragem obtida no estrato. $\mathrm{Na}$ forragem obtida pelo método do pastejo simulado, as determinações da fibra insolúvel em detergente neutro (FDN), fibra insolúvel em detergente ácido (FDA), nitrogênio ligado à fração de fibra insolúvel em detergente neutro ( $\mathrm{N}$ FDN), nitrogênio ligado à fração de fibra insolúvel em detergente ácido (N-FDA) e lignina foram feitas segundo procedimentos descritos por Pereira \& Róssi Júnior (1994). As frações de FDN, FDA, N-FDN E N-FDA no concentrado foram estimadas de acordo com as composições individuais dos ingredientes e seus respectivos percentuais de inclusão no concentrado. Isto foi feito em virtude da farinha de peixe não conter essas frações mas, que em função dos problemas de filtragem durante as determinações, iria produzir valores irreais para as respectivas frações.

\subsubsection{Estimativa do consumo}

Para estimativa do consumo, os animais foram dosificados com uma cápsula de liberação controlada contendo $8 \mathrm{~g}$ de $\mathrm{n}$-dotriacontano $\left(\mathrm{C}_{32}\right)$ e $8 \mathrm{~g}$ de n-hexatriacontano $\left(\mathrm{C}_{36}\right)$ (MCM Alkanes código 60421 - Captec, NZ), já descrita no Capítulo 1. A quantidade liberada de indicador utilizada para cálculo das estimativas de consumo foi de $345 \mathrm{mg}^{-\mathrm{dia}^{-1}}$, com base nos resultados obtidos no Capítulo 1. A partir do oitavo dia, inclusive, do fornecimento das cápsulas, foram coletadas amostras de fezes do reto dos animais durante cinco dias, 
imediatamente após o término das ordenhas da manhã $(06: 30 \mathrm{~h})$ e da tarde (16:30 h). As amostras foram armazenadas em freezer, separadas por turno (manhã ou tarde), animal e dia de coleta.

A secagem das amostras de fezes foi feita em estufa com ventilação forçada a $60^{\circ} \mathrm{C}$ até massa constante e, posteriormente, estas foram moídas em peneira de malha de $1 \mathrm{~mm}$. A composição das amostras para o período, nos períodos 1 e 2, foi feita juntando-se sub-amostras de cada coleta por animal e por turno com base no peso, retirando-se 5 gramas de cada dia, dentro de cada turno. Assim, obteve-se, para cada animal, uma amostra para o turno da manhã e uma para a tarde. No período 3 as amostras foram secas e analisadas individualmente, por dia e por turno.

\subsubsection{Extração de alcanos}

Nas amostras de forragem, concentrados e fezes, a extração e determinação do conteúdo de n-alcanos foram feitas em duplicata utilizando-se a metodologia descrita por Dillon \& Stakelum (1990a), com as seguintes modificações: a) o solvente utilizado foi o $n$-heptano em substituição ao $n$ hexano e b) Utilizou-se um aparelho de banho-maria substituindo o bloco aquecedor durante a saponificação. Uma amostra de 1,5 g para silagem e concentrados, e outra de $0,5 \mathrm{~g}$ para fezes foram colocadas em tubos de ensaio Pyrex de $25 \times 200 \mathrm{~mm}$ (silagem e concentrados) e $20 \times 100 \mathrm{~mm}$ (fezes) com tampas com rosca. Adicionou-se a cada amostra $0,25 \mathrm{mg}$ de n-tetratriacontano $\left(\mathrm{C}_{34}\right.$, Sigma) como um padrão interno. Em seguida, foram adicionados $14 \mathrm{~mL}$ para silagem e concentrados e $7 \mathrm{~mL}$ para fezes de uma solução etanólica de Hidróxido de Potássio ( $\mathrm{KOH}$, Carlo Herba) $1 \mathrm{M}$, permanecendo os tubos em repouso por 30 minutos e colocados em banho-maria a $90^{\circ} \mathrm{C}$ por quatro horas. Após o resfriamento das amostras, em torno de 20 minutos, foram adicionados $14 \mathrm{~mL}$ de $\mathrm{n}$-heptano (Sigma) mais $4 \mathrm{~mL}$ de água destilada para os alimentos e 7 $\mathrm{mL}$ de $\mathrm{n}$-heptano mais $2 \mathrm{~mL}$ de água destilada para fezes. O conteúdo dos 
tubos foi agitado vigorosamente por 30 segundos. A camada superior foi removida e retida em béquer de $50 \mathrm{~mL}$, e fez-se outra adição de $\mathrm{n}$-heptano sendo a extração repetida e adicionada à primeira. $O$ conteúdo dos béqueres foi evaporado em capela com exaustão à temperatura ambiente.

A camada removida foi reconstituída em $2,5 \mathrm{~mL}$ de n-heptano e aplicada no topo de uma coluna descartável (Alltech código 17312) ou em seringas plásticas descartáveis de $5 \mathrm{~mL}$, segundo Oliveira et al. (2002), contendo sílica gel 70-230 mesh (Merck) suspensa em n-heptano, com um volume de leito de 5 $\mathrm{mL}$. Os alcanos foram eluídos em vidros transparentes com $20 \mathrm{~mL}$ de $\mathrm{n}$ heptano e evaporados à temperatura ambiente em capela com exaustão.

Os eluatos dos alimentos e fezes foram redissolvidos em 1,9 mL de $\mathrm{n}$ heptano e colocados em vidros para cromatografia (Hewlett Packard código 5182-0714) previamente à análise cromatográfica.

\subsubsection{Análise cromatográfica}

A análise cromatográfica foi feita utilizando-se uma coluna capilar CP-Sil $8 \mathrm{CB}$ (Crompack) com $30 \mathrm{~m} \times 0,25 \mathrm{~mm} \times 0,25 \mu \mathrm{m}$ de espessura de filme, em um cromatógrafo a gás (Thermoquest, Thermofinningam - USA) com detector de ionização de chama. A temperatura do injetor foi de $280^{\circ} \mathrm{C}$ e a do detector de $310^{\circ} \mathrm{C}$. A temperatura da coluna foi programada para iniciar com $200^{\circ} \mathrm{C}$ por 1 minuto e posteriormente a taxa de aquecimento foi de $6^{\circ} \mathrm{C}$ por minuto com uma temperatura final de $300^{\circ} \mathrm{C}$ mantida por 15 minutos. $\mathrm{O}$ gás carregador foi $\mathrm{o}$ hélio, com velocidade linear de $32 \mathrm{~cm}$.segundo ${ }^{-1}$. Os gases da chama, nitrogênio, hidrogênio e oxigênio, tiveram taxas de fluxo de 30, 35 e 430 $\mathrm{mL}$.minuto ${ }^{-1}$, respectivamente. O modo de injeção foi do tipo "split" com uma razão de 20:1 e a amostra de $2 \mu \mathrm{l}$ foi injetada automaticamente.

A área sob cada pico referente a cada n-alcano foi determinada utilizando-se um software da ChromQuest (Chromquest versão 2.53) em um microcomputador. A identificação de cada n-alcano foi feita através da análise 
de correlação e regressão linear entre o número de carbonos da cadeia e o logarítmo dos tempos de retenção. As áreas de cada pico foram convertidas nas quantidades de cada n-alcano por referência ao padrão interno (ntetratriacontano), segundo Mc Nair \& Bonnelli (1968). Também foram feitas extrações sem a adição do padrão interno nas amostras de alimentos, chamadas de "extrações em branco" para verificar se esse n-alcano não era um componente natural do perfil de alcanos dos alimentos. Onde ele foi encontrado, sua área foi subtraída daquela detectada usando o padrão. Os cálculos do fator de resposta para cada n-alcano foram feitos por referência ao padrão interno usando os procedimentos de Untz (1982).

Em seguida, foram calculadas as quantidades de cada $n$-alcano em um quilograma de matéria seca de alimentos e fezes. O consumo foi determinado utilizando-se a equação (1) de Mayes et al. (1986a) descrita a seguir:

$$
C=\left\{F_{i} / F_{p} \times\left[D_{p}+\left(C_{c} \times C_{p}\right)\right]-\left(C_{c} \times C_{i}\right)\right\} /\left[F_{o i}-\left(F_{i} / F_{p}\right) \times F_{o p}\right]
$$

Onde:

$\mathrm{C}=$ consumo diário de forragem $\left(\mathrm{kg} \mathrm{MS} \cdot \mathrm{dia}^{-1}\right)$;

$\mathrm{F}_{\mathrm{i}}=$ concentração (mg. $\mathrm{kg}^{-1}$ de MS) do n-alcano de cadeia ímpar nas fezes;

$F_{p}=$ concentração (mg. $\mathrm{kg}^{-1}$ de MS) do n-alcano de cadeia par nas fezes;

$D_{p}=$ quantidade do n-alcano sintético de cadeia par, fornecido $\left(\mathrm{mg}^{-d i a}{ }^{-1}\right)$;

$F_{\mathrm{oi}}=$ concentração $\left(\mathrm{mg} \cdot \mathrm{kg}^{-1}\right.$ de $\left.\mathrm{MS}\right)$ do n-alcano de cadeia ímpar natural da forragem;

$F_{o p}=$ concentração $\left(\mathrm{mg} \cdot \mathrm{kg}^{-1}\right.$ de MS) do n-alcano de cadeia par natural da forragem;

$\mathrm{C}_{\mathrm{c}}=$ consumo de concentrado $\left(\mathrm{kg} \mathrm{MS} \cdot \mathrm{dia}^{-1}\right)$;

$\mathrm{C}_{\mathrm{p}}=$ concentração (mg.kg-1 de MS) do n-alcano de cadeia par natural do concentrado;

$\mathrm{C}_{\mathrm{i}}=$ concentração $\left(\mathrm{mg} \cdot \mathrm{kg}^{-1}\right.$ de $\left.\mathrm{MS}\right)$ do n-alcano de cadeia ímpar natural do concentrado; 
A estimativa das partes de plantas consumidas foi feita através das concentrações de n-alcanos das frações lâmina foliar, haste+bainha das folhas e fezes, segundo descrito por Dove \& Moore (1995), com a utilização do software "EATWHAT" (Diet Selection Calculator, versão 1.2, CSIRO, 1996). Para esse cálculo, houve a necessidade de correção para recuperação fecal dos n-alcanos a serem utilizados e os valores utilizados foram 91,5, 89,8 e 91,8 $\%$, obtidos por Oliveira (1995) para os n-alcanos $C_{31}, C_{33}$ e $\quad C_{35}$, respectivamente.

\subsubsection{Cálculos}

A metodologia de medições e amostragens de leite para composição, avaliação do escore de condição corporal e peso vivo dos animais foram descritas por Medeiros (2002). Para os cálculos das exigências de energia, proteína e o teor de energia metabolizável dos alimentos utilizou-se o Sistema de Cornell (Sistema de Carboidratos e Proteína Líquidos de Cornell - CNCPS versão 5.026, Fox et al., 2000).

\subsubsection{Análise estatística}

O delineamento experimental utilizado foi o completamente casualizado. As variações nas concentrações fecais dos n-alcanos $C_{31}, C_{32}, C_{33}, C_{35}$ e $C_{36}$ bem como das relações fecais entre o $\mathrm{C}_{31}: \mathrm{C}_{32}, \mathrm{C}_{33}: \mathrm{C}_{32}$ e $\mathrm{C}_{35}: \mathrm{C}_{36}$ entre os turnos da manhã e tarde nos períodos 1 e 2 e, entre os turnos e entre os 5 dias de coleta e as interações no período 3 foram feitas usando-se o procedimento PROC MIXED. Considerou-se como efeitos fixos o tratamento, turno e dia de coleta e as interações.

O aporte e as exigências de energia metabolizável foram analisadas através de regressão linear pelo procedimento PROC REG. Através dos comandos $r$, cli e clm dentro do procedimento citado, fez-se a análise dos 
resíduos estudentizados ("Student Residual"), a qual foi utilizada para indicar observações "outliers" na estimativa dos parâmetros. Se o resíduo estudentizado ficou fora da faixa -2 a 2, então ele foi considerado como um "outlier" e retirado da análise. Fez-se também o teste para verificar se o coeficiente de regressão (b) diferiu da unidade usando-se o comando TEST do PROC REG. Para testar a acurácia ("bias") das estimativas do aporte de energia metabolizável fez-se o teste " $\mathrm{t}$ " de Student para comparações emparelhadas. Os dados de consumo de matéria seca e eficiências biológicas para gordura e proteína foram analisados pelo procedimento PROC GLM utilizando o comando "LSMEANS". O nível de significância adotado foi $10 \%$. Ambas análises foram feitas usando o pacote estatístico do SAS (2001).

\subsection{Resultados e Discussão}

Os períodos 1, 2 e 3 foram analisados separadamente, mas os resultados foram discutidos conjuntamente.

\subsubsection{Perfil de n-alcanos das amostras de forragem e de seus componentes}

O perfil de n-alcanos das amostras de forragem e de seus componentes morfológicos lâmina foliar e haste+bainha das folhas e, dos concentrados nos períodos 1, 2 e 3 para n-alcanos de cadeia ímpar e par, respectivamente, podem ser observados nas Tabelas 2 e 3 abaixo: 
Tabela 2. Concentrações de n-alcanos de cadeia ímpar (mg. $\mathrm{kg}^{-1} \mathrm{MS}$ ) nas amostras de forragem, em seus componentes morfológicos e dos concentrados nos períodos 1,2 e 3

\begin{tabular}{lccccccc}
\hline Período/Amostra & $\mathrm{C}_{23}$ & $\mathrm{C}_{25}$ & $\mathrm{C}_{27}$ & $\mathrm{C}_{29}$ & $\mathrm{C}_{31}$ & $\mathrm{C}_{33}$ & $\mathrm{C}_{35}$ \\
\hline Período 1 & & & & & & & \\
\$PS Forragem (dia1+dia2) & 6 & 15 & 31 & 39 & 79 & 114 & 25 \\
Lâmina Foliar & 12 & 25 & 58 & 90 & 122 & 133 & 15 \\
Haste+Bainha das folhas & 43 & 83 & 118 & 113 & 180 & 256 & 76 \\
Concentrado P1 & 2 & 3 & 3 & 3 & 1 & $\mathrm{nd}$ & $\mathrm{nd}$ \\
& & & & & & & \\
Período 2 & & & & & & & \\
\$PS Forragem (dia1+dia2) & 17 & 25 & 37 & 51 & 107 & 171 & 37 \\
Lâmina Foliar & 2 & 6 & 21 & 49 & 108 & 141 & 18 \\
Haste+Bainha das folhas & 5 & 10 & 13 & 24 & 82 & 157 & 39 \\
Concentrado P2 & 50 & 79 & 54 & 26 & 10 & 6 & 3 \\
& & & & & & & \\
Período 3 & & & & & & & \\
\$PS Forragem (dia1+dia2) & 35 & 55 & 68 & 71 & 106 & 137 & 27 \\
Lâmina Foliar & 55 & 88 & 99 & 128 & 127 & 168 & 24 \\
Haste+Bainha das folhas & 7 & 12 & 17 & 31 & 88 & 163 & 36 \\
Concentrado P3 & 50 & 79 & 54 & 26 & 10 & 6 & 3 \\
\hline
\end{tabular}

${ }^{\text {nd }}$ Indica que o n-alcano não foi detectado; ${ }^{\$}$ Amostra obtida pelo método do pastejo simulado 
Tabela 3. Concentrações de n-alcanos de cadeia par $\left(\mathrm{mg} \cdot \mathrm{Kg}^{-1}\right.$ de $\left.\mathrm{MS}\right)$ nas amostras de forragem, em seus componentes morfológicos e dos concentrados nos períodos 1,2 e 3

\begin{tabular}{|c|c|c|c|c|c|c|c|}
\hline Período/Amostra & $\mathrm{C}_{22}$ & $\mathrm{C}_{24}$ & $\mathrm{C}_{26}$ & $\mathrm{C}_{28}$ & $\mathrm{C}_{30}$ & $\mathrm{C}_{32}$ & $\mathrm{C}_{36}$ \\
\hline \multicolumn{8}{|l|}{ Período 1} \\
\hline${ }^{\$}$ PS Forragem (dia1+dia2) & 2 & 4 & 5 & 12 & 4 & 10 & nd \\
\hline Lâmina Foliar & 4 & 16 & 8 & 17 & 10 & 7 & nd \\
\hline Haste+Bainha das folhas & 23 & 52 & 70 & 68 & 51 & 29 & nd \\
\hline Concentrado P1 & nd & 3 & 3 & 3 & 2 & nd & nd \\
\hline \multicolumn{8}{|l|}{ Período 2} \\
\hline${ }^{\$}$ PS Forragem (dia1+dia2) & 8 & 17 & 21 & 19 & 13 & 10 & nd \\
\hline Lâmina Foliar & nd & 2 & 6 & 7 & 6 & 5 & nd \\
\hline Haste+Bainha das folhas & 3 & 5 & 6 & 5 & 4 & 3 & nd \\
\hline Concentrado P2 & 24 & 71 & 71 & 34 & 15 & 8 & nd \\
\hline \multicolumn{8}{|l|}{ Período 3} \\
\hline${ }^{\$}$ PS Forragem (dia1+dia2) & 20 & 41 & 49 & 84 & 26 & 20 & nd \\
\hline Lâmina Foliar & 34 & 71 & 82 & 85 & 72 & 37 & nd \\
\hline Haste+Bainha das folhas & nd & 5 & 6 & 5 & 5 & 5 & nd \\
\hline Concentrado P3 & 24 & 71 & 71 & 34 & 15 & 8 & nd \\
\hline
\end{tabular}

Nas amostras de forragem e seus componentes morfológicos foram identificados e quantificados n-alcanos com cadeias de carbono com comprimentos de $\mathrm{C}_{22}$ a $\mathrm{C}_{35}$, sendo este último encontrado somente no período 3.

Houve uma predominância dos n-alcanos de cadeia ímpar sobre os pares, sendo $\mathrm{C}_{33}, \mathrm{C}_{31}$ e $\mathrm{C}_{29}$ encontrados em maiores quantidades (Tabela 2) com as maiores concentrações para $\circ \mathrm{C}_{33}$ tanto na amostra total como nos 
componentes morfológicos. Foram encontradas também quantidades consideráveis dos $\mathrm{n}$-alcanos de cadeia par, principalmente no primeiro e terceiro períodos, nas frações haste+bainha das folhas e lâmina foliar, respectivamente. Sobre o perfil de n-alcanos em plantas, Kolattukudy (1976) afirmou que os $\mathrm{n}$-alcanos $\mathrm{C}_{29}$ e $\mathrm{C}_{31}$ são os principais do reino vegetal. Essas observações vêm ao encontro daquelas obtidas por Mayes et al. (1986a) em ovinos alimentados com azevém perene (Lolium perenne L.), Laredo et al. (1991) com sete espécies de plantas tropicais, e por Oliveira et al. (1997) com fenos de plantas tropicais cultivadas e de campo nativo composto de espécies predominantemente estivais, de três regiões do Rio Grande do Sul. Genro (1999) trabalhou com três gramíneas tropicais (Brachiaria brizantha cv. Marandu, Panicum maximum cv. Mombaça e Pennisetum purpureum cv. Cameroon) e também encontrou esses mesmos n-alcanos de cadeia ímpar como predominantes em relação aos de cadeia par.

Trabalhando com seis espécies de gramíneas, dentre essas Cynodon nlemfüensis, oito leguminosas e três arbustivas utilizadas para alimentação animal, Delgado et al. (2000) também encontraram esses mesmos n-alcanos em maiores concentrações. É conveniente ressaltar que na amostra de Cynodon nlemfüensis estudada por esses autores, a concentração do $C_{29}(30,9$ $\mathrm{mg} \cdot \mathrm{kg}^{-1} \mathrm{de} \mathrm{MS}$ ) foi próxima da obtida neste trabalho no período 1 (39 mg. $\mathrm{kg}^{-1} \mathrm{de}$ MS). Com relação às concentrações dos n-alcanos de cadeia par, assim como neste trabalho, os autores citados anteriormente encontraram também os $\mathrm{n}$ alcanos $\mathrm{C}_{26}, \mathrm{C}_{28}$ e $\mathrm{C}_{30}$, como os principais. Conforme comentado por Dove \& Mayes (1991) e por Oliveira \& Prates (2000), tanto em plantas de clima temperado como de clima tropical há maiores concentrações dos n-alcanos com número ímpar de carbonos.

Observa-se que houve mudanças nas concentrações dos n-alcanos nas amostras de forragem bem como dos componentes morfológicos e, principalmente, daqueles de interesse como indicadores internos neste estudo $\left(C_{31}, C_{33}\right.$ e $\left.C_{35}\right)$ entre os períodos. Laredo et al. (1991) já haviam comentado 
sobre a mudança das concentrações de n-alcanos entre folhas de diferentes idades para as espécies de Pennisetum glaucum e Sorghum sp, sendo que Oliveira et al. (1997) também verificaram essas mudanças em fenos de napier. Genro (1999) trabalhou com três gramíneas tropicais (Brachiaria brizantha cv. Marandu, Panicum maximum cv. Mombaça e Pennisetum purpureum cv. Cameroon) com hábitos de crescimento distinto desta e encontrou variações nas concentrações de alcanos entre estratos das diversas forragens estudadas. Neste estudo, a área experimental foi atingida por uma inundação que a deixou submersa por mais de 36 horas, conforme pode-se observar na Figura 1.

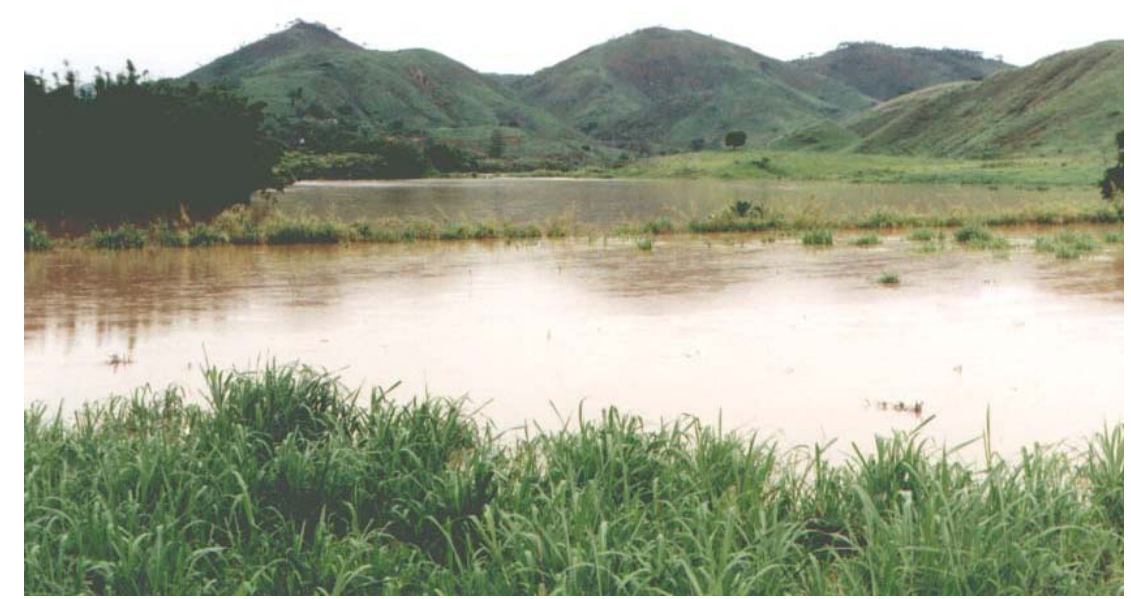

Figura 1 - Vista da área experimental sob enchente

Além disso, após a inundação, houve uma infestação por lagarta do cartucho (Spodoptera frugiperda, Figura 2) e um ataque de formigas cortadeiras. Embora os efeitos desses eventos não tenham sido estudados, pode-se especular que o estresse imposto à planta forrageira pode, de alguma forma, ter alterado a síntese dos compostos presentes na cera cuticular incluindo a fração de alcanos. 


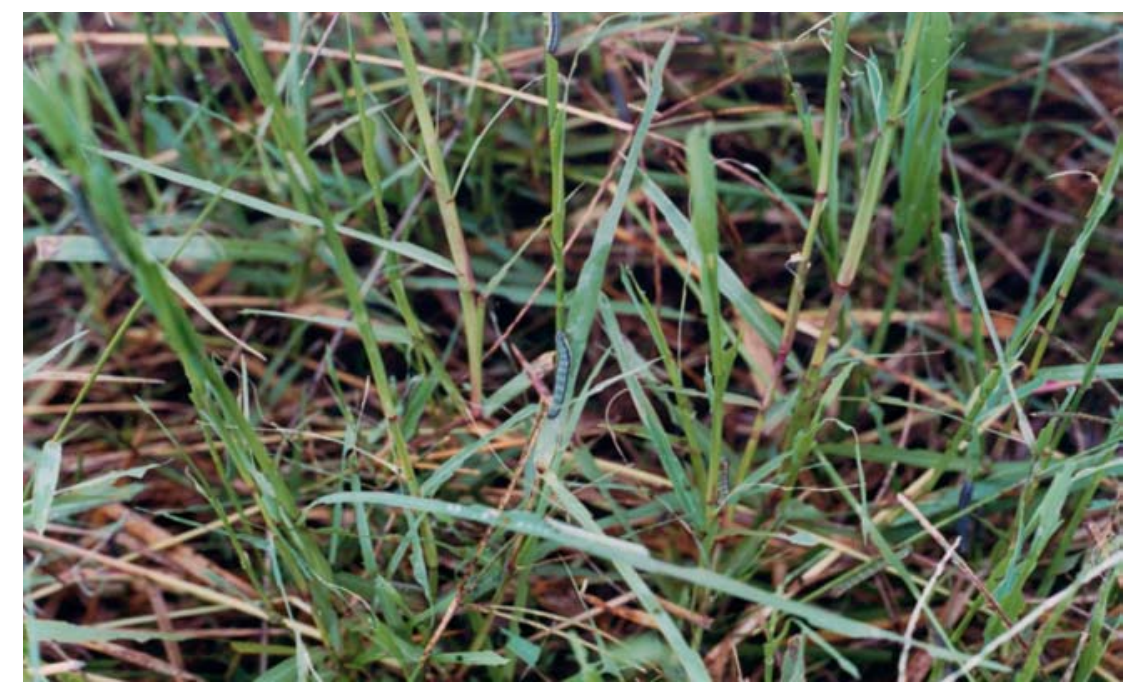

Figura 2 - Detalhe da infestação da "lagarta do cartucho" (Spodoptera frugiperda)

Neste trabalho não foi detectado o $\mathrm{n}$-alcano $\mathrm{C}_{34}$ nas "extrações em branco" comumente utilizado como padrão interno nas amostras para identificação e quantificação dos outros componentes do perfil. Entretanto, Delgado et al. (2000) identificaram e quantificaram o $\mathrm{C}_{34}$, e Oliveira et al. (1997) também encontraram o $\mathrm{C}_{34}$ como um componente natural do perfil de fenos de setária (Setaria vaginata, Spreng), milheto (Pennisetum americanum, Schum) e capim napier (Pennisetum purpureum, Schum).

Com relação ao perfil dos concentrados, no período 1 as quantidades dos n-alcanos tanto de cadeia ímpar como aqueles de cadeia par, independente do comprimento, foram muito pequenas. Nos períodos 2 e 3 foram encontradas quantidades expressivas dos n-alcanos com comprimento da cadeia até 30

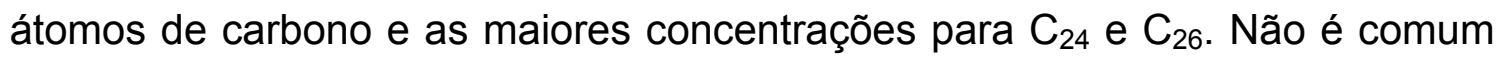
encontrar essas concentrações de n-alcanos em alimentos concentrados, principalmente neste trabalho onde $25 \%$ do concentrado fornecido aos animais foi constituído por farinha de peixe, um ingrediente que possui baixas concentrações de n-alcanos. Em um trabalho com peixes, Gudmundsson \& Halldorsdottir (1995) encontraram pequenas quantidades de n-alcanos em 
várias farinhas de peixe utilizadas como alimento, mas em quase todas elas os n-alcanos com número par de carbonos na cadeia foram encontrados em quantidades iguais ou até maiores do que aqueles com número ímpar de carbonos.

Neste trabalho, uma possibilidade para explicação dessas quantidades consideráveis de n-alcanos pares pode ter estado relacionada ao fato de que no momento da coleta da amostra o material não estivesse bem homogêneo. Outra possibilidade é o erro analítico quando se trabalha com material onde a concentração de n-alcanos é baixa. Contudo, as concentrações dos n-alcanos $\mathrm{C}_{32}$ e $\mathrm{C}_{33}$ do concentrado nos períodos 2 e 3 foram muito pequenas e não influenciaram no cálculo da estimativa do consumo.

\subsubsection{Estimativas de consumo obtidas com n-alcanos}

Segundo Dove \& Mayes (1991), as recuperações fecais dos n-alcanos $\mathrm{C}_{33}$, das forragens, e $\mathrm{C}_{32}$, usado como um indicador externo, são similares, razão pela qual este par é o mais comumente utilizado nas estimativas de consumo de forragem. Partindo desse pressuposto, estimou-se o consumo de forragem nos períodos 1, 2 e 3 utilizando-se esse par de n-alcanos, embora haja possibilidade de utilizar os pares $\mathrm{C}_{31}: \mathrm{C}_{32}$ e $\mathrm{C}_{35}: \mathrm{C}_{36}$.

$\mathrm{Na}$ Tabela 4 são apresentados como valores médios de três piquetes, algumas características da pastagem, por período. 
Tabela 4. Massa de forragem em pré e pós-pastejo (Mfpré, Mfpós, kg MS.ha-1 ${ }^{-1}$, altura do dossel forrageiro em pré e pós-pastejo (Altpré, Altpós, $\mathrm{cm}$ ), densidade volumétrica da forragem em pré e pós-pastejo (DVpré, Dvpós, kg MS.hac ${ }^{-\mathrm{cm}}$ )

\begin{tabular}{|c|c|c|c|c|c|c|}
\hline \multirow[b]{2}{*}{ Períodos } & \multicolumn{6}{|c|}{ Características } \\
\hline & MFpré & MFpós & Altpré & Altpós & DVpré & DVpós \\
\hline \multicolumn{7}{|l|}{ Período 1} \\
\hline Média & 3815 & 1735 & 91 & 46 & 42 & 37 \\
\hline CV(\%) & 0,6 & 20 & 6 & 1 & 6 & 20 \\
\hline \multicolumn{7}{|l|}{ Período 2} \\
\hline Média & 4290 & 1606 & 82 & 47 & 53 & 34 \\
\hline CV $(\%)$ & 14 & 8 & 14 & 7 & 11 & 8 \\
\hline \multicolumn{7}{|l|}{ Período 3} \\
\hline Média & 1801 & 1305 & 44 & 29 & 41 & 45 \\
\hline CV(\%) & 1 & 22 & 6 & 10 & 5 & 14 \\
\hline
\end{tabular}

$\mathrm{Na}$ Tabela 5 são apresentados os percentuais dos componentes morfológicos das amostras dos estratos da pastagem obtidas por piquete e por período. 
Tabela 5. Percentuais de lâminas foliares (LF), haste+bainha de folhas (HB) e material senescente/morto (SM) nas amostras do estrato da pastagem nos 3 períodos de estudo

\begin{tabular}{lccc}
\hline Piquetes & L F & HB & SM \\
\hline 1 & 44,3 & Período 1 & 0,5 \\
2 & 49,7 & 55,2 & 0,6 \\
3 & 49,7 & 49,7 & 0,6 \\
Média & 47,9 & 49,7 & 0,6 \\
CV(\%) & 6,5 & 51,5 & 10 \\
& & 6,2 & \\
1 & & & \\
2 & 33,3 & 55,3 & 11,4 \\
3 & 25,2 & 62,0 & 12,8 \\
Média & 39,8 & 39,8 & 20,4 \\
CV(\%) & 32,8 & 52,4 & 14,9 \\
& 22,3 & 21,8 & 32,2 \\
1 & & & \\
2 & & Período 3 & 1,3 \\
3 & 33,3 & 1,0 \\
Média & 65,4 & 49,5 & 12,8 \\
CV(\%) & 49,5 & 49,7 & 5,0 \\
\hline
\end{tabular}

$\mathrm{Na}$ Tabela 6 são mostrados os resultados da composição química dos alimentos para os períodos 1, 2 e 3 . 
Tabela 6. Composição química determinada na matéria seca da amostra de forragem obtida por pastejo simulado (PS), de lâminas foliares (LF), haste+bainha das folhas (HB) e dos concentrados, nos períodos 1, 2 e 3

\begin{tabular}{lccccccccc}
\hline Amostra & $\begin{array}{c}\text { PB } \\
(\%)\end{array}$ & $\begin{array}{c}\text { EE } \\
(\%)\end{array}$ & $\begin{array}{c}\text { FDN } \\
(\%)\end{array}$ & $\begin{array}{c}\text { NFDN } \\
(\%)\end{array}$ & $\begin{array}{c}\text { FDA } \\
(\%)\end{array}$ & $\begin{array}{c}\text { NFDA } \\
(\%)\end{array}$ & $\begin{array}{c}\text { LIGN } \\
(\%)\end{array}$ & $\begin{array}{c}\text { MM } \\
(\%)\end{array}$ & $\begin{array}{c}\text { EM }^{£} \\
\left(M^{\varepsilon} \text { cal.kg }\right.\end{array}$ \\
\hline Período 1 & & & & & & & & & \\
\$PS & 13,9 & 2,1 & 61,4 & 6,5 & 28,6 & 2,2 & 2,7 & 8,9 & 2,18 \\
LF & 18,6 & 2,6 & 62,7 & 10,0 & 27,0 & 2,2 & 3,0 & 8,5 & 2,25 \\
HB & 10,6 & 0,8 & 66,6 & 4,8 & 31,3 & 2,4 & 4,2 & 8,6 & 1,98 \\
Concent. & 35,3 & 5,4 & $11^{*}$ & $6,6^{*}$ & $3,9^{*}$ & $2,5^{*}$ & $3,3^{*}$ & 21,5 & 2,66
\end{tabular}

Período 2

$\begin{array}{lccccccccc}{ }^{\$} P S & 13,1 & 1,6 & 65,1 & 5,6 & 31,6 & 2,3 & 3,6 & 9,0 & 2,18 \\ \text { LF } & 15,9 & 2,2 & 68,4 & 11,2 & 30,0 & 2,5 & 2,1 & 7,4 & 2,32 \\ \text { HB } & 11,5 & 0,8 & 73,7 & 7,0 & 36,7 & 1,7 & 4,0 & 9,2 & 1,97 \\ \text { Concent. } & 25,5 & 5,6 & 11^{*} & 6,6^{*} & 3,9^{*} & 2,5^{*} & 3,3^{*} & 16,1 & 2,86\end{array}$

Período 3

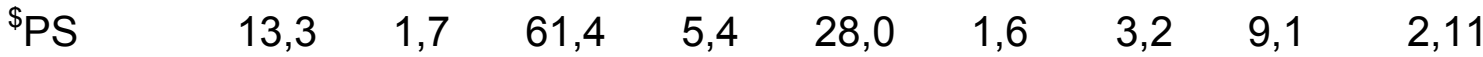

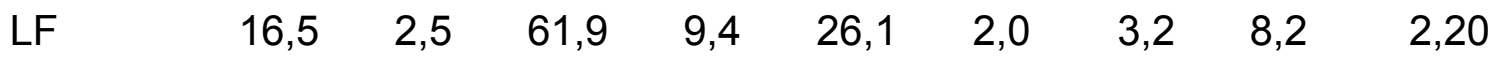

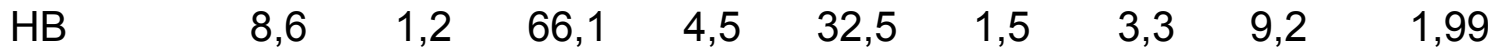

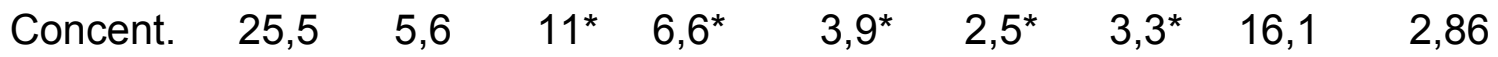

*estimados de acordo com a análise individual dos ingredientes e seus respectivos percentuais de inclusão no concentrado; ${ }^{£}$ estimados pelo CNCPS versão 5.026; ${ }^{\$}$ Amostra obtida pelo método do pastejo simulado

Através das composições químicas acima foram criadas, no CNCPS 5.026, matrizes de composição nutricional para os respectivos alimentos. Com a caracterização individual de cada animal através dos parâmetros peso vivo, idade, produção e composição do leite, número e dias em lactação e escore de 
condição corporal, mais os dados relativos às condições ambientais, gerou-se individualmente as exigências de energia metabolizável (Mcal.dia ${ }^{-1}$ ) (Apêndice $4)$.

No período 1 os consumos foram precisos e acurados conforme pode-se observar nas Figura 3 abaixo.

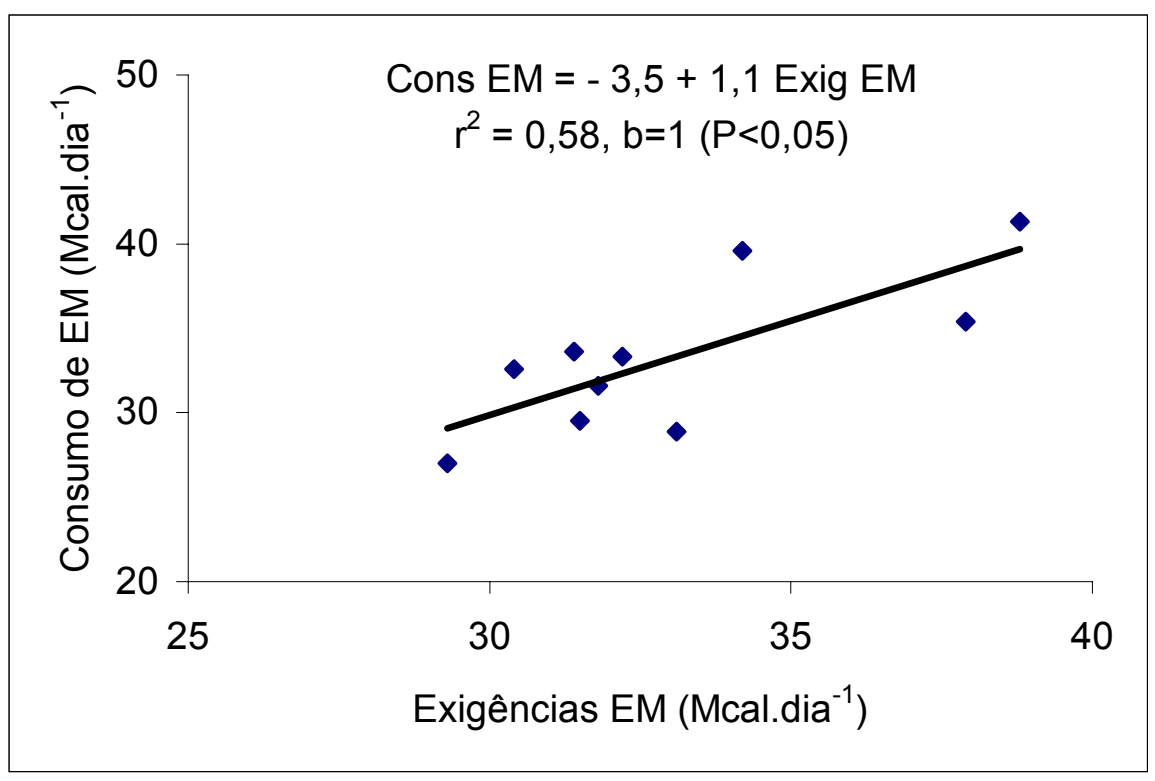

Figura 3 - Relação entre as exigências diárias e o aporte de energia metabolizável no período 1

Utilizando-se as concentrações dos n-alcanos $C_{31}, C_{33}$ e $C_{35}$ nos componentes morfológicos da forragem, corrigidos para as respectivas recuperações fecais, e as concentrações fecais individuais, estimou-se o consumo relativo das frações lâminas foliares e haste+bainha das folhas. Multiplicando-se os percentuais de cada fração pelo consumo de forragem obteve-se as quantidades de cada fração. Através da matriz nutricional de cada fração, mais o consumo medido do concentrado, obteve-se o aporte de energia metabolizável, sendo a forragem separada nos componentes (Apêndice 4). A relação entre as exigências e este aporte de energia é mostrado na Figura 4. 


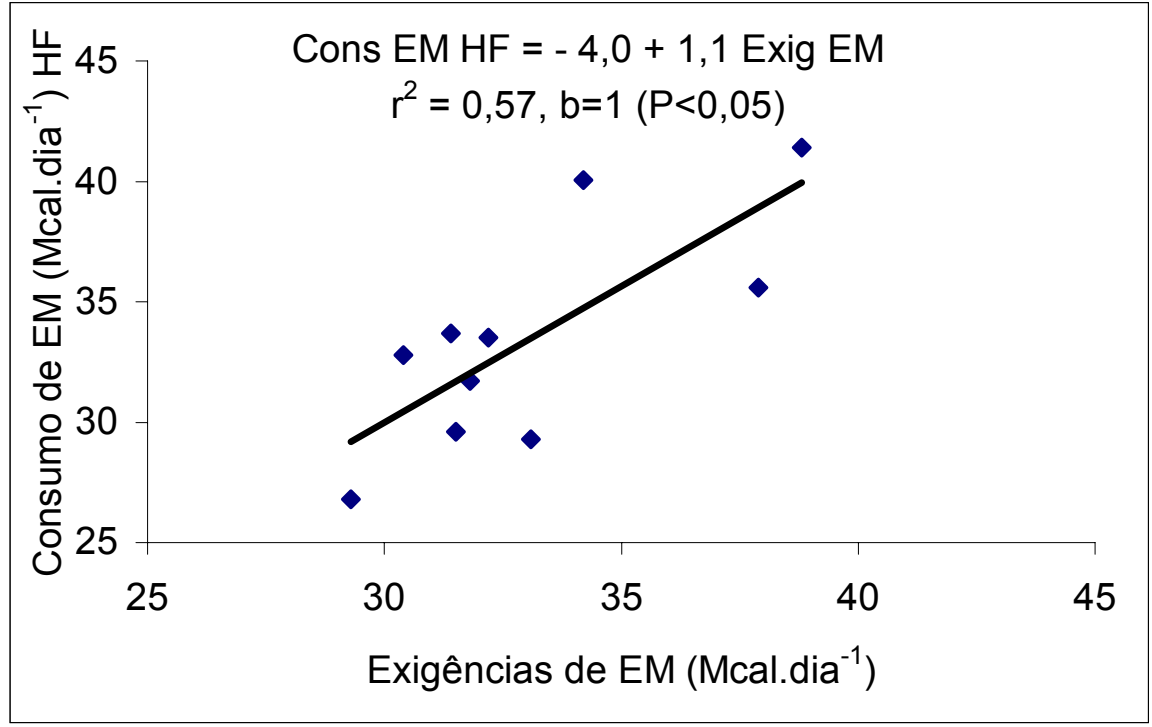

Figura 4 - Relação entre as exigências diárias e o aporte de energia metabolizável sendo a energia da forragem separada nas frações lâminas foliares e haste+bainha das folhas, no período 1

Embora os coeficientes de determinação de ambas as equações não sejam altos, houve uma relação linear entre as variáveis estudadas e o coeficiente angular (b) não diferiu da unidade, indicando que a variação em uma unidade de exigência foi respondida igualmente em consumo. A acurácia das medidas foi avaliada através do teste "t" para comparações emparelhadas, que resultou em probabilidades da diferença média (Ď) entre o consumo e a exigência de energia metabolizável ser igual a zero de $\mathrm{P}>0,91$ e $\mathrm{P}>0,83$, para a amostra de forragem e aquela separada nas frações lâminas foliares e haste+bainha das folhas, respectivamente. Conseguiu-se estimar o consumo de partes das plantas da forragem em oferta, mostrando que a metodologia pode ser promissora na área de estudos de composição morfológica e/ou botânica utilizando animais intactos, não dependendo de animais fistulados no esôfago ou rúmen. Com esses resultados pode-se assumir que os indicadores em questão foram capazes de estimar adequadamente o consumo de forragem, 
acomodando possíveis diferenças entre a capacidade individual de enchimento do rúmen, de digestibilidade da dieta selecionada e até intrínsecas dos animais.

$\mathrm{Na}$ Tabela 7 são apresentados os valores estimados de consumo de forragem e de seus componentes.

Tabela 7. Consumo individual de forragem $\left(\mathrm{kg} \mathrm{MS} \cdot \mathrm{dia}^{-1}\right)$ e percentuais de lâminas foliares (LF) e haste+bainha das folhas (HB) estimados com os n-alcanos $\mathrm{C}_{31}, \mathrm{C}_{33}$ e $\mathrm{C}_{35}$ para o período 1

\begin{tabular}{lccc}
\hline Animal & Consumo $(\mathrm{kg} \mathrm{MS})$ & LF & HB \\
\hline 0625 CLA & 11,1 & 85,8 & 14,2 \\
2545 CLA & 14,3 & 91,0 & 9,0 \\
6484 CLA & 10,7 & 87,9 & 12,1 \\
6415 CLA & 8,9 & 99,7 & 0,3 \\
2653 CLA & 11,2 & 83,0 & 17,0 \\
6542 MEG & 10,6 & 85,9 & 14,1 \\
1470 MEG & 12,5 & 87,4 & 12,6 \\
3435 MEG & 9,3 & 86,9 & 13,1 \\
7465 MEG & 8,1 & 72,5 & 27,5 \\
3507 MEG & 14,8 & 84,0 & 16,0 \\
Média & 11,1 & 86,4 & 13,6 \\
CV(\%) & 20 & 7,9 & 50 \\
\hline
\end{tabular}

No período 2 fez-se as mesmas comparações com as estimativas obtidas com o mesmo par de n-alcanos e os resultados são mostrados nas Figuras 5 e 6. 


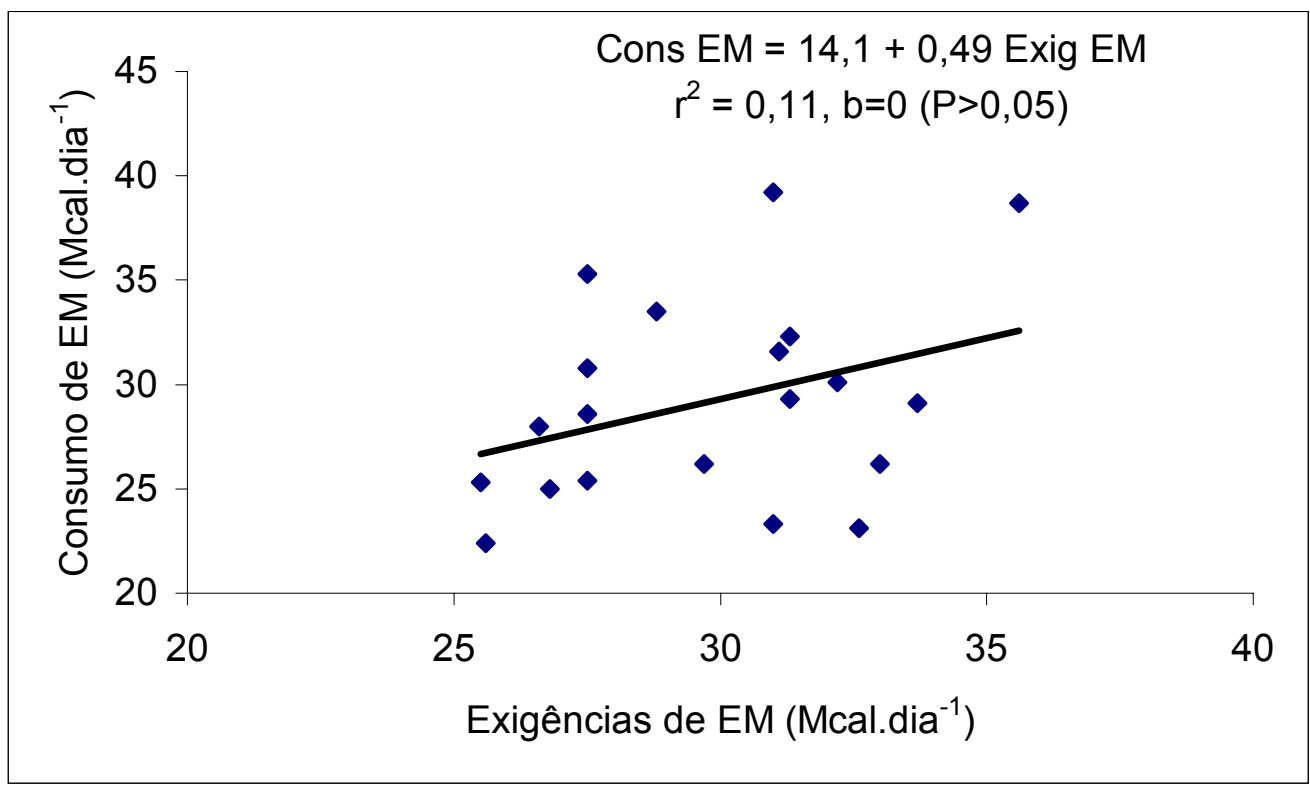

Figura 5 - Relação entre as exigências diárias e o aporte de energia metabolizável no período 2

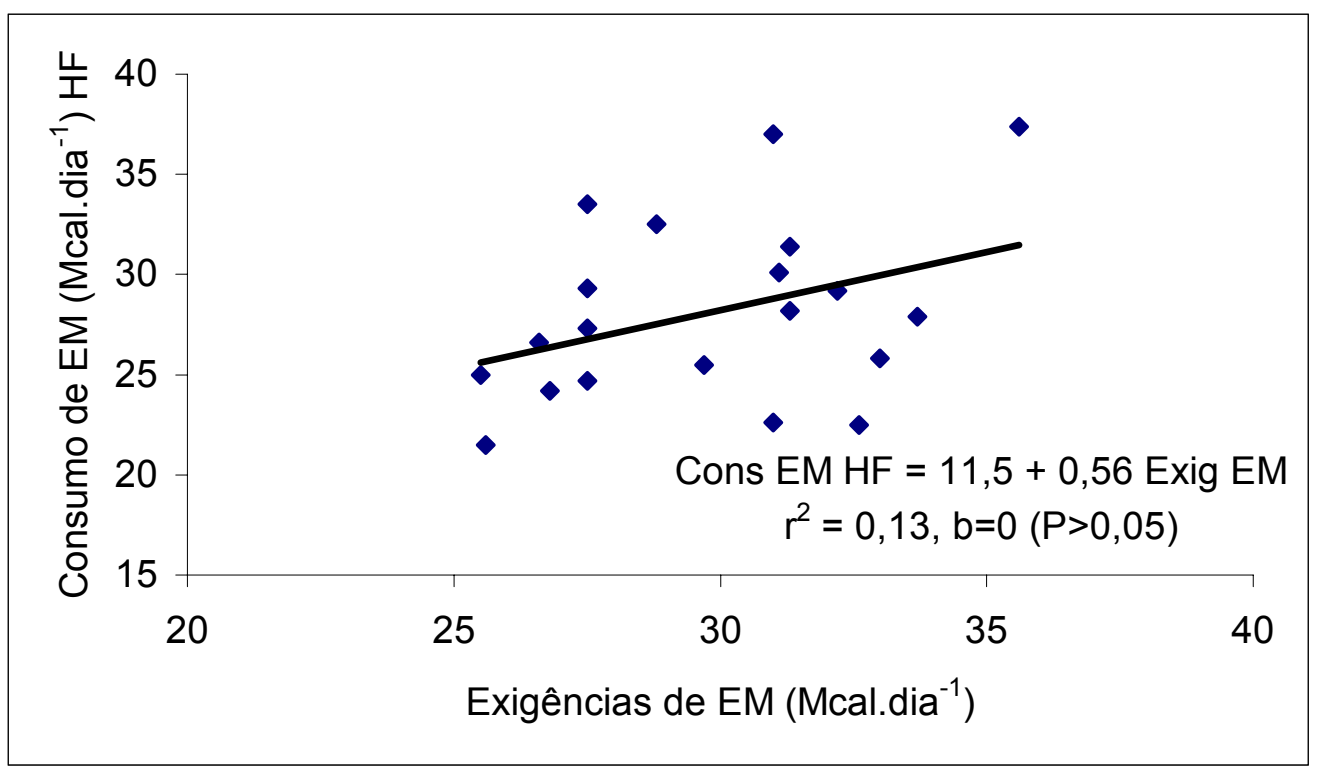

Figura 6 - Relação entre as exigências diárias e o aporte de energia metabolizável sendo a energia da forragem separada nas frações lâminas foliares e haste+bainha das folhas, no período 2 
Não houve relação entre exigências de energia e consumo, para o período 2. Esse fato foi contrastante ao observado no período 1, onde a relação foi clara e linear.

A Figura 7 mostra os resultados para o período 3.

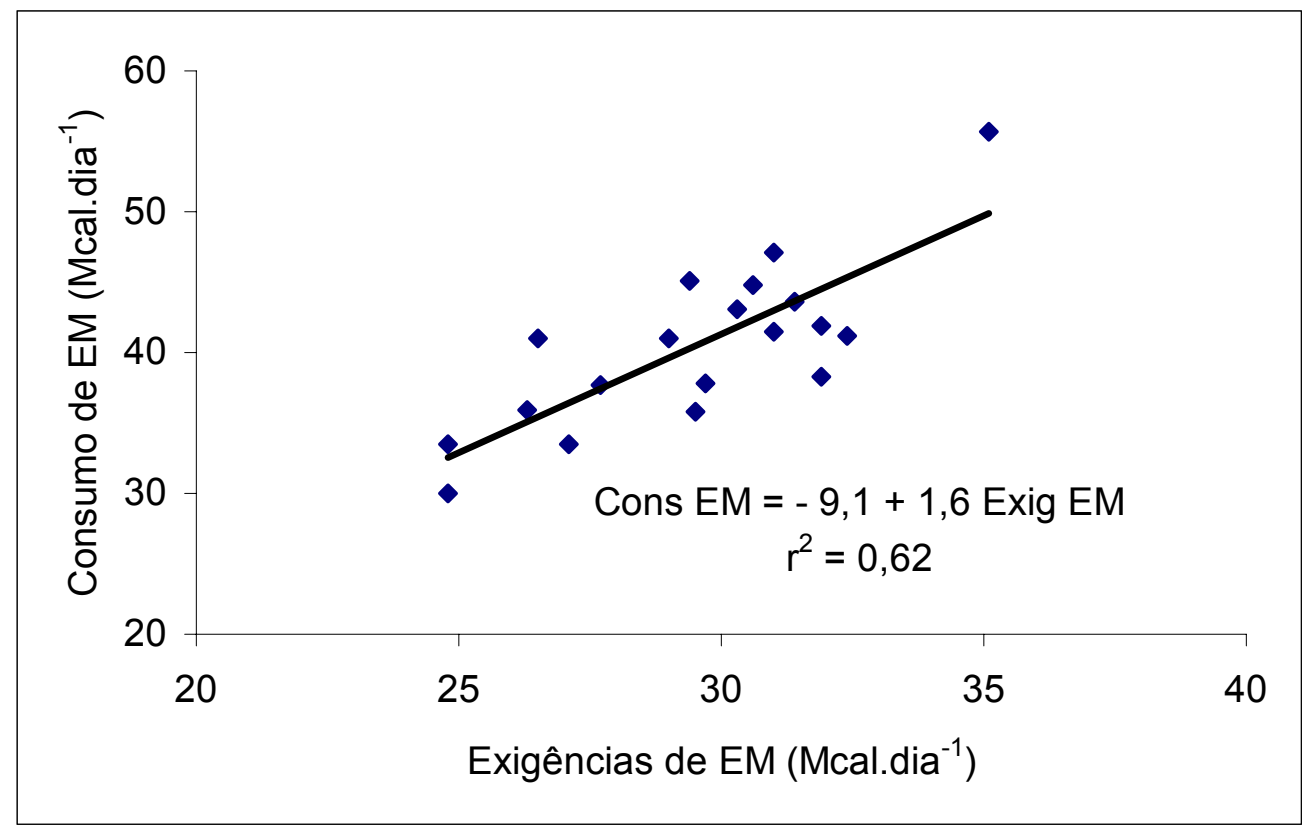

Figura 7 - Relação entre as exigências diárias e 0 aporte de energia metabolizável no período $3(E P R=3,6, b \neq 1, P>0,05)$

Houve uma relação linear entre as exigências e o consumo de energia metabolizável, mas o coeficiente angular diferiu da unidade, indicando baixa precisão. Além disso, não houve acurácia na estimativa, medida pelo teste " $\mathrm{t}$ " para comparações emparelhadas, com uma probabilidade da diferença média entre o consumo e as exigências ser igual a zero $(\Sigma=0)$ de $P<0,0001$. Com a energia metabolizável vinda da forragem sendo separada nas frações de lâminas foliares e haste+bainha das folhas, a equação resultante foi: Cons EM $\mathrm{HF}=-8,7+1,7$ Exig EM, com um $\mathrm{r}^{2}=0,62, \mathrm{~b} \neq 1(\mathrm{P}>0,05)$ e $\mathrm{CV}=8,9 \%$ e $\mathrm{EPR}=$ 3,6. Da mesma forma que a estimativa anterior, a probabilidade da diferença média entre o consumo e as exigências ser igual a zero $(\check{D}=0)$ foi $P<0,0001$. 
$\mathrm{O}$ padrão de comportamento do par de n-alcanos $\mathrm{C}_{33}: \mathrm{C}_{32}$ usado nas estimativas mudou entre os períodos de estudo, produzindo resultados diferentes nos períodos 2 e 3 . Numa tentativa de entender as prováveis causas dessa variação, foi realizado uma avaliação do comportamento dos n-alcanos estudados durante o experimento.

\subsubsection{Comportamento dos $n$-alcanos de cadeia ímpar da dieta $\left(C_{31}, C_{33}\right.$ e $\left.C_{35}\right)$ e de cadeia par fornecidos via cápsula $\left(C_{32}\right.$ e $\left.C_{36}\right)$}

Há 17 anos o trabalho pioneiro de Mayes et al. (1986a) sugeriu que seria possível obter estimativas confiáveis do consumo de forragem por ovinos em pastejo e recebendo um suplemento concentrado com o uso simultâneo de um par de n-alcanos, um com cadeia ímpar, naturalmente presente na forragem, e um de cadeia par, fornecido como indicador externo. Esses pesquisadores estabeleceram que a condição fundamental para que a técnica funcionasse era que as recuperações fecais do par de n-alcanos utilizado que deveriam ser similares ou muito próximas, mesmo que não fossem integrais. Avaliaram, também, a variabilidade diurna e diária das concentrações da relação fecal entre o n-alcano natural de cadeia ímpar e o fornecido de cadeia par, sendo essa variabilidade na concentração mais importante para a relação fecal entre o par do que as variações nas concentrações individuais de cada n-alcano. Esses autores estabeleceram que para a obtenção de estimativas do consumo de forragem era fundamental que não houvesse variação diurna e/ou diária na relação entre as concentrações dos alcanos nas fezes, embora fossem admitidas variações nas excreções individuais de cada n-alcano.

$\mathrm{Na}$ Tabela 8 são apresentadas as concentrações médias das individuais e as relações fecais das concentrações dos n-alcanos possíveis de serem utilizados como indicadores, e as probabilidades estatísticas para as variações para os períodos 1 e 2 . 
Tabela 8. Médias das concentrações fecais individuais do $\mathrm{C}_{31}, \mathrm{C}_{32}, \mathrm{C}_{33}, \mathrm{C}_{35}, \mathrm{C}_{36}$ e das relações $\mathrm{C}_{31}: \mathrm{C}_{32}, \mathrm{C}_{33}: \mathrm{C}_{32}$ e $\mathrm{C}_{35}: \mathrm{C}_{36}\left(\mathrm{mg} \cdot \mathrm{kg}^{-1} \mathrm{MS}\right)$

\begin{tabular}{llll}
\hline Alcano & $\mathrm{P}^{1}$ & $\mathrm{P}^{3}$ & $\mathrm{P}^{2}$ \\
& &
\end{tabular}

/Relaç.

\begin{tabular}{|c|c|c|c|c|c|c|c|c|c|c|}
\hline & $\mathrm{M}^{4}$ & $T^{5}$ & $\operatorname{Tr}^{6}$ & $\mathrm{Tu}^{7}$ & $\operatorname{TrXTu}^{8}$ & $\mathrm{M}^{4}$ & $T^{5}$ & $\operatorname{Tr}^{6}$ & $\mathrm{Tu}^{7}$ & $\mathrm{TrXTu}^{8}$ \\
\hline $\mathrm{C}_{31}$ & 217,8 & 240,8 & ns & * & ns & 253,7 & 275,7 & ns & $* *$ & ns \\
\hline $\mathrm{C}_{32}$ & 89,9 & 93,3 & ns & ns & ns & 123,5 & 137,1 & ns & $* *$ & ns \\
\hline $\mathrm{C}_{33}$ & 236,4 & 261,9 & ns & ** & ns & 420,8 & 453,0 & ns & $* *$ & ns \\
\hline $\mathrm{C}_{35}$ & 42,4 & 47,5 & ns & ** & ns & 92,3 & 99,2 & ns & ** & ns \\
\hline $\mathrm{C}_{36}$ & 34,5 & 37,5 & ns & ns & ns & 91,9 & 100,2 & ns & $* *$ & ns \\
\hline$C_{31}: C_{32}$ & 2,43 & 2,64 & ns & ns & ns & 2,14 & 2,32 & $* *$ & $* *$ & ns \\
\hline $\mathrm{C}_{33}: \mathrm{C}_{32}$ & 2,64 & 2,88 & $\mathrm{~ns}$ & ns & ns & 3,56 & 3,84 & $* *$ & $* *$ & ns \\
\hline $\mathrm{C}_{35}: \mathrm{C}_{36}$ & 1,45 & 1,67 & ns & ns & ns & 1,03 & 1,11 & $* *$ & $* *$ & ns \\
\hline
\end{tabular}

Observa-se no período 1 que não houve efeito de tratamento nem da interação entre tratamento e turno $(P>0,05)$ sobre as concentrações fecais dos $\mathrm{n}$-alcanos individuais e das relações entre eles. Ocorreram variações entre turnos nas concentrações fecais dos $n$-alcanos naturais da forragem $C_{31}$ $(P=0,05), C_{33}$ e $C_{35}(P=0,01)$, sendo maiores no turno da tarde. Os $n$-alcanos $\mathrm{C}_{32}$ e $\mathrm{C}_{36}$, fornecidos via cápsula de liberação controlada, não variaram entre os turnos. Entretanto, pode-se observar que a premissa básica para que a metodologia fornecesse resultados satisfatórios foi cumprida, não havendo variação entre os turnos $(P>0,05)$ nas relações entre as concentrações fecais para os 3 pares de $n$-alcanos estudados (concentrações para o cálculo de consumo no Apêndice 1).

Já no período 2 não foi encontrado efeito da interação entre tratamento e turno $(P>0,05)$ sobre as concentrações fecais dos $n$-alcanos individuais e das relações entre eles, nem de tratamento sobre as concentrações fecais dos n- 
alcanos individuais $(P>0,05)$. Contudo, houve efeito de tratamento sobre as relações das concentrações fecais para os 3 pares de n-alcanos estudados, sendo sempre maiores para os animais tratados com CLA $(P=0,01)$ (concentrações para o cálculo de consumo no Apêndice 2). No trabalho de Mayes et al. (1986a), com ovinos, metade dos animais receberam a dose dos nalcanos sintéticos de cadeia par $\left(\mathrm{C}_{28}\right.$ e $\left.\mathrm{C}_{32}\right)$ na forma de péletes misturados com os ácidos palmítico e esteárico com o objetivo de facilitar a emulsificação e distribuição no trato digestivo. Embora nesse trabalho a gordura fornecida não tivesse um objetivo nutricional, os autores encontraram menores concentrações fecais com os animais que receberam os péletes misturados com os ácidos graxos somente para os $n$-alcanos naturais da dieta $C_{27}$ e $C_{29}$, mas não encontraram efeito do tipo de pélete sobre as relações das concentrações fecais entre os $n$-alcanos naturais da forragem e sintéticos fornecidos. Trabalhando com vacas não lactantes da raça Holandês, Ohajuruka \& Palmquist (1991) investigaram a recuperação fecal do n-alcano $C_{31}$ e se esta seria influenciada pela adição de gordura (500 g de Megalac.vaca.dia ${ }^{-1}$ ) em uma dieta a base de feno de gramínea ou alfafa. Esses autores não encontraram efeito da adição de gordura nem da interação entre a adição de gordura e o tipo de feno. De forma expeculativa, uma possibilidade de explicação é que o CLA, por ser um tipo de gordura mais insaturada do que o Megalac, poderia dissociar-se mais no rúmen, alterando a digestão da fibra e a taxa de passagem, modificando as concentrações fecais dos n-alcanos em estudo.

Houve efeito de turno sobre as concentrações fecais dos n-alcanos individuais e de suas relações ( $P=0,01)$, e este pode ser explicado pelo manejo imposto aos animais durante o experimento. Os animais passavam a noite no piquete e eram trazidos para a ordenha às 5 horas. Imediatamente após a ordenha, recebiam a metade do concentrado e retornavam para a pastagem em torno de 7:30, onde permaneciam até às 11:30 em função do calor e por não haver sombra nos piquetes. Nesse horário, eram trazidos para um abrigo onde 
ficavam até a ordenha da tarde, em torno das 14:30. Depois de ordenhados recebiam a segunda metade do concentrado e, em torno das 16 horas, eram levados para o piquete onde permaneciam até o próximo dia. No período da manhã o tempo para o pastejo era relativamente curto razão pela qual o pastejo concentrava-se à tardinha e à noite. Observações visuais durante o experimento revelaram que alguns animais iniciavam o pastejo imediatamente na chegada à tarde nos piquetes, interrompendo-o em torno das 20 horas, e retomando-o por volta das 23 horas. Consequentemente, o maior "pool" de enchimento ruminal era nesse, horário resultando em maiores excreções e concentrações fecais na tarde seguinte.

No período 3 foi investigado $o$ efeito de tratamento sobre as concentrações individuais, as relações nas concentrações fecais e a variação entre turnos e dias de coleta. As concentrações fecais médias individuais e as relações fecais são apresentadas na Tabela 9.

Houve efeito de tratamento $(C L A=226,9 \mathrm{mg}$ vs. $M E G=211,3 \mathrm{mg}$, $\mathrm{P}=0,01$ ), de turno (manhã $=203,3 \mathrm{mg}$ vs. tarde $=235,1 \mathrm{mg}, \mathrm{P}=0,0001$ ) e um efeito linear de dia de coleta $\left(-9,6 \mathrm{~g} \cdot \mathrm{dia}^{-1}\right)$ sobre a concentração fecal do $C_{31}$. Com o n-alcano $C_{32}$ houve um efeito de turno (manhã $=102,5 \mathrm{mg}$ vs. tarde= $109,4 \mathrm{mg}, P=0,0001)$ e um efeito quadrático de dia $(P=0,0001)$ sobre a concentração fecal. Investigando-se a concentração fecal da relação entre o par $\mathrm{C}_{31}: \mathrm{C}_{32}$, encontrou-se efeito de turno (manhã $=2,16 \mathrm{mg}$ vs. tarde $=2,33 \mathrm{mg}$, $\mathrm{P}=0,0007)$. O possível efeito do tratamento já foi mencionado anteriormente para o período 2 e mostra-se válido neste período também. Nas Figuras 8, 9 e 10 abaixo são mostrados os comportamentos dos n-alcanos individuais e do par $\mathrm{C}_{31}: \mathrm{C}_{32}$. 


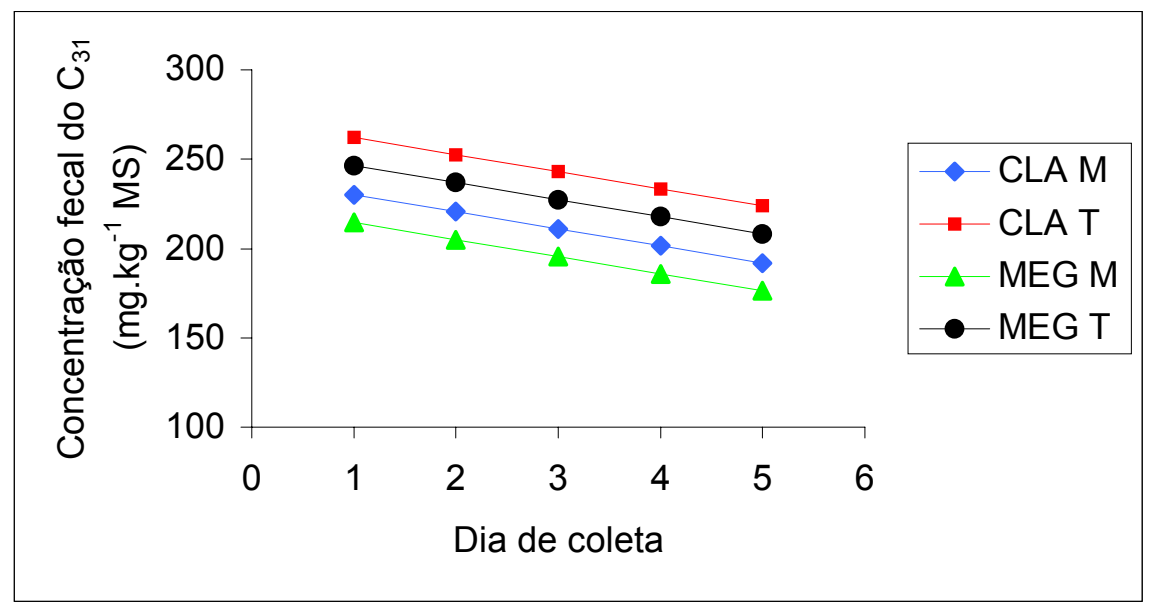

Figura 8 - Variação na concentração fecal do $C_{31}$ entre tratamentos, turnos e dias durante o período 3 (CLA Manhã, $\mathrm{mg} \mathrm{C}_{31}=239,8$ - 9,6 Dia; CLA Tarde, $\mathrm{mg} \mathrm{C}_{31}=271,6$ - 9,6 Dia; MEG Manhã, $\mathrm{mg} \mathrm{C}_{31}=224,2$ - 9,6 Dia; MEG Tarde, $\left.\mathrm{mg} \mathrm{C}_{31}=256,0-9,6 \mathrm{Dia}\right)$

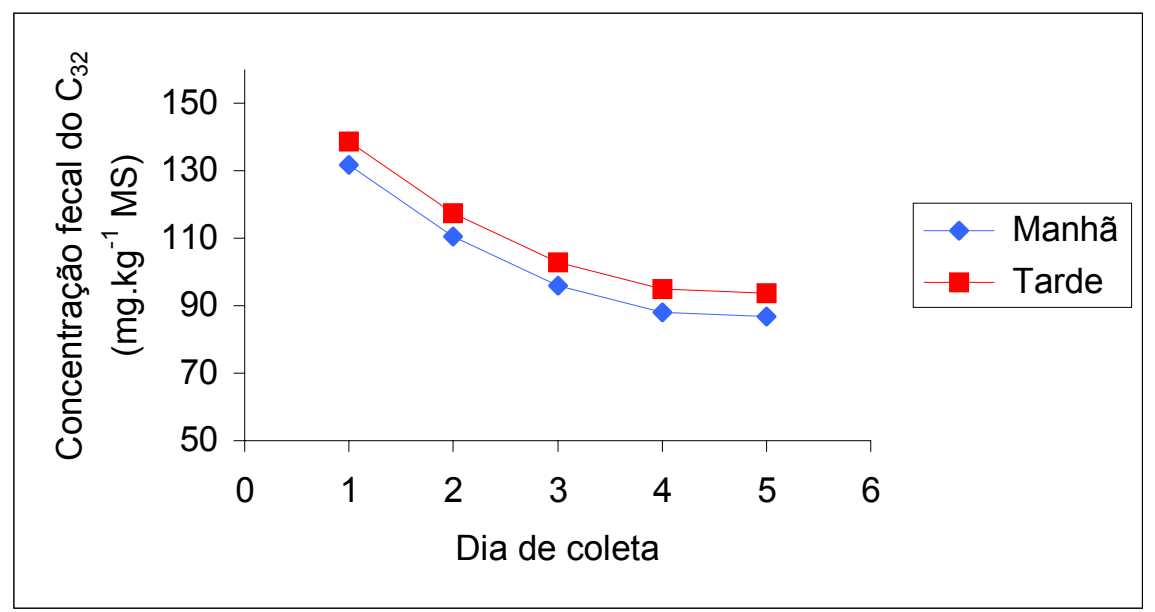

Figura 9 - Variação na concentração fecal $\mathrm{C}_{32}$ entre turnos e dias durante o período 3 (Manhã: $\mathrm{mg} \mathrm{C}_{32}=159,8-31,6 \mathrm{Dia}+3,4 \mathrm{Dia}^{2}$; Tarde: $\mathrm{mg}$ $\left.\mathrm{C}_{32}=166,7-31,6 \mathrm{Dia}+3,4 \mathrm{Dia}^{2}\right)$ 


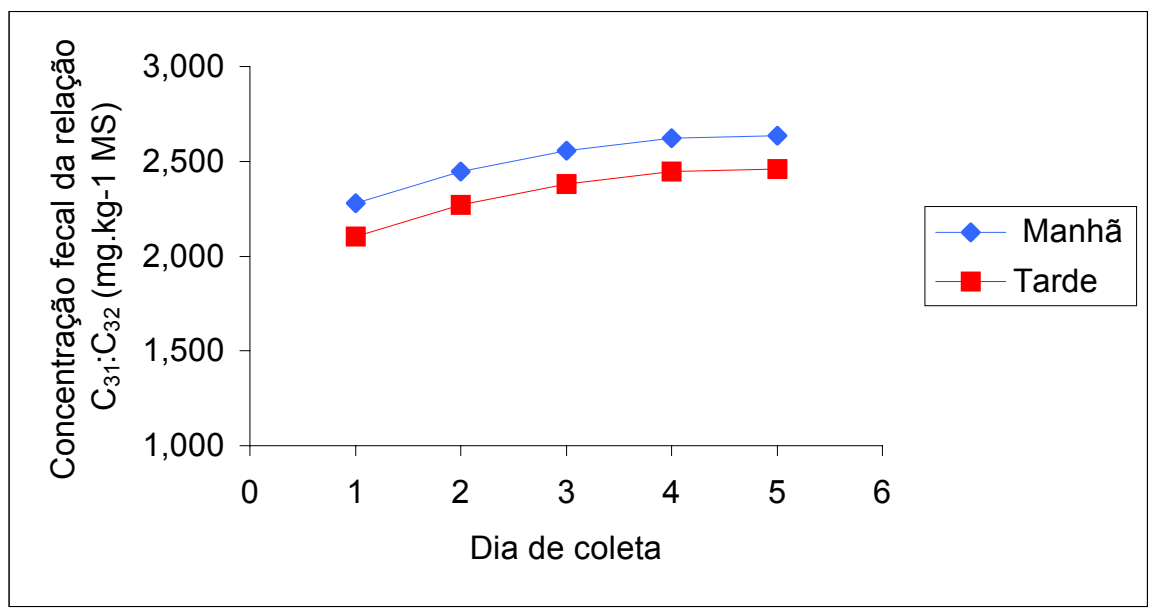

Figura 10 - Variação na concentração fecal da relação entre $C_{31}: C_{32}$ entre turnos e dias durante o período 3 (Manhã: $\mathrm{mg} \mathrm{C}_{31}: \mathrm{C}_{32}=2,07+0,24$ Dia - 0,025 $\mathrm{Dia}^{2}$; Tarde: $\mathrm{mg} \mathrm{C}_{31}: \mathrm{C}_{32}=1,89+0,24 \mathrm{Dia}-0,025 \mathrm{Dia}^{2}$ )

A diminuição linear na concentração fecal do $C_{31}$ entre os dias de coleta pode ser reflexo de variações estruturais da pastagem (composição morfológica). Pode-se observar na Tabela 2 que $\circ \mathrm{C}_{31}$ foi encontrado em maiores concentrações na fração lâmina foliar. Como o tempo de permanência em cada piquete foi de 2 dias, essa diminuição na concentração pode refletir uma diminuição na fração de lâmina foliar a medida que o pastejo prosseguia. Entretanto, poderia-se esperar um aumento na concentração a medida que os animais entrassem em um piquete novo (ex. dia 3) mas, como pode-se observar da Tabela 5, que o percentual de lâminas foliares foi diminuindo entre os piquetes 1, 2 e 3 . Isso vem reforçar a idéia de que em experimentos com animais em pastejo, mesmo que o objetivo seja produção, mas onde parâmetros como o consumo são medidos, deve-se ter muito cuidado em manter constante o dossel da pastagem ou pelo menos, descrever as mudanças estruturais que ocorrem ao longo do período de coleta de fezes dos animais.

Neste trabalho, pensou-se em não restringir o consumo ofertando-se uma grande massa de forragem, exceção feita no último período devido ao 
Tabela 9. Concentrações fecais médias individuais e das relações entre os pares de n-alcanos estudados (mg. $\mathrm{kg}^{-1} \mathrm{MS}$ ) entre os 5 dias e 2 tratamentos no período 3

\begin{tabular}{|c|c|c|c|c|c|c|c|c|c|c|c|c|c|c|c|c|c|c|c|c|}
\hline & \multicolumn{4}{|c|}{$\mathrm{D} 1^{\mathrm{a}}$} & \multicolumn{4}{|c|}{$\mathrm{D} 2^{\mathrm{a}}$} & \multicolumn{4}{|c|}{$\mathrm{D}^{\mathrm{a}}$} & \multicolumn{4}{|c|}{$\mathrm{D} 4^{\mathrm{a}}$} & \multicolumn{4}{|c|}{$\mathrm{D}^{\mathrm{a}}$} \\
\hline & \multicolumn{2}{|c|}{$\mathrm{Cla}^{\mathrm{b}}$} & \multicolumn{2}{|c|}{ Meg } & \multicolumn{2}{|c|}{ Cla } & \multicolumn{2}{|c|}{ Meg } & \multicolumn{2}{|c|}{ Cla } & \multicolumn{2}{|c|}{ Meg } & \multicolumn{2}{|c|}{ Cla } & \multicolumn{2}{|c|}{ Meg } & \multicolumn{2}{|c|}{ Cla } & \multicolumn{2}{|c|}{ Meg } \\
\hline & $\mathrm{M}^{\mathrm{c}}$ & $T$ & $M$ & $\mathrm{~T}$ & $M$ & $\mathrm{~T}$ & $M$ & $\mathrm{~T}$ & $M$ & $\mathrm{~T}$ & $M$ & $\mathrm{~T}$ & $M$ & $\mathrm{~T}$ & $\mathrm{M}$ & $\mathrm{T}$ & $M$ & $\mathrm{~T}$ & $M$ & $\mathrm{~T}$ \\
\hline $\mathrm{C}_{31}$ & 245 & 283 & 223 & 252 & 313 & 369 & 334 & 361 & 208 & 240 & 212 & 230 & 218 & 246 & 220 & 242 & 213 & 248 & 189 & 230 \\
\hline $\mathrm{C}_{32}$ & 134 & 135 & 125 & 122 & 157 & 160 & 158 & 166 & 96 & 99 & 95 & 112 & 98 & 101 & 100 & 99 & 92 & 96 & 84 & 103 \\
\hline $\mathrm{C}_{33}$ & 290 & 328 & 267 & 301 & 416 & 497 & 453 & 506 & 299 & 345 & 304 & 328 & 312 & 361 & 318 & 356 & 304 & 346 & 265 & 311 \\
\hline $\mathrm{C}_{35}$ & 55 & 63 & 55 & 59 & 81 & 100 & 86 & 102 & 63 & 73 & 64 & 69 & 68 & 84 & 70 & 80 & 70 & 77 & 57 & 65 \\
\hline $\mathrm{C}_{36}$ & 76 & 72 & 71 & 68 & 106 & 109 & 107 & 114 & 69 & 74 & 74 & 72 & 71 & 82 & 80 & 69 & 66 & 66 & 62 & 61 \\
\hline \multirow[t]{2}{*}{$\mathrm{C}_{31}: \mathrm{C}_{32}$} & 1,8 & 2,1 & 1,8 & 2,1 & 2,1 & 2,3 & 2,1 & 2,2 & 2,2 & 2,4 & 2,2 & 2,1 & 2,2 & 2,5 & 2,2 & 2,4 & 2,3 & 2,6 & 2,2 & 2,2 \\
\hline & 6 & 3 & 4 & 4 & 4 & 8 & 7 & 1 & 0 & 4 & 2 & 5 & 5 & 0 & 0 & 5 & 5 & 2 & 6 & 5 \\
\hline \multirow[t]{2}{*}{$\mathrm{C}_{33}: \mathrm{C}_{32}$} & 2,2 & 2,4 & 2,2 & 2,5 & 2,8 & 3,2 & 2,9 & 3,1 & 3,1 & 3,5 & 3,2 & 3,0 & 3,2 & 3,6 & 3,1 & 3,6 & 3,3 & 3,6 & 3,1 & 3,0 \\
\hline & 0 & 7 & 1 & 6 & 7 & 2 & 5 & 2 & 6 & 0 & 1 & 7 & 4 & 7 & 8 & 2 & 7 & 5 & 9 & 6 \\
\hline \multirow[t]{2}{*}{$\mathrm{C}_{35}: \mathrm{C}_{36}$} & 0,7 & 0,8 & 0,8 & 0,9 & 0,7 & 0,9 & 0,8 & 0,9 & 0,9 & 1,0 & 0,8 & 0,9 & 0,9 & 1,1 & 0,8 & 1,1 & 1,1 & 1,1 & 0,9 & 1,0 \\
\hline & 6 & 9 & 2 & 2 & 9 & 6 & 4 & 3 & 4 & 0 & 9 & 8 & 6 & 1 & 8 & 5 & 0 & 9 & 3 & 7 \\
\hline
\end{tabular}


evento climático, mas não atentou-se previamente que a medida que os animais iam desfolhando a pastagem, iam mudando também a estrutura da mesma na forma das relações entre seus componentes morfológicos. Embora tenha-se procurado obter amostras da forragem o mais semelhante possível daquela colhida pelos animais (Figura 11), é difícil acompanhar mudanças sutis na estrutura do dossel forrageiro, o que pode levar a uma amostragem que não represente aquilo que foi efetivamente ingerido pelos animais afetando diretamente as estimativas de consumo de forragem. A esse respeito, Vulich et al. (1993) sugeriram que a forragem fosse amostrada através de vários dias durante o período experimental porque encontraram variações nas concentrações dos n-alcanos entre dias dentro de uma mesma semana e entre semanas diferentes.

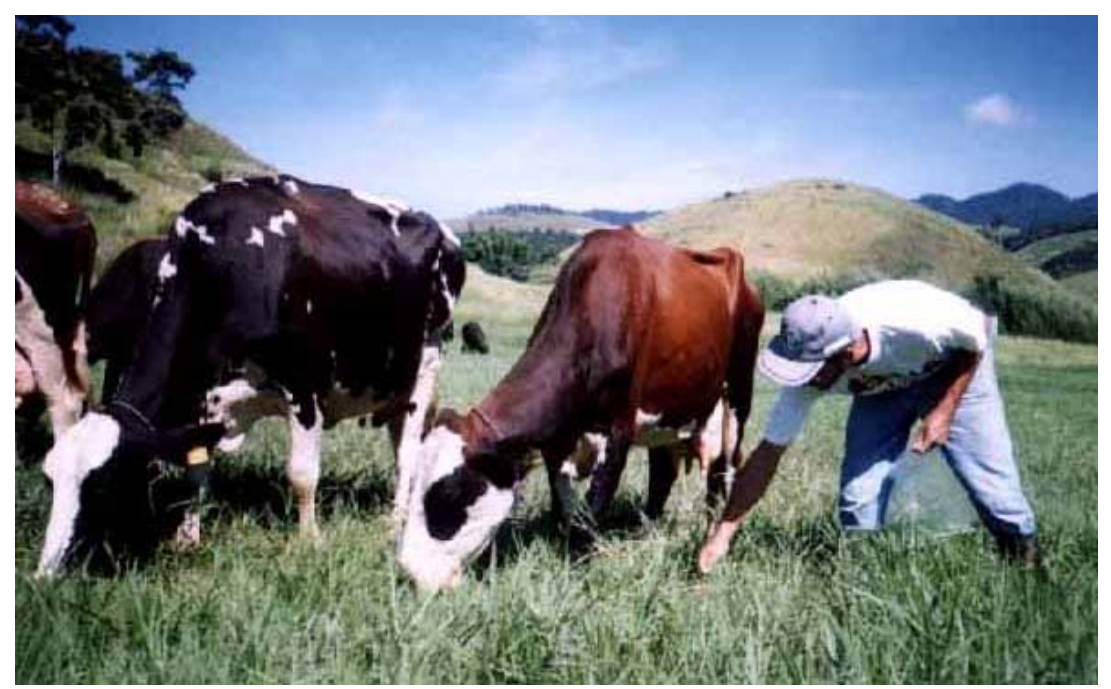

Figura 11 - Coleta da amostra de forragem através da técnica do pastejo simulado.

Com relação a concentração fecal do $n$-alcano $\mathrm{C}_{32}$, a relação mostrada na Figura 9 representa tanto $\circ \mathrm{C}_{32}$ vindo da forragem consumida como aquele da cápsula. A característica da curva apresentada é o reflexo da diminuição do $\mathrm{C}_{32}$ consumido visto que, este alcano foi encontrado em maior concentração na 
fração lâmina foliar, que diminui a cada dia e diminuiu a cada piquete ocupado, mais àquele liberado de forma constante. A variação entre os turnos é reflexo do manejo dos animais, já discutido anteriormente.

A concentração fecal do $\mathrm{C}_{33}$, que forma o outro par possível com o $\mathrm{C}_{32}$, variou entre turnos (manhã $=304,4 \mathrm{mg}$ vs. tarde $=338,7 \mathrm{mg}, \mathrm{P}=0,0001$ ). Podese observar na Tabela 2 que este n-alcano esteve presente praticamente na mesma concentração tanto na fração lâmina foliar como na haste+bainha das folhas. Essa constatação pode justificar a constância na concentração fecal durante os dias de coleta sendo, entretanto, maior no turno da tarde pelos motivos já comentados (Figura 12).

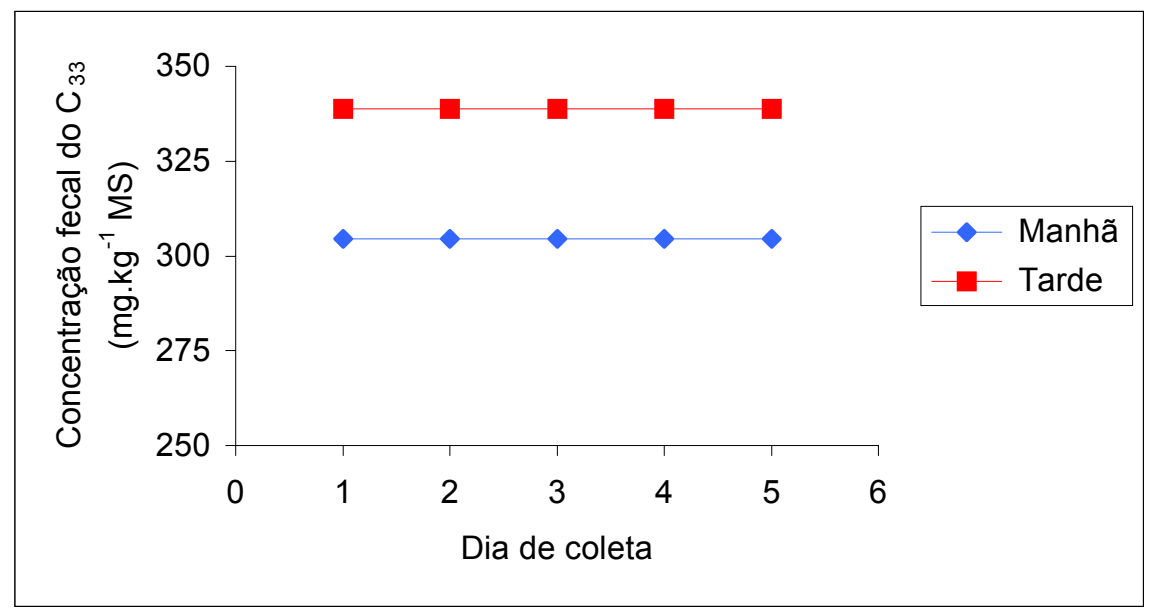

Figura 12 - Variação na concentração fecal $C_{33}$ entre turnos e dias durante o período 3

Usando-se o mesmo raciocínio de que há uma diminuição na quantidade de folhas com o passar do tempo devido ao pastejo, a concentração fecal é mantida por conta de um aumento do consumo da fração haste+bainha das folhas. Essa suposição pode ser suportada pelas proporções de lâminas foliares e haste+bainha de folhas na forragem consumida estimada com os nalcanos $C_{31}, C_{33}$ e $C_{35}$, nesse período: $68,9 \%( \pm 11,6)$ e $31,1 \%( \pm 25,8)$, respectivamente. Se comparados com o período 1 esses valores são 18,3 \% 
menor e $116 \%$ maior, respectivamente, para lâminas foliares e haste+bainha das folhas.

Com relação ao par $\mathrm{C}_{33}: \mathrm{C}_{32}$, foi constatado efeito de turno ( manhã $=2,96 \mathrm{mg}$ vs. tarde $=3,19 \mathrm{mg}, \mathrm{P}=0,0009$ ) e um efeito quadrático de dia de coleta $(P=0,0001)$ sobre a concentração fecal. Em função da concentração fecal constante do $\mathrm{C}_{33}$, pode-se afirmar que a variação entre dias na concentração fecal da relação do par foi causada pela variação na concentração fecal do $\mathrm{C}_{32}$. Na Figura 13 abaixo é mostrada esta relação.

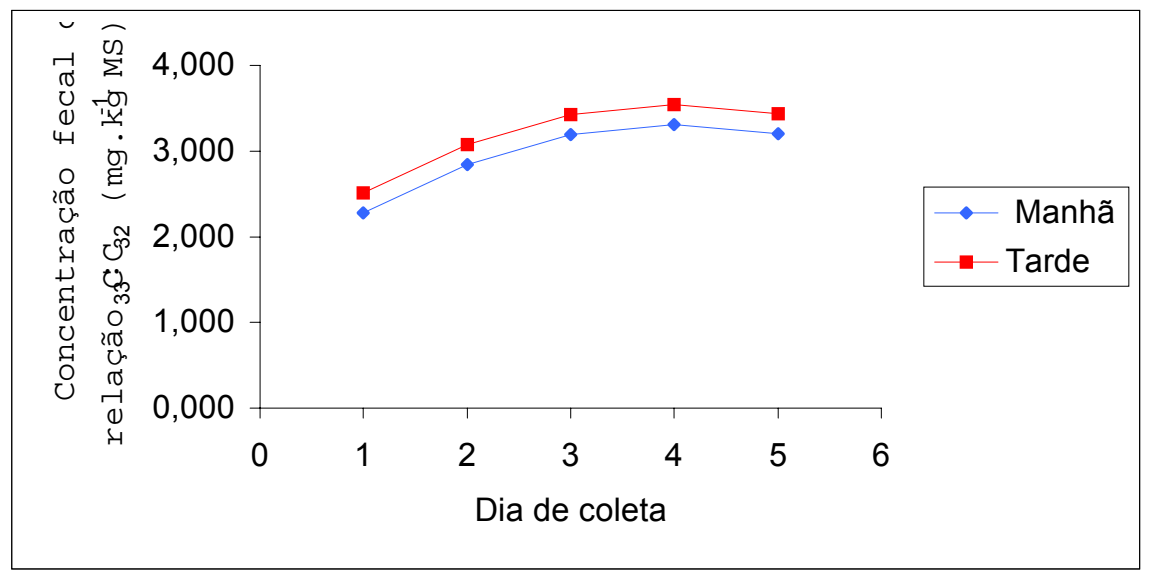

Figura 13 - Variação na concentração fecal da relação entre $C_{33}: C_{32}$ entre turnos e dias durante o período 3 (Manhã: $\mathrm{mg} \mathrm{C}_{33}: \mathrm{C}_{32}=1,47+0,91$ Dia - 0,11 Dia ${ }^{2}$; Tarde: $\mathrm{mg} \mathrm{C}_{33}: \mathrm{C}_{32}=1,71+0,91 \mathrm{Dia}-0,11 \mathrm{Dia}^{2}$ )

Embora Dove et al. (1991) mostraram que houve variação entre dias nas concentrações fecais individuais do n-alcano $C_{29}$, natural da dieta, e $C_{28}$ e $C_{32}$, fornecidos oralmente via cápsula de liberação controlada, e $\mathrm{C}_{36}$, na forma de péletes de papel, mostraram também que as relações das concentrações fecais dos pares $\mathrm{C}_{28}: \mathrm{C}_{29}, \mathrm{C}_{33}: \mathrm{C}_{32}$ permaneceram constantes no mesmo período em que variaram as concentrações individuais. Todavia, encontraram uma acentuada variação diária na relação da concentração fecal do par $\mathrm{C}_{35}: \mathrm{C}_{36}$. Sob esse aspecto, Dove et al. (2002) encontraram uma interação entre o nível de 
consumo e a frequência da alimentação sobre a concentração fecal do n-alcano $\mathrm{C}_{31}$ e um efeito do nível de consumo sobre a concentração fecal do $C_{33}$ e $C_{35} \mathrm{e}$, sobre os n-alcanos fornecidos $\mathrm{C}_{28}, \mathrm{C}_{32}$ e $\mathrm{C}_{36}$. É possível que neste experimento a mudança da massa de forragem entre os 2 dias de ocupação dos piquetes tenha produzido um efeito semelhante, sugerindo um alto nível de alimentação no dia 1 e um baixo nível no dia 2, influenciando as concentrações fecais dos nalcanos e seus pares. Trabalhando com vacas leiteiras, Stakelum \& Dillon (1990) utilizaram essa metodologia para estimar o consumo de gramíneas cortadas e fornecidas aos animais. Esses autores testaram o efeito de diferentes padrões e níveis de alimentação (5 tratamentos) sobre a recuperação fecal e o padrão de excreção dos n-alcanos naturais e fornecidos $\left(C_{32}\right.$ e $\left.C_{36}\right)$. Em 2 dos tratamentos estudados havia uma alteração na quantidade fornecida entre os dias 1 e 2 de alimentação. Nesses 2 tratamentos os autores encontraram significativa variação diurna na relação da concentração fecal dos pares $\mathrm{C}_{31}: \mathrm{C}_{32}, \mathrm{C}_{33}: \mathrm{C}_{32}$ e $\mathrm{C}_{35}: \mathrm{C}_{36}$. Encontraram, também, significativa variação entre os dias 1 e 2 para as mesmas relações. É importante salientar que nesse estudo os autores não mostraram as comparações do consumo estimado com o observado para os tratamentos onde encontraram as variações, mas em outros 2 tratamentos, onde fizeram a coleta total, comentaram e mostraram que o consumo estimado com o par $\mathrm{C}_{33}: \mathrm{C}_{32}$ foi idêntico ao observado. Fazendo um paralelo desse estudo com o que foi realizado, a extensão dessa variação diurna e/ou diária é importante em situações onde o padrão de consumo muda de maneira repetitiva, como neste estudo. Dillon \& Stakelum (1990b) utilizaram a metodologia de $n$-alcanos para estimar o consumo de forragem com vacas leiteiras alimentadas com dietas a base de silagem de gramínea e 5 tipos de concentrados de diferentes composições, fornecidos em diferentes níveis. Nesse experimento encontraram, também, variações diurnas na relação da concentração fecal dos mesmos pares citados anteriormente.

Observando o comportamento da concentração fecal do $n$-alcano $C_{35}$, foi encontrado efeito de tratamento $(C L A=62,3 \mathrm{mg}$ vs. $M E G=54,9 \mathrm{mg}, P=0,0001)$, 
de turno (manhã $=54,5 \mathrm{mg}$ vs. tarde $=62,7 \mathrm{mg}, \mathrm{P}=0,0001$ ) e um efeito linear de dia de coleta $(P=0,0001)$. Os efeitos de tratamento e turno já foram discutidos anteriormente. $O$ efeito linear do aumento na concentração fecal entre dias de coleta (Figura 14) representa também um aumento no consumo da fração de haste+bainha das folhas em relação a fração lâmina foliar, visto que este nalcano foi encontrado em maior concentração na fração de haste+bainha das folhas (Tabela 2).

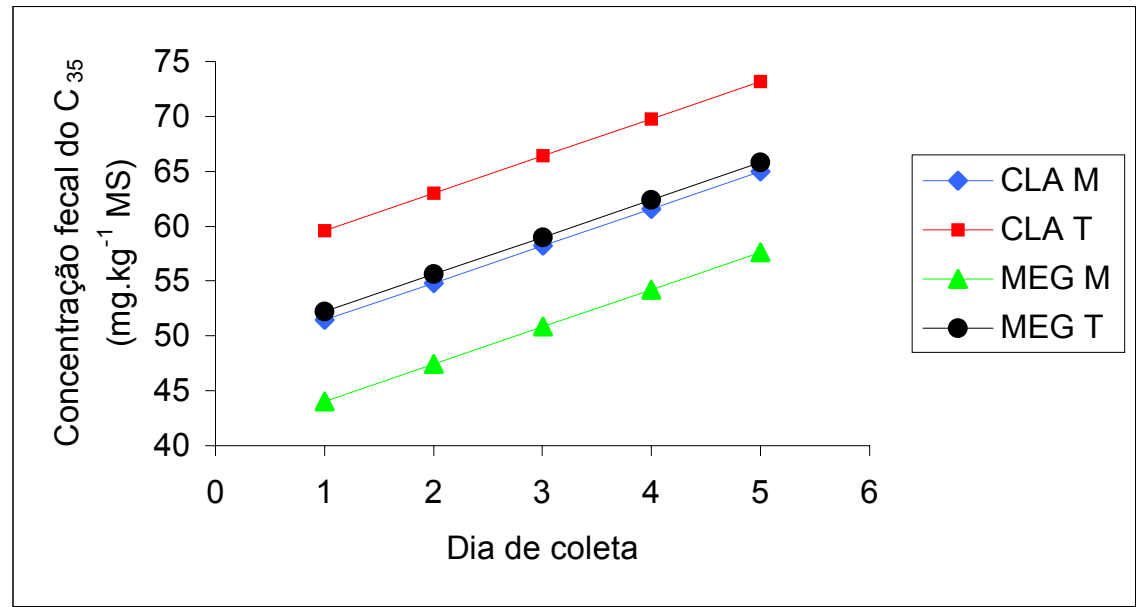

Figura 14 - Variação na concentração fecal do $C_{35}$ entre tratamentos, turnos e dias durante o período 3 (CLA Manhã, $\mathrm{mg} \mathrm{C}_{35}=48,1+3,4$ Dia; CLA Tarde, $\mathrm{mg} \mathrm{C}_{35}=56,2+3,4$ Dia; MEG Manhã, $\mathrm{mg} \mathrm{C}_{35}=40,7+3,4$ Dia; MEG Tarde, $\left.\mathrm{mg} \mathrm{C}_{35}=48,9+3,4 \mathrm{Dia}\right)$

Analisando a variação na concentração fecal do $C_{36}$, foi encontrado um efeito quadrático de dia de coleta, e isso pode ser observado na Figura 15. 


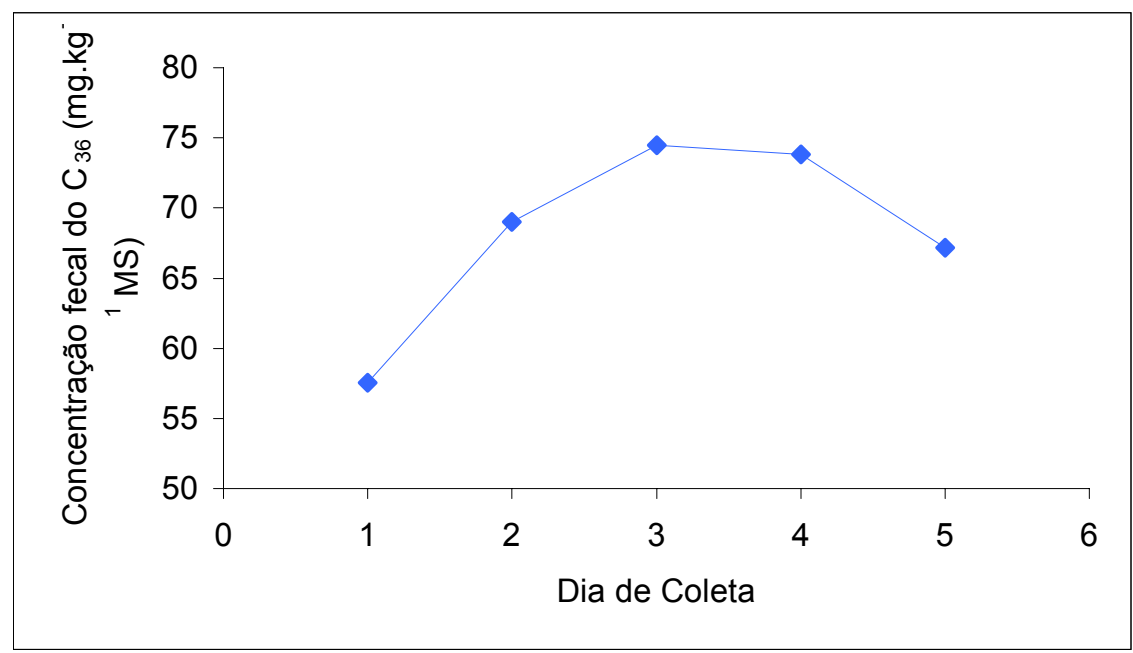

Figura 15 - Variação na concentração fecal $C_{36}$ entre dias durante o período 3 $\left(m g \mathrm{C}_{36}=40,02+20,5 \mathrm{Dia}-3,02 \mathrm{Dia}^{2}\right)$

A concentração fecal deste n-alcano, fornecido via cápsula, mostrou um comportamento totalmente diferente do $C_{32}$. Embora Dove et al. (1991) tenham mostrado que o n-alcano $\mathrm{C}_{36}$ teve a concentração fecal mais errática entre dias, naquele trabalho o indicador foi fornecido na forma de péletes de papel. Embora não tenha sido estudado, prováveis mudanças no enchimento do rúmen em função do manejo imposto aos animais podem ter levado a esse comportamento.

Assim sendo, utilizou-se também o par $\mathrm{C}_{31}: \mathrm{C}_{32}$ para estimar o consumo de forragem e de partes de plantas no período 3 (Tabela 10) (concentrações para o cálculo de consumo no Apêndice 3 ). A equação de regressão obtida entre as exigências e o consumo de energia metabolizável foi: Cons $E M=0,31$ $+1,2$ Exig EM, com o $b=1$, o $r^{2}=0,73$ e um $C V=5,1 \%$. Com o consumo de energia metabolizável vindo das frações de lâmina foliar e haste+bainha de folhas a equação foi: Cons $E M=2,5+1,1$ Exig $E M$, com $b=1, r^{2}=0,73$ e um $C V=$ 4,8\% (Apêndice 5). Porém, em ambas as medidas a probabilidade da diferença média entre o consumo e as exigências ser igual a zero $(\check{D}=0)$ foi $P<0,0001$. 
Tabela 10. Consumo individual de forragem ( $\left.\mathrm{kg} \mathrm{MS} \cdot \mathrm{dia}^{-1}\right)$ e percentuais de lâminas foliares (LF) e haste+bainha das folhas (HB) estimados com os n-alcanos $\mathrm{C}_{31}, \mathrm{C}_{33}$ e $\mathrm{C}_{35}$ para o período 3

\begin{tabular}{lccc}
\hline Animal & Consumo $(\mathrm{kg} \mathrm{MS})$ & LF & HB \\
\hline 0674 CLA & 10,8 & 76,1 & 23,9 \\
1643 CLA & 15,4 & 74,1 & 25,9 \\
2521 CLA & 15,0 & 64,8 & 35,2 \\
3414 CLA & 14,7 & 59,9 & 40,1 \\
0371 CLA & 11,9 & 69,3 & 30,7 \\
4882 CLA & 13,0 & 59,4 & 40,6 \\
0669 MEG & 17,7 & 59,4 & 40,6 \\
3461 MEG & 14,1 & 72,7 & 27,3 \\
1450 MEG & 16,0 & 62,9 & 37,1 \\
4689 MEG & 15,3 & 69,7 & 30,3 \\
0675 MEG & 18,3 & 60,4 & 39,6 \\
9752 MEG & 15,7 & 69,3 & 30,7 \\
1938 MEG & 10,7 & 72,0 & 28,0 \\
3401 MEG & 12,2 & 84,2 & 15,8 \\
0697 MEG & 9,4 & 83,9 & 16,1 \\
3510 MEG & 16,4 & 64,5 & 35,5 \\
Média & 14,2 & 68,9 & 31,1 \\
CV & 18,3 & 11,6 & 25,8 \\
\hline
\end{tabular}

Em função da regressão linear obtida usando o par $\mathrm{C}_{31}: \mathrm{C}_{32}$ ter apresentado um coeficiente de determinação maior, um menor coeficiente de variação e menor erro padrão de regressão, utilizou-se os valores de consumo obtidos com esse par para as medições subsequentes no período 3. Após esta avaliação do comportamento dos indicadores fez-se o estudo dos efeitos dos tratamentos CLA ou Megalac somente para os períodos 1 e 3. 
Em função do CLA atuar como um modificador metabólico, as hipóteses iniciais foram: a) os animais tratados reduziriam a secreção de energia e consequentemente consumiriam menos matéria seca em função de uma menor demanda energética; b) os animais tratados consumiriam a mesma quantidade de matéria seca que os controle, mas produziriam mais leite contendo menor teor de gordura sem alteração na secreção de energia; ou c) os animais tratados consumiriam a mesma quantidade de matéria seca que os controle e ganhariam peso vivo e/ou escore de condição corporal. 
As médias de consumo de concentrado, peso vivo e escore de condição corporal (escala de 1 a 9) são mostrados na Tabela 11.

Tabela 11. Médias do consumo de concentrado, peso vivo, escore de condição corporal e coeficientes de variação ( $C V, \%)$, nos períodos 1 e 3

\begin{tabular}{|c|c|c|}
\hline Estimativa/Tratamento/Período & Média & $\mathrm{CV}$ \\
\hline \multicolumn{3}{|l|}{ Período 1} \\
\hline \multicolumn{3}{|c|}{ Consumo de concentrado (kg MS.dia $\left.{ }^{-1}\right)$} \\
\hline CLA & $3,4^{\mathrm{a}}$ & 1,3 \\
\hline MEG & $3,3^{\mathrm{a}}$ & 7,9 \\
\hline \multicolumn{3}{|l|}{ Peso vivo $(\mathrm{kg})$} \\
\hline CLA & $495^{\mathrm{a}}$ & 3,4 \\
\hline MEG & $493^{a}$ & 19,6 \\
\hline \multicolumn{3}{|c|}{ Escore de condição corporal (ECC) } \\
\hline CLA & $3,9^{a}$ & 8,9 \\
\hline MEG & $3,6^{\mathrm{a}}$ & 10,0 \\
\hline \multicolumn{3}{|l|}{ Período 3} \\
\hline \multicolumn{3}{|c|}{ Consumo de concentrado (kg MS.dia $\left.{ }^{-1}\right)$} \\
\hline CLA & $3,6^{\mathrm{a}}$ & 3,4 \\
\hline MEG & $3,5^{\mathrm{a}}$ & 7,9 \\
\hline \multicolumn{3}{|l|}{ Peso vivo (kg) } \\
\hline CLA & $485^{a}$ & 7,7 \\
\hline MEG & $463^{a}$ & 10,9 \\
\hline \multicolumn{3}{|c|}{ Escore de condição corporal (ECC) } \\
\hline CLA & $3,8^{a}$ & 20,0 \\
\hline MEG & $3,6^{\mathrm{a}}$ & 15,7 \\
\hline
\end{tabular}

${ }^{\mathrm{a}}$ Médias seguidas de mesma letra dentro da coluna não diferem significativamente $(P>0,05)$ 
De acordo com a Tabela 11 observa-se que não houve diferenças significativas para o consumo de concentrado, peso vivo e escore de condição corporal.

Com relação ao consumo estimado de matéria seca de forragem e matéria seca total que incluem o suplemento concentrado, os dados estão na Tabela 12.

Tabela 12. Consumos médios de matéria seca de forragem e matéria seca total (kg MS.dia $\left.{ }^{-1}\right)$ e coeficientes de variação (CV, \%) para os períodos 1 e 3

\begin{tabular}{lll}
\hline Estimativa/Tratamento/Período & Média & CV \\
\hline Período 1 &
\end{tabular}

Consumo MS de forragem $(\mathrm{kg})$

CLA

MEG

Consumo MS total $(\mathrm{kg})$

CLA

MEG

Período 3

Consumo MS de forragem $(\mathrm{kg})$

CLA

MEG

Consumo MS total $(\mathrm{kg})$

CLA

MEG

${ }^{a}$ Médias

Médias

Na Tabela 13 estão os dados de produção e teores dos componentes do leite. 
Tabela 13. Médias de produção de leite $\left(\mathrm{kg} \cdot \mathrm{dia}^{-1}\right)$, dos teores dos componentes do leite $(\%)$ e coeficientes de variação $(\mathrm{CV}, \%)$ para os períodos 1 e 3

\begin{tabular}{lcc}
\hline Estimativa/Tratamento/Período & Média & CV \\
\hline Período 1 & & \\
Produção de leite $\left(\mathrm{kg} \cdot \mathrm{dia}^{-1}\right)$ & $17,9^{\mathrm{a}}$ & 12,8 \\
CLA & $17,5^{\mathrm{a}}$ & 11,6 \\
MEG & & \\
$\%$ de gordura do leite & $2,1^{\mathrm{b}}$ & 10,8 \\
CLA & $2,8^{\mathrm{a}^{*}}$ & 17,7 \\
MEG & & \\
$\%$ de proteína do leite & $3,2^{\mathrm{a}^{* *}}$ & 7,5 \\
CLA & $2,6^{\mathrm{b}}$ & 8,1 \\
MEG &
\end{tabular}

Período 3

Produção de leite (kg.dia ${ }^{-1}$ )

CLA

MEG

$\%$ de gordura do leite

CLA

MEG

$\%$ de proteína do leite

CLA

MEG

${ }^{a}$ Médias seguidas de letras diferentes dentro da coluna diferem significativamente ${ }^{*}(P<0,05)$, ${ }^{* *}(P<0,01)^{3}(P<0,10)$

O CLA diminuiu em média $25 \%$ o teor de gordura do leite no período 1 e $15 \%$ no período 3 . De acordo com as hipóteses iniciais, deste resultado esperarse-ia uma possível queda no consumo, mas pode-se observar também que nos animais tratados com CLA houve um aumento médio de $23 \%$ do teor de proteína 
do leite no período 1 e $7 \%$ no período 3 . Os efeitos do CLA nesses animais já foram discutidos por Medeiros (2002), mas relacionando-se esses efeitos com o consumo de alimentos pode-se especular que a demanda energética dos animais que receberam CLA não foi diferente daquela dos animais que receberam Megalac, provavelmente por um eventual redirecionamento da energia ingerida para a maior produção de proteína no leite, não modificando o consumo de alimentos.

Isto pode ser melhor visualizado nas Figuras 16 e 17, para os períodos 1 e 3 , respectivamente.

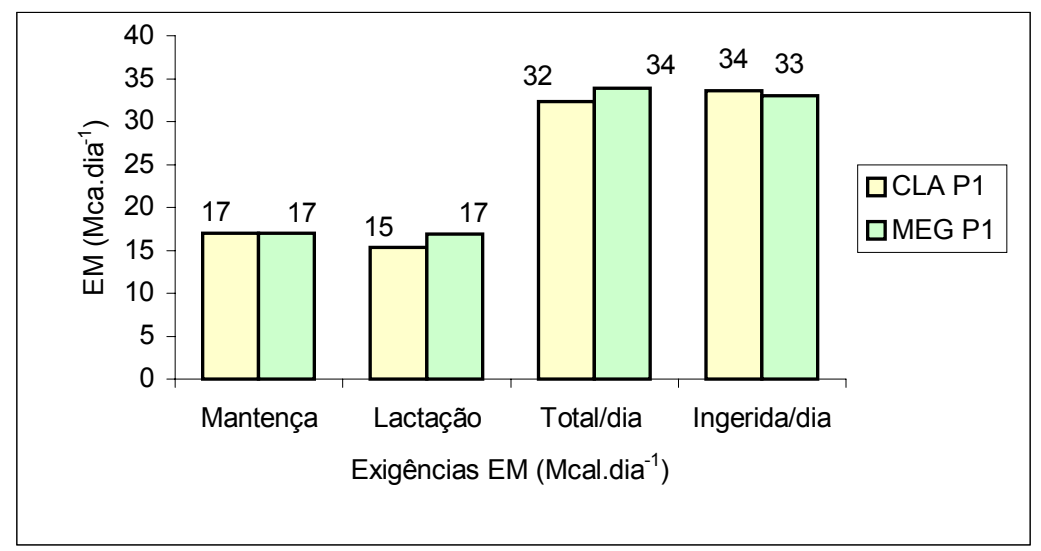

Figura 16 - Exigências de mantença, lactação, total e ingestão de energia metabolizável para os animais tratados com CLA e controle (MEG) no período 1 


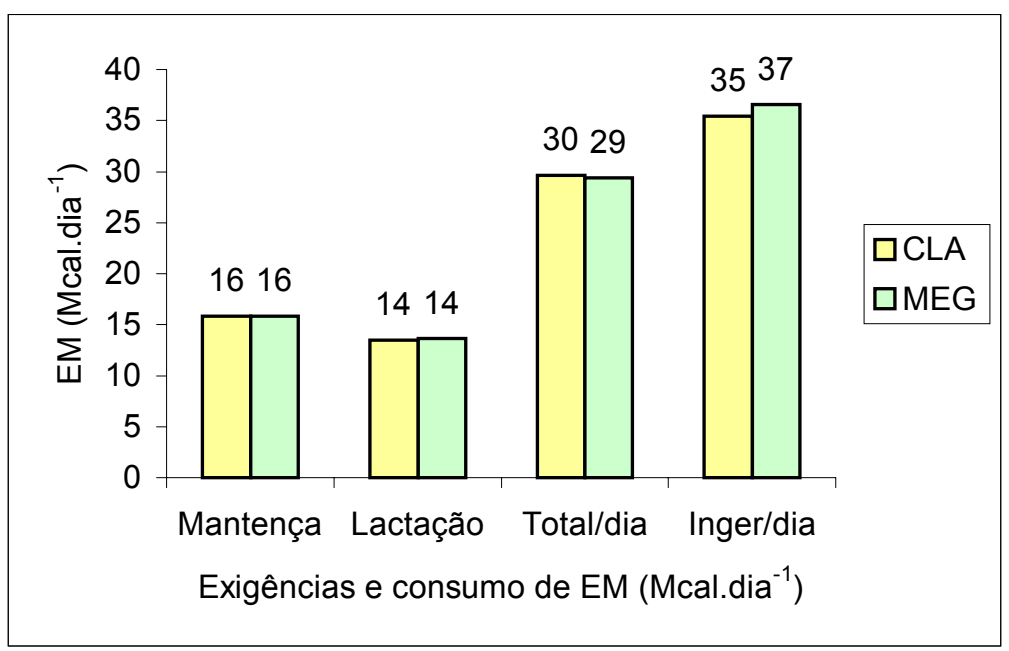

Figura 17 - Exigências de mantença, lactação, total e ingestão de energia metabolizável para os animais tratados com CLA e controle (MEG) no período 3

As exigências de mantença, lactação e total não diferiram entre os grupos de animais dos diferentes tratamentos em ambos períodos $(P>0,05)$. Devido às mudanças nos teores de gordura e proteína do leite nos dois períodos, encontrouse também diferenças na eficiência de produção desses componentes, conforme ilustrado nas Tabelas 14 e 15, respectivamente para o período 1 e 3. 
Tabela 14. Médias da eficiência de produção $\left(\mathrm{g} \cdot \mathrm{kg}^{-1} \mathrm{MS}\right)$, para gordura e proteína do leite e coeficientes de variação $(\mathrm{CV}, \%)$ para o período 1

\begin{tabular}{lcc}
\hline Estimativa/Tratamento/Período & Média & CV \\
\hline Período 1 & & \\
Eficiência para gordura & $25^{\mathrm{b}}$ & 15,8 \\
CLA & $34^{\mathrm{a}^{*}}$ & 10,0 \\
MEG & & \\
Eficiência para proteína & $40^{\mathrm{a}^{*}}$ & 16,1 \\
CLA & $32^{\mathrm{b}}$ & 8,2 \\
MEG & & \\
$\begin{array}{l}{ }^{\mathrm{a}} \text { Médias seguidas de letras diferentes dentro da coluna diferem significativamente }{ }^{*}(P<0,05) \\
{ }^{* *}(P<0,01)\end{array}$
\end{tabular}

Tabela 15. Médias da eficiência biológica $\left(\mathrm{g}^{\mathrm{kg}} \mathrm{g}^{-1} \mathrm{MS}\right)$, para gordura e proteína do leite e coeficientes de variação $(\mathrm{CV}, \%)$ para o período 3

\begin{tabular}{lcc}
\hline Estimativa/Tratamento/Período & Média & CV \\
\hline Período 3 & & \\
Eficiência para gordura & $24^{\mathrm{a}}$ & 12,5 \\
CLA & $26^{\mathrm{a}}$ & 14,9 \\
MEG & & \\
Eficiência para proteína & $28^{\text {aə }}$ & 21,0 \\
CLA & $24^{\mathrm{b}}$ & 13,3 \\
MEG &
\end{tabular}

${ }^{a}$ Médias seguidas de letras diferentes dentro da coluna diferem significativamente ${ }^{3}(P<0,10)$

A medida da eficiência bruta de produção de gordura ou proteína é o quociente entre o produto da concentração do componente e a produção diária de leite e o consumo total diário de matéria seca. Do consumo total de matéria seca, a forragem foi estimada com os pares $C_{33}: C_{32}$ e $C_{31}: C_{32}$ para os período 1 e 3 , respectivamente. Das tabelas acima, pode-se afirmar que os indicadores utilizados foram suficientemente precisos e permitiram detectar diferenças entre os dois 
tratamentos, sendo os animais que receberam o CLA mais eficientes na produção diária de proteína ( $P=0,05$, no período 1 e $P=0,07$ no período 3 ) e aqueles que receberam Megalac mais eficientes na produção diária de gordura no período 1 ( $P$ $=0,05)$.

Com relação a eficiência bruta de conversão de proteína bruta ingerida, envolve o quociente entre o produto da concentração da proteína e a produção diária de leite e o consumo total diário de proteína bruta. Os resultados estão nas Figuras 18 e 19 para os períodos 1 e 3 , respectivamente.

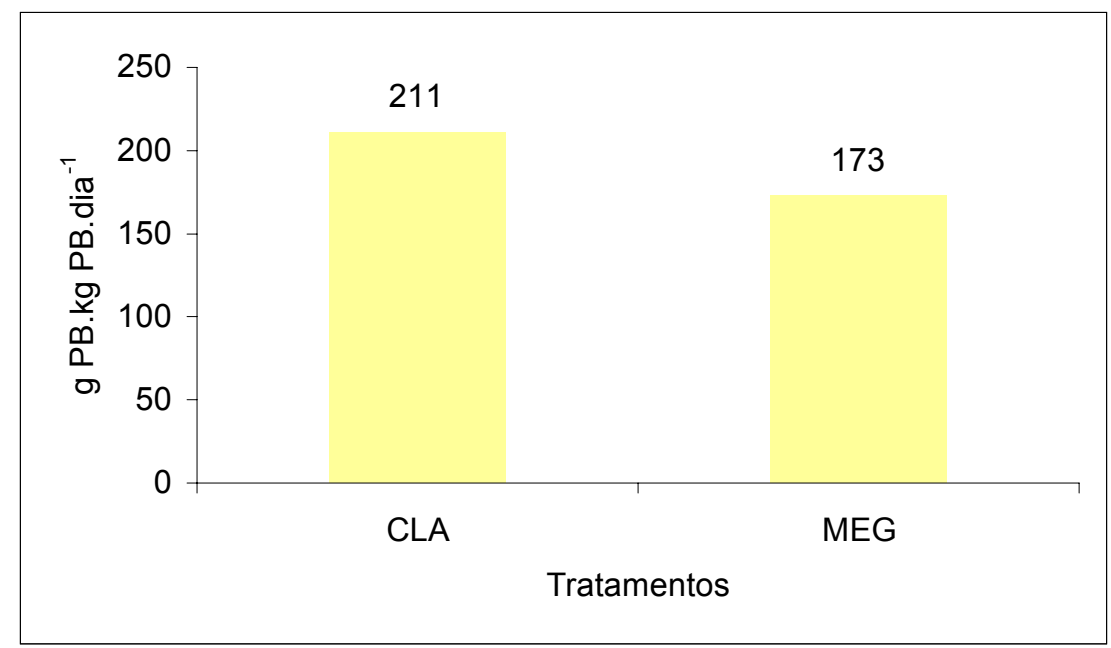

Figura 18 - Eficiência bruta de conversão de proteína bruta ingerida, no período 1 , $(P=0,02)$ 


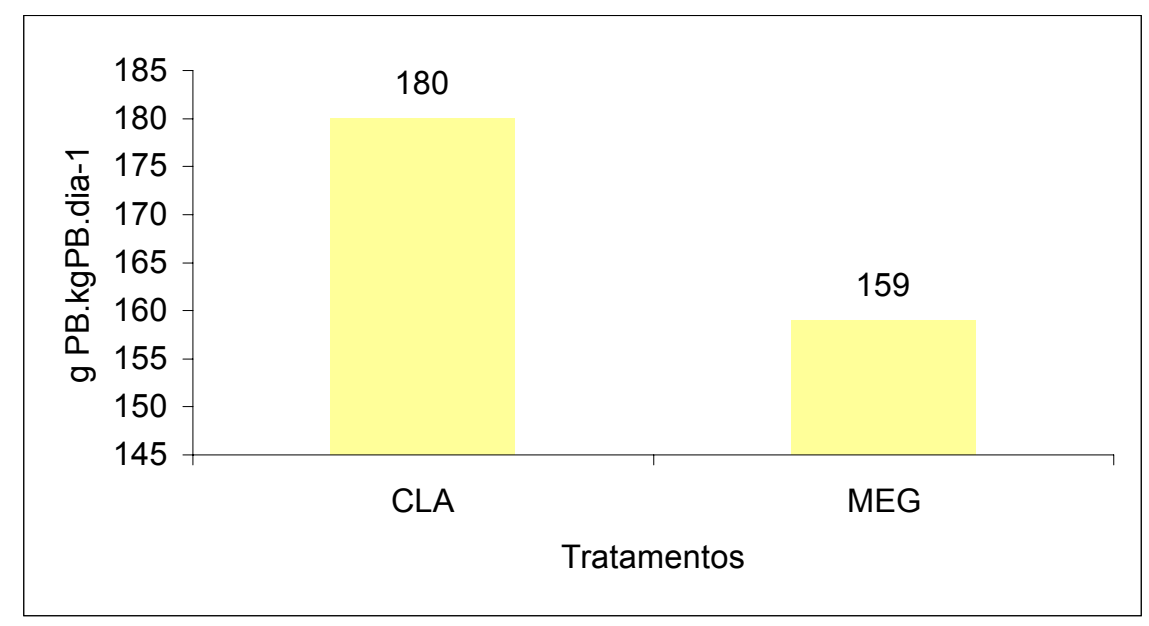

Figura 19 - eficiência bruta de conversão de proteína bruta ingerida, no período $3(P=0,08)$

Neste trabalho, para os períodos 1 e 3 de estudo, os indicadores mostraram-se capazes de contribuir na estimativa do consumo de forragem, de forma a permitir que fossem detectadas diferenças entre tratamentos nas eficiências de produção de dois componentes importantes do leite e na eficiência bruta de conversão de proteína.

Isto mostra que os indicadores em questão foram capazes de estimar adequadamente o consumo de forragem acomodando possíveis diferenças entre a capacidade individual de enchimento do rúmen, de digestibilidade da dieta selecionada e até intrínsecas dos animais, permitindo avaliar de forma mais criteriosa substâncias com impacto sobre a produção.

\subsection{Conclusões}

A metodologia de n-alcanos funcionou quando a relação das concentrações fecais do par de n-alcanos utilizados como indicadores não variaram diurna e/ou diariamente. 
A metodologia permitiu estimar o consumo de forragem e o consumo de partes de plantas.

É fundamental a obtenção de amostras de forragem que verdadeiramente representem a forragem ingerida pelos animais, visto que os animais podem selecionar espécies e/ou partes diferentes de plantas.

É necessário manter constante as condições do dossel da pastagem, mesmo em estudos onde a planta forrageira não seja o objetivo principal de estudo, em experimentos com animais em pastejo ou então deve-se monitorar e descrever os padrões de variação das condições do dossel forrageiro durante o período de coleta. 


\section{CONCLUSÕES GERAIS}

\subsection{Uso de n-alcanos em estudos de digestibilidade}

O uso de n-alcanos em estudos com ruminantes é algo relativamente novo no país. Os primeiros estudos foram iniciados com Oliveira (1995) utilizando n-alcanos como indicadores internos de digestibilidade com ovinos e atualmente há estudos com veados-catingueiro (Mazama gouazoubira) Barbosa $^{1}$, (2003). Desses dois estudos ficou claro que há limitações em usar nalcanos como indicadores fecais para estimar a digestibilidade devido as recuperações fecais serem inferiores a $100 \%$.

\subsection{Uso de n-alcanos em estudos de consumo de forragem}

No país, os estudos estão incipientes. Genro et al. (2000a) trabalharam com bovinos de corte consumindo três espécies de gramíneas tropicais e concluíram que os resultados obtidos foram razoáveis. Genro et al. (2000b) compararam o fornecimento de n-alcanos sob a forma de péletes de papel impregnado ou cápsulas de liberação controlada e concluíram que não se pode afirmar se há superioridade de um método sobre o outro em estudos com animais em pastejo. Entretanto, como na forma de cápsula de liberação controlada o distúrbio imposto aos animais é menor, parece ser a forma mais recomendável.

\footnotetext{
${ }^{1}$ BARBOSA, J.S. (Escola Superior de Agricultura "Luiz de Queiroz”, Piracicaba, SP). Utilização de nalcanos como indicadores para estudos nutricionais em veados catingueiros (Mazama gouazoubira). (Projeto de mestrado em andamento).
} 
O presente estudo mostrou que as cápsulas de liberação controlada são uma forma útil de fornecer n-alcanos usados como indicadores. Além disso este estudo veio confirmar que similares recuperações fecais são fundamentais para o êxito da técnica em estimativas de consumo de forragem.

Com relação aos procedimentos experimentais e delineamento de experimentos em pastejo, chama-se a atenção para manejos que alterem muito a rotina de pastejo dos animais porque podem fazer com que as concentrações fecais dos indicadores não sejam constantes entre turnos e com isso, outros procedimentos de coleta de fezes devem ser avaliados que não somente duas vezes ao dia porque podem não representar as concentrações médias de alcanos nas fezes.

Ressalta-se também a necessidade de um maior controle das condições do dossel forrageiro oferecido aos animais em pastejo. Variações nos componentes estruturais do dossel podem alterar os padrões de consumo de forragem, modificando as concentrações fecais dos n-alcanos e influenciando diretamente as estimativas de consumo, principalmente porque não se consegue obter uma amostra de forragem que represente fielmente aquela que foi ingerida pelos animais.

\subsection{Pesquisas futuras}

As estimativas de consumo de forragem com plantas tropicais utilizando técnica de n-alcanos deve ser melhor validada, uma vez que os estudos existentes com plantas de clima temperado e onde a técnica se mostrou eficiente em estimar o consumo foram realizados com animais em gaiolas de metabolismo. Experimentos que avaliem métodos de coleta de forragem são fundamentais para o sucesso da técnica, principalmente com animais em pastejo e em sistemas onde a pastagem não esteja mantida em "steady-state". 


\section{REFERÊNCIAS BIBLIOGRÁFICAS}

ASSOCIATION OF OFFICIAL ANALYTICAL CHEMISTS. Official methods of analysis. 16 ed. Arlington, 1995. 1298p.

BERRY, N.R.; SCHEEDER, M.R.L.; SUTTER, F.; KRÖBER, T.F.; KREUZER, $M$. The accuracy of intake estimation based on the use of alkane controlledrelease capsules and faeces grab sampling in cows. Annales Zootechnie, v.49, p.3-13, 2000.

BURNS, J.C.; POND, K.R.; FISHER, D.S. Measurement of forage intake. In: FAHEY Jr., G.C. Forage quality, evaluation and utilization. Lincoln: University of Nebraska; American Society of Agronomy, 1994, p.494-532.

CHEN, W.; LEFROY, R.D.B.; SCOTT, J.M.; BLAIR, G.J. Field variations in alkane signatures among plant species in "degraded" and perennial pastures on the Northern Tablelands of New South Wales. Australian Journal of Agricultural Research, v.49, p. 263-268, 1998.

CLAUSS, M.; LECHNER-DOLL, M.; FLACH, E.J.; TACK, C.; HATT, J.M. Comparative use of four different marker systems for the estimation of digestibility and low food intake in a group of captive giraffes (Giraffa camelopardalis). Zoo Biology, v.20, p.315-329, 2001.

DELGADO, D.C.; OLIVEIRA, M.C.; NAVARRO, A. Composition of cuticular nalkanes in tropical plants. Their potential as markers to estimate consumption and selection of grazing ruminants. Cuban Journal of Agricultural Science, v.34, p.147-152, 2000. 
DILLON, P.; STAKELUM, G. The analysis of $n$-alkanes in faeces and herbage. In: EUROPEAN GRAZING WORKSHOP, 7., Wageningen,1990. Proceedings. Wageningen: Ed Institut voor Veevoedingsoderzoek, 1990a. $1 \mathrm{v}$.

DILLON, P.; STAKELUM, G. Dosed and herbage alkanes for predicting silage intake with dairy cows: The effect of concentrate type and level of feeding. In: EUROPEAN GRAZING WORKSHOP, 7., Wageningen,1990. Proceedings. Wageningen: Ed Institut voor Veevoedingsoderzoek, 1990b. $1 \mathrm{v}$.

DOVE, $H$. Using the $n$-alkanes of plant cuticular wax to estimate the species composition of herbage mixtures. Australian Journal of Agricultural Reseasrch, v.43, p. 1711-1724, 1992.

DOVE, H.; MAYES, R.W. The use of plant wax alkanes as marker substances in studies of the nutrition of herbivores: a review. Australian Journal of Agricultural Reseasrch, v.42, p. 913-952, 1991.

DOVE, H.; MOORE, A.D. Using a least-squares optimization procedure to estimate botanical composition based on the alkanes of plant cuticular wax. Australian Journal of Agricultural Reseasrch, v.46, p. 1535-1544, 1995.

DOVE, H.; FREER, M.; FOOT, J.Z. Alkane capsules for measuring pasture intake. In: NUTRITION SOCIETY AUSTRALIAN 13, Melbourne, 1988. Proceedings. Melbourne: Australian Academy of Science, 1988. p. 131.

DOVE, H.; MAYES, R.W.; FREER, M. Using cuticular wax alkanes to estimate herbage intake in animals fed supplements. Annales Zootechnie, v.44, suppl.1, p.237, Sept., 1995.

DOVE, H.; MAYES, R.W.; FREER, M. Effects of species, plant part, and age on the n-alkane concentrations in the cuticular wax of pasture plants. Australian Journal of Agricultural Research, v.47, p. 1333-1347, 1996. 
DOVE, H.; MAYES, R.W.; LAMB, C.S.; ELLIS, K.J. Evaluation of an intraruminal controlled-release device for estimating herbage intake using synthetic and plant cuticular wax alkanes. In: INTERNATIONAL SYMPOSIUM NUTRITION HERBIVORES, 3, Penang, 1991. Proceedings. Penang: Ed Malasyan Society of Animal Production, 1991. p.82.

DOVE, H.; MAYES, R.W.; LAMB, C.S.; ELLIS, k.J. Factors influencing the release rate of alkanes from na intra-ruminal, controlled-release device, and the resultant accuracy of intake estimation in sheep. Australian Journal of Agricultural Research, v.53, p. 681-696, 2002.

DOVE, H.; MAYES, R.W.; FREER, M.; COOMBE, J.B.; FOOT, J.Z. Faecal recoveries of $n$-alkanes of plant cuticular waxes in penned and grazing sheep. In: INTERNATIONAL GRASSLAND CONGRESS, 16, Nice, 1989. Proceedings. Nice, 1989. p. 1093-1094.

DOVE, H.; SIEVER-KELLY, C.; LEURY, B.J; GATFORD, K.L.; SIMPSON, R.J. Using plant wax alkanes to quantify the intake of plant parts by grazing animals. In: NUTRITION SOCIETY AUSTRALIAN 13, Melbourne, 1992. Proceedings. Melbourne: Australian Academy of Science, 1992. p. 149.

EUCLIDES, V.P.B.; MACEDO, M.CM.; OLIVEIRA, M.P. Avaliação de diferentes métodos de amostragem sob pastejo. Revista Brasileira de Zootecnia, v.21, n.4, p. 691-702, 1992.

FAICHNEY, G.J. The use of markers to partition digestion within the gastrointestinal tract of ruminants. In: MC DONALD, I.D.; WARNER, A.C.I. Digestion and metabolism in the ruminant. Armidale: University of New England, 1975. p.277-291.

FOX, D.G.; TYLUTKI, T.P.; PELL, A. N.; AMBURGH, M.E. Vam; CHASE, L.E.; PITT, R.E.; RASMUSSEN, C.N.; TEDESCHI, L.O.; DURBAL, V.M. The net carbohidrate and protein system for evaluating herd nutrition and nutrient excretion. Ithaca: Cornell University, Animal Science Department, 1999. 144p. (MIMEO 213). 
FOX, D.G.; TYLUTKI, T.P.; AMBURGH, M.E. Vam; CHASE, L.E.; PELL, A. N.; OVERTON, T.R.; TEDESCHI, L.O.; RASMUSSEN, C.N.; DURBAL, V.M. The net carbohidrate and protein system for evaluating herd nutrition and nutrient excretion. Ithaca: Cornell University, Animal Science Department, 2000. 236p. (MIMEO 213).

FRIEND, M.A.; ROBARDS, G.E.; LINDSAY, A.R.; CHAMPION, S.C. The relative intake of three Merino strains under different grazing regimes estimated using alkane technology. Proceedings of the New Zealand Society of Animal Production, v.55, p.127-129, 1995.

GARCÍA, S.C.; HOLMES, C.W.; HODGSON,J.; MACDONALD, A. The combination of the $\mathrm{n}$-alkanes and ${ }^{13} \mathrm{C}$ techniques to estimate individual dry matter intakes of herbage and maize silage by grazing dairy cows. Journal of Agricultural Science, v.135, p.47-55, 2000.

GEDIR, J.V.; HUDSON, R.J. Estimating dry matter digestibility and intake in wapiti (Cervus elaphus canadensis) using the double $n$-alkane ratio technique. Small Ruminant Research, v.36, p.57-62, 2000b.

GEDIR, J.V.; HUDSON, R.J. Seasonal intake determination in reproductive wapiti hinds (Cervus elaphus canadensis) using n-alkane markers. Canadian Journal of Animal Science, v.80, p.137-144, 2000a.

GENRO, T. C. M. Estimativas de consumo em pastejo e suas relações com os parâmetros da pastagem em gramíneas tropicais. Porto Alegre, 1999. 130p. Tese (Doutorado) -Universidade Federal do Rio Grande do Sul.

GENRO, T.C.M.; PRATES, E.R.; HERRERO, M.; THIAGO, L.R.L.S.; XAVIER, G.F. Estimativas de consumo de bovinos em pastejo utilizando n-alcanos como indicadores em gramíneas tropicais (compact disc). In: REUNIÃO ANUAL DA SOCIEDADE BRASILEIRA DE ZOOTECNIA, 37., Viçosa, 2000, Anais. Viçosa: SBZ, 2000. 
GENRO, T.C.M.; PRATES, E.R.; THIAGO, L.R.L.S.; HERRERO, M.; SABATEL, $V$. Identification and quantification of n-alkanes in three tropical grasses. In: INTERNATIONAL GRASSLAND CONGRESS, 19., Águas de São Pedro, 2001. Proceedings. Piracicaba: FEALQ, 2001a. p.402-403.

GENRO, T.C.M.; THIAGO, L.R.L.S.; PRATES, E.R.; HERRERO, M.; SABATEL, $V$. Determination of $n$-alkanes at different stratum heights in a pasture of Panicum maximum cv. Mombaça. In: INTERNATIONAL GRASSLAND CONGRESS, 19., Águas de São Pedro, 2001. Proceedings. Piracicaba: FEALQ, 2001b. p.401-402.

GRACE, N.D.; BODY, D.R. The possible use of long chain (C19-C32) fatty acids in herbage as na indigestible faecal marker. Journal of Agricultural Science, v.97, p.743-745, 1981.

GUDMUNDSSON, O.; HALLDORSDOTTIR, K. The use of $n$-alkanes as markers for determination of intake and digestibility of fish feed. Journal Applied Ichthyology v.11, p.354-358, 1995.

HAMELEERS, A.; MAYES, R.W. The use of n-alkanes to estimate herbage intake and diet composition by dairy cows offered a perennial ryegrass/white clover mixture. Grass and Forage Science, v.53, p.164-169, 1998.

HATT, J.M.; LECHNER-DOLL, M.; MAYES, R.W. The use of dosed and herbage $\mathrm{n}$-alkanes as markers for the determination of digestive strategies of captive giraffes (Giraffa camelopardalis). Zoo Biology, v.17, p.295-309, 1998.

HATT, J.M.; MAYES, R.W.; CLAUSS, M.; LECHNER-DOLL, M. Use of artificially applied $n$-alkanes as markers for the estimation of digestibility, food selection and intake in pigeons (Columba livia). Animal Feed Science and Technology, v.94, p.65-76, 2001.

HODGSON, J. Ingestive behaviour. In: LEAVER, J.D. Herbage intake handbook. Hurley: British Grassland Society, 1982. p.113-138. 
HOFMANN, R.R. Evolutionary steps of ecophysiological adaptation and diversification of ruminants: a comparative view of their digestive system. Oecologia, v.78, p.443-457, 1989.

HOLECHEK, J.L.; VAVRA, M.; PIEPER, R.D. Methods for determining the nutritive quality of range ruminant diets: a review. Journal of Animal Science, v.54, p.363-376, 1982.

HULBERT, I,A.R.; IASON, G.R.; MAYES, R.W. The flexibility of na intermediate feeder: dietary selection by mountain hares measured using faecal $n$ alkanes. Oecologia, v.129, p.197-205, 2001.

HULBERT, I,A.R.; ANDERSEN, R. Food competition between a large ruminant and a small hindgut fermentor: the case of the roe deer and mountain hare. Oecologia, v.129, p.1-17, 2001.

KAISER, M.A. High-resolution gas chromatography. In: GROB, R. L. (Ed.). Modern practice of gas chromatography. 2. ed. New York: Wiley Interscience, 1985. p. 159-186.

KOLATTUKUDY, P.E. Introduction to natural waxes. In: KOLATTUKUDY, P.E. (Ed.). Chemistry and biochemistry of natural waxes. New York: Elsevier, 1976. p.1-15.

KOTB, A.R.; LUCKEY, T.D. Markers in nutrition. Nutrition Abstacts and Reviews. Series B, v.42, n.3, p. 813-845, 1972.

LAREDO, M.A.; SIMPSON, G.D.; MINSON, D.J.; ORPIN, C.G. The potential for using n-alkanes in tropical forages as a marker for determination of dry matter by grazing ruminants. Journal of Agricultural Science, v.117, n.3, p.355-361, 1991.

LE DU, Y.L.P.; PENNING, P.D. Animal based techniques for estimating herbage intake. In: LEAVER, J.D. Herbage intake handbook. Hurley: British Grassland Society, 1982. p.37-75. 
MARAIS, J.P.; FIGENSCHOU, P.L.; ESCOTT-WATSON, P.L.; WEBBER, L.N. Administration in suspension-form of n-alkane external markers for dry matter intake and diet selection studies. Journal of Agricultural Science, v. 126, p.207-210, 1996.

MAYES, R.W.; DOVE, H. Measurement of dietary nutrient intake in free-ranging mammalian herbivores. Nutrition Research Reviews, v.13, p.107-138, 2000.

MAYES, R.W.; LAMB, C.S. The possible use of n-alkanes in herbage as indigestible faecal markers. Proceedings of Nutrition Society, v.43, n.1/3, p.39, 1984.

MAYES, R.W.; LAMB, C.S.; COLGROVE, P.M. The use of dosed and herbage $\mathrm{n}$-alkanes as markers for determination of herbage intake. Journal of Agricultural Science, v.107, n.1, p.161-170, 1986a.

MAYES, R.W.; LAMB, C.S.; COLGROVE, P.M. Determination of herbage intake of suckling lambs using long chain $\mathrm{n}$-alkanes as markers. British Society of Animal Production, v.42, p.457, 1986b.

MAYES, R.W.; WRIGHT, I.A.; LAMB, C.S.; MCBEAN, A. The use of long-chain $\mathrm{n}$-alkanes as markers for estimating intake and digestibility of herbage in cattle. British Society of Animal Production, v.42, p.457, 1986c.

Mc NAIR, H.M.; BONNELLI, E.J. Basic chromatography. 4. ed. Palo Alto; Varian Instrument Division Offices, 1968. p.137-167: Quantitative analysis.

MEDEIROS, S.R. Ácido linoléico conjugado: teores nos alimentos e seu uso no aumento da produção de leite com maior teor de proteína e perfil de ácidos graxos modificado. Piracicaba, 2002. 98p. Tese (Doutorado) - Escola Superior de Agricultura Luiz de Queiroz, Universidade de São Paulo.

MEIJS, J.A.C.; WALTERS, R.J.K.; KEEN, A. Sward methods. In: LEAVER, J.D. Herbage intake handbook. Hurley: British Grassland Society, 1982. p.1136. 
MERCHANT, M. The intake of grass and rush (Juncus effusus L.) by goats grazing rush-infested grass pasture. Grass and Forage Science, v.51, p.81-87, 1996.

MORRISON, R.; BOYD, R.N. Química orgânica. 6. ed. Boston: Fundação Calouste Gulbenkian, 1972. cap. 4: Alcanos, p.110-172.

NETER, J.; WASERMAN, W. Topics in regression analysis. In: NETER, J.; WASERMAN, W. Applied linear statistical models. Homewood: Illinois, 1996. cap.5, p.160-169.

NEWMAN, J.A.; THOMPSON, W.A.; PENNING, P.D.; MAYES, R.W. Leastsquares estimation of diet composition from n-alkanes in herbage and faeces using matrix mathematics. Australian Journal of Agricultural Research, v.46, p. 793-805, 1995.

OHAJURUKA, O.A.; PALMQUIST, D.L. Evaluation of n-alkanes as digesta markers in dairy cows. Journal of Animal Science, v.69, n.4, p.1726-1732, Apr., 1991.

O'KEEFE, N.M.; MCMENIMAN, N.P. The recovery of natural and dosed nalkanes from the horse. Animal Production in Australia, v.22, p.337, 1998.

OLIVEIRA, D.E. Digestibilidade determinada pelo método indireto usando nalcanos. Porto Alegre, 1995. 93p. Dissertação (Mestrado), Universidade Federal do Rio Grande do Sul.

OLIVEIRA, D.E.; PRATES, E.R. Utilização dos componentes da cera das plantas, em especial os n-alcanos, em estudos de nutrição de ruminantes. Ciência Rural, v.30, n.3, p.549-557, 2000.

OLIVEIRA, D.E.; ETCHEGARAY, M.A.L.; LANNA, D.P.D. Seringas plásticas substituindo colunas plásticas descartáveis na extração de n-alcanos utilizados em estudos nutricionais com herbívoros. (compact disc). In: REUNIÃO ANUAL DA SOCIEDADE BRASILEIRA DE ZOOTECNIA, 39., Recife, 2002, Anais. Recife: SBZ, 2002. 
OLIVEIRA, D.E.; PRATES, E.R.; PERALBA, M.C.R. Identificação e quantificação de $n$-alcanos presentes nas ceras de plantas forrageiras. Revista Brasileira de Zootecnia, v.26, n.5, p.881-886, set./out. 1997.

OLIVEIRA, D.E.; PRATES, E.R.; PERALBA, M.C.R. Digestibilidade determinada pelo método indireto usando o n-alcano C35. Revista Brasileira de Zootecnia, v.29, n.3, p.848-852, maio/jun. 2000.

ORDAKOWSKI, A.L.; KRONFELD, D.S.; HOLLAND, J.L.; HARGREAVES, B.J.; GAY, L.S.; HARRIS, P.A.; DOVE, H.; SKLAN, D. Alkanes as internal markers to estimate digestibility of hay or hay plus concentrate diets in horses. Journal of Animal Science, v.79, p.1516-1522, 2001.

ORÓ, J.; NOONER, D.W.; WIKSTRÖN, S.A. Paraffinic hydrocarbons in pasture plants. Science, v.147, n.3659, p.870-873, Feb. 1965.

OSORO,K.; OLIVÁN, M.; CELAYA, R.; MARTÍNEZ, A. Effects of genotype on the performance and intake characteristics of sheep grazing contrasting hill vegetation communities. Animal Science, v.69, p.419-426, 1999.

PARKER, W.J.; MCCUTCHEON, S.N.; CARR, D.H. Effect of herbage type and level of intake on the release of chromic oxide from intraruminal controlled release capsules in sheep. New Zealand Journal of Agricultural Research, v.32, p. 537-546, 1989.

PEREIRA, J.L.; RÓSSI JÚNIOR, P. Manual de análise de laboratório. Piracicaba: FEALQ, 1994. 35p.

PIAGGIO, L.M. Avaliação do cromo mordente como indicador externo da produção fecal e das cinzas insolúveis em ácido, fibra em detergente ácido indigestível e lignina em detergente ácido indigestível como indicadores internos da digestibilidade. Porto Alegre, 1989. 94p. Dissertação (Mestrado) - Universidade Federal do Rio Grande do Sul.

PIASENTIER, E.; PISON, S.; BOVOLENTA, S. Impiego degli n-alcani negli studi sulla digeribilitá in vivo dei foraggi. Zootecnia Nutrition Animale, v.15, p.691-696, 1989. 
ROONEY, V.A. The nutritive value of mature annual legumes for sheep in southern australia. Sydney, 2000. 207p. Ph.D. (Thesis) - University of Sydney.

SAS INSTITUTE. SAS/STAT: Guide for personal computers. Cary, 2000. 1v. SCHNEIDER, B.H.; FLATT, W.P. The evaluation of feeds through digestibility experiments. Athens: University of Georgia Press, 1975. 423p.

SMITH, D.G.; MAYES, R.W.; RAATS, J.G. Effect of species, plant part, and season of harvest on n-alkane concentrations in the cuticular wax of common rangeland grasses from southern Africa. Austalian Journal of Agricultural Research, v.52, p. 875-882, 2001.

STAKELUM, G.; DILLON, P. Dosed and herbage alkanes as feed intake predictors with dairy cows: The effect of feeding level and frequency of perennial ryegrass. In: EUROPEAN GRAZING WORKSHOP, 7., Wageningen,1990. Proceedings. Wageningen: Ed Institut voor Veevoedingsoderzoek, 1990c. 1v.

TULLOCH, A. P. Chemistry of waxes of higher plants. In: KOLATTUKUDY, P.E. (Ed.). Chemistry and biochemistry of natural waxes. New York: Elsevier, 1976, p.235-287.

UNAL, Y.;GARNSWORTHY, P. C.; GORTON, P. The use of n-alkanes for prediction of intake in dairy cows. In: ANNUAL MEETING OF THE BRITISH SOCIETY OF ANIMAL SCIENCE, Penicuick, 1997. Proceedings. Penicuick: British Society of Animal Science, 1997. p.137.

UNTZ, G.; TRANCHANT, J. (Ed.). Manuel pratique de chromatographie en phase gazeuse. 3. ed. Paris: Masson, Détecteur à ionisation de flamme. p.61-72, 1982.

VULICH, S.A.; O'RIORDAN, E.G.; HANRAHAN, J.P. Use of n-alkanes for estimation of herbage intake in sheep: accuracy and precision of the estimates. Journal of Agricultural Science, v.116, n.2, p.319-323, 1991. 
VULICH, S.A.; HANRAHAN, J.P.; O'RIORDAN, E.G. Pasture sampling for estimation of herbage intake using n-alkanes: evaluation of alternative sampling procedures. Irish Journal of Agricultural and Food Research, v.32, p.1-11, 1993.

WILlIAMSON, P.J.; HENNESSY, D.W.; GOGEL, B.J.; BARLOW, R. The estimation of faeces output in penned cattle by controlled release of chromium oxide and the subsequent accuracy of predicting forage intake with in vitro digestibility. Journal of Agricultural Science, v.135, p.297-304, 2000. 
APÊNDICES 
Apêndice 1. Concentrações fecais (mg.kg ${ }^{-1} \mathrm{MS}$ ) dos n-alcanos $C_{31}, C_{32}, C_{33}, C_{35}$ e $\mathrm{C}_{36}$, na amostra de forragem, concentrado e fezes dos animais e, consumo individual de concentrado ( $\mathrm{kg} \mathrm{MS}$ ) no período 1

\begin{tabular}{lcccccc}
\hline Alimento/Animal & $\mathrm{C}_{31}$ & $\mathrm{C}_{32}$ & $\mathrm{C}_{33}$ & $\mathrm{C}_{35}$ & $\mathrm{C}_{36}$ & \\
\hline \$PS (dia 1 + dia 2) & 78,9 & 10,05 & 113,6 & 25,2 & 0 & \\
Concentrado P1 & 1,4 & 0 & 0 & 0 & 0 & Cons. Concent. \\
& & & & & & 3,4 \\
0625 CLA & 199,0 & 79,9 & 221,3 & 38,4 & 35,9 & 3,3 \\
2545 CLA & 246,0 & 78,0 & 258,8 & 46,6 & 9,6 & 3,4 \\
6484 CLA & 267,0 & 106,6 & 287,2 & 52,6 & 37,4 & 3,4 \\
6415 CLA & 270,4 & 113,3 & 264,6 & 46,0 & 42,6 & 3,4 \\
2653 CLA & 215,4 & 88,8 & 246,3 & 42,0 & 35,4 & 3,2 \\
6542 MEG & 201,6 & 84,7 & 225,3 & 38,3 & 36,4 & 2,9 \\
1470 MEG & 267,1 & 95,9 & 29,02 & 52,0 & 34,2 & 3,4 \\
3435 MEG & 217,4 & 98,9 & 238,8 & 41,9 & 44,1 & 3,4 \\
7465 MEG & 179,8 & 95,5 & 206,7 & 44,3 & 54,8 & 3,4 \\
3507 MEG & 229,5 & 74,2 & 252,5 & 47,7 & 29,4 & 3,3 \\
Média & 229,3 & 91,6 & 249,2 & 45,0 & 36,0 & 4,8 \\
CV (\%) & 14,0 & 13,9 & 11,0 & 11,1 & 32,2 & \\
\hline S Am
\end{tabular}

${ }^{\$}$ Amostra da forragem pelo método do pastejo simulado 
Apêndice 2. Concentrações fecais (mg. $\mathrm{kg}^{-1} \mathrm{MS}$ ) dos n-alcanos $\mathrm{C}_{31}, \mathrm{C}_{32}, \mathrm{C}_{33}, \mathrm{C}_{35}$ e $\mathrm{C}_{36}$, na amostra de forragem, concentrado e fezes dos animais e, consumo individual de concentrado (kg MS) no período 2

\begin{tabular}{lcccccc}
\hline Alimento/Animal & $\mathrm{C}_{31}$ & $\mathrm{C}_{32}$ & $\mathrm{C}_{33}$ & $\mathrm{C}_{35}$ & $\mathrm{C}_{36}$ & \\
\hline \$PS (dia 1+ dia 2) & 107,5 & 9,6 & 170,7 & 36,9 & 0 & \\
Concentrado P1 & 9,6 & 8,1 & 6,1 & 2,6 & 0 & Cons. Concent. \\
& & & & & & 3,4 \\
0625 CLA & 237,0 & 111,5 & 423,2 & 87,1 & 79,4 & 3,3 \\
2545 CLA & 268,6 & 98,0 & 478,7 & 104,0 & 78,6 & 3,0 \\
6484 CLA & 240,5 & 108,1 & 417,4 & 93,4 & 82,2 & 3,4 \\
6415 CLA & 230,4 & 133,3 & 374,0 & 90,2 & 107,6 & 3,4 \\
2653 CLA & 255,2 & 103,8 & 450,5 & 99,3 & 82,8 & 3,4 \\
0371 CLA & 251,8 & 187,3 & 441,8 & 105,0 & 134,1 & 3,4 \\
0644 CLA & 295,8 & 116,5 & 473,2 & 100,0 & 90,8 & 3,3 \\
2473 CLA & 287,9 & 134,3 & 473,2 & 113,0 & 99,3 & 3,4 \\
2521 CLA & 273,7 & 115,0 & 447,3 & 85,9 & 80,0 & 3,4 \\
3414 CLA & 242,9 & 119,6 & 407,9 & 93,7 & 86,5 & 3,2 \\
6542 MEG & 305,7 & 150,4 & 445,9 & 97,6 & 119,9 & 2,6 \\
1470 MEG & 336,1 & 150,3 & 497,5 & 111,0 & 98,6 & 3,4 \\
3435 MEG & 217,2 & 115,8 & 383,3 & 88,2 & 100,1 & 3,3 \\
7465 MEG & 266,5 & 147,7 & 433,2 & 86,3 & 118,2 & 3,3 \\
3507 MEG & 275,2 & 94,5 & 449,2 & 89,9 & 54,5 & 3,4 \\
0675 MEG & 245,0 & 157,3 & 393,0 & 91,6 & 116,8 & 3,4 \\
0697 MEG & 287,5 & 125,8 & 455,2 & 95,9 & 79,0 & 3,4 \\
1938 MEG & 243,6 & 125,2 & 421,0 & 96,5 & 89,3 & 3,3 \\
3401 MEG & 255,0 & 162,7 & 422,8 & 90,1 & 117,7 & 3,3 \\
3461 MEG & 279,6 & 149,2 & 449,5 & 94,4 & 104,6 & 3,3 \\
Média & 264,8 & 130,3 & 436,9 & 95,7 & 96,0 & 5,8 \\
CV (\%) & 10,8 & 18,6 & 7,3 & 8,3 & 20,0 &
\end{tabular}

${ }_{\$}^{\$}$ Amostra da forragem pelo método do pastejo simulado 
Apêndice 3. Concentrações fecais (mg. $\mathrm{kg}^{-1} \mathrm{MS}$ ) dos n-alcanos $\mathrm{C}_{31}, \mathrm{C}_{32}, \mathrm{C}_{33}, \mathrm{C}_{35}$ e $\mathrm{C}_{36}$, na amostra de forragem, concentrado e fezes dos animais e, consumo individual de concentrado (kg MS) no período 3

\begin{tabular}{lcccccc}
\hline Alimento/Animal & $\mathrm{C}_{31}$ & $\mathrm{C}_{32}$ & $\mathrm{C}_{33}$ & $\mathrm{C}_{35}$ & $\mathrm{C}_{36}$ & \\
\hline \$PS (dia 1+ dia 2) & 106,0 & 20,4 & 136,5 & 26,8 & 0 & \\
Concentrado P1 & 9,6 & 8,1 & 6,1 & 2,6 & 0 & Cons. Concent. \\
& & & & & & 3,7 \\
0674 CLA & 248,1 & 130,5 & 328,9 & 71,5 & 82,7 & 3,6 \\
1643 CLA & 278,3 & 121,6 & 375,6 & 76,8 & 86,7 & 3,3 \\
2521 CLA & 225,7 & 103,3 & 314,3 & 65,3 & 71,3 & 3,7 \\
3414 CLA & 213,3 & 99,0 & 297,6 & 67,6 & 67,8 & 3,7 \\
0371 CLA & 278,7 & 143,8 & 383,9 & 77,2 & 97,1 & 3,7 \\
0644 CLA & 291,9 & 102,5 & 370,2 & 70,9 & 62,2 & 3,7 \\
0722 CLA & 241,6 & 117,8 & 333,9 & 68,0 & 86,8 & 3,6 \\
2473 CLA & 235,1 & 85,6 & 320,2 & 67,4 & 58,8 & 3,7 \\
3839 CLA & 288,8 & 127,2 & 386,2 & 76,3 & 88,1 & 3,7 \\
4882 CLA & 266,9 & 131,1 & 368,1 & 89,5 & 86,4 & 3,4 \\
0669 MEG & 252,6 & 107,4 & 356,3 & 77,1 & 74,9 & 2,8 \\
3461 MEG & 243,1 & 111,6 & 330,3 & 66,9 & 73,4 & 3,7 \\
1450 MEG & 251,2 & 112,1 & 352,0 & 73,6 & 78,9 & 3,6 \\
4689 MEG & 245,4 & 110,3 & 339,4 & 66,0 & 78,9 & 3,6 \\
0675 MEG & 259,8 & 108,4 & 365,1 & 79,0 & 70,9 & 3,7 \\
9752 MEG & 240,3 & 106,3 & 330,8 & 66,7 & 66,1 & 3,7 \\
1938 MEG & 239,4 & 130,0 & 324,2 & 67,9 & 81,7 & 3,7 \\
3401 MEG & 256,0 & 124,4 & 336,0 & 65,5 & 82,7 & 3,5 \\
0697 MEG & 262,8 & 145,9 & 336,5 & 76,1 & 104,7 & 3,7 \\
3510 MEG & 231,6 & 102,1 & 325,5 & 64,6 & 61,8 & 3,6 \\
Média & 252,5 & 116,0 & 343,8 & 71,7 & 78,1 & 6,0 \\
CV (\%) & 8,2 & 13,4 & 7,2 & 8,9 & 15,4 &
\end{tabular}

${ }_{\$}^{\$}$ Amostra da forragem pelo método do pastejo simulado 
Apêndice 4. Exigências e consumo de energia metabolizável ( $\left.\mathrm{Mcal}^{\mathrm{dia}}{ }^{-1}\right)$, com a amostra de forragem pelo método do pastejo simulado (PS) e separada nas frações lâminas foliares e haste+bainha das folhas (HF) para o período 1

\begin{tabular}{lccc}
\hline Animal & Exigências de EM & Consumo EM (PS) & Consumo EM (HF) \\
\hline 0625 CLA & 32,2 & 33,3 & 33,5 \\
2545 CLA & 34,2 & 39,6 & 40,1 \\
6484 CLA & 30,4 & 32,6 & 32,8 \\
6415 CLA & 33,1 & 28,9 & 29,3 \\
2653 CLA & 31,4 & 33,6 & 33,7 \\
6542 MEG & 31,8 & 31,6 & 31,7 \\
1470 MEG & 37,9 & 35,4 & 35,6 \\
3435 MEG & 31,5 & 29,5 & 29,6 \\
7465 MEG & 29,3 & 27,0 & 26,8 \\
3507 MEG & 38,8 & 41,3 & 41,4 \\
Média & 33,1 & 33,3 & 33,4 \\
CV (\%) & 9,4 & 13,6 & 13,8 \\
\hline
\end{tabular}


Apêndice 5. Exigências e consumo de energia metabolizável (Mcal.dia $\left.{ }^{-1}\right)$, com a amostra de forragem pelo método do pastejo simulado (PS) e separada nas frações lâminas foliares e haste+bainha das folhas (HF) para o período 3

\begin{tabular}{lccc}
\hline Animal & Exigências de EM & Consumo EM (PS) & Consumo EM (HF) \\
\hline 0674 CLA & 27,1 & 32,1 & 31,9 \\
1643 CLA & 31,9 & 39,1 & 38,7 \\
2521 CLA & 29,0 & 36,5 & 36,0 \\
3414 CLA & 32,4 & 37,0 & 36,5 \\
0371 CLA & 26,3 & 32,9 & 32,6 \\
4882 CLA & 29,7 & 34,6 & 34,1 \\
0669 MEG & 29,4 & 39,5 & 38,8 \\
3461 MEG & 27,7 & 34,8 & 34,4 \\
1450 MEG & 31,4 & 38,7 & 38,1 \\
4689 MEG & 31,0 & 37,7 & 37,2 \\
0675 MEG & 31,0 & 41,3 & 40,5 \\
9752 MEG & 30,3 & 39,1 & 38,6 \\
1938 MEG & 24,8 & 31,3 & 31,0 \\
3401 MEG & 29,5 & 34,5 & 34,2 \\
0697 MEG & 24,8 & 29,6 & 30,2 \\
3510 MEG & 30,6 & 39,6 & 39,0 \\
Média & 29,2 & 36,1 & 35,7 \\
CV (\%) & 8,2 & 9,5 & 8,9 \\
\hline
\end{tabular}

